Document downloaded from:

http://hdl.handle.net/10251/148458

This paper must be cited as:

Prosdocimi, M.; Burguet, M.; Di Prima, S.; Sofia, G.; Terol, E.; Rodrigo Comino, J.; Cerda, A.... (2017). Rainfall simulation and Structure-from-Motion photogrammetry for the analysis of soil water erosion in Mediterranean vineyards. The Science of The Total Environment. 574:204-215. https://doi.org/10.1016/j.scitotenv.2016.09.036

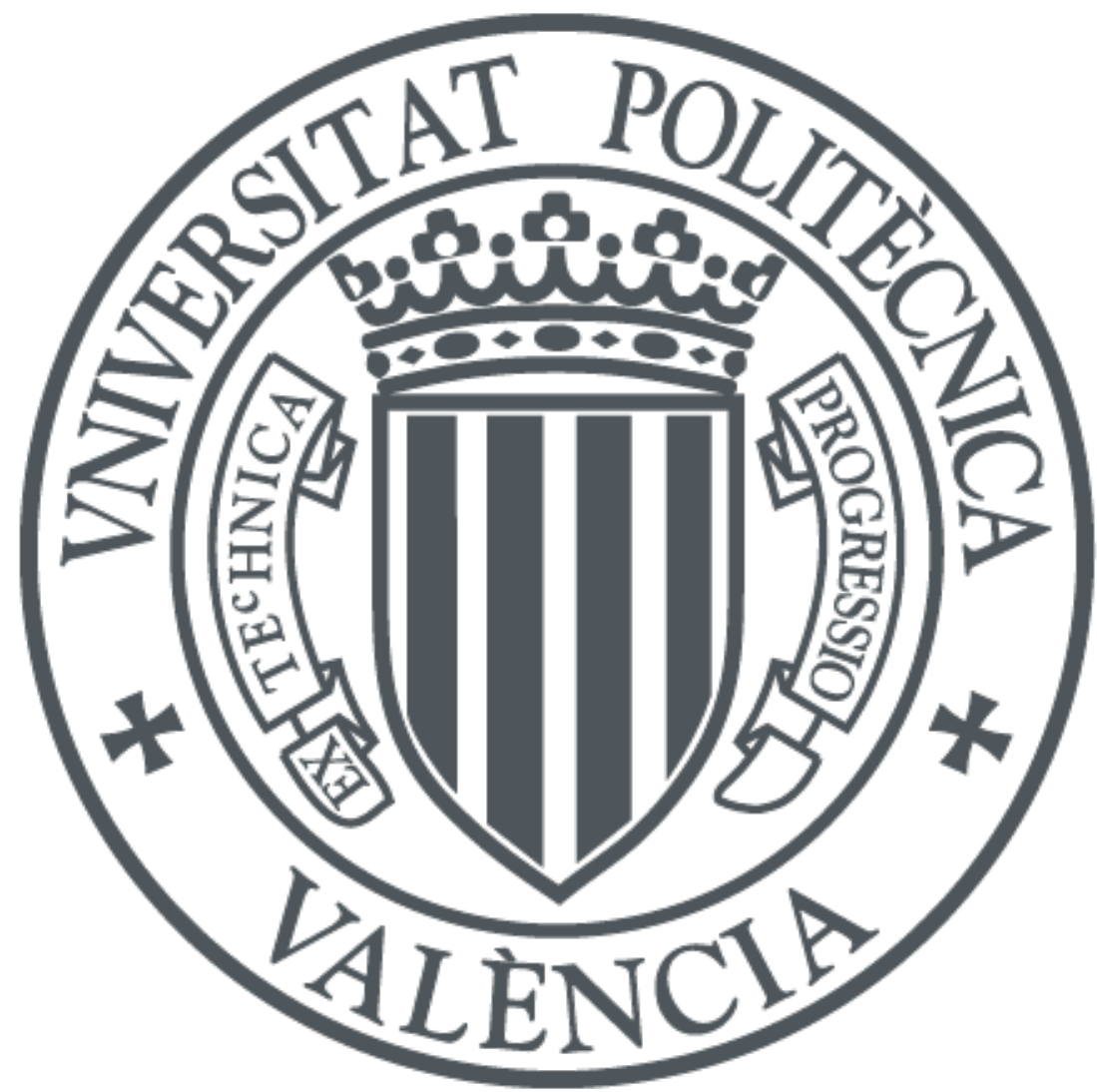

The final publication is available at

https://doi.org/10.1016/j.scitotenv.2016.09.036

Copyright Elsevier

Additional Information 
the Total Environment

Elsevier Editorial system(tm) for Science of

Manuscript Draft

Manuscript Number: STOTEN-D-16-03202R1

Title: Rainfall simulation and Structure-from-Motion photogrammetry for the analysis of soil water erosion in Mediterranean vineyards

Article Type: Research Paper

Keywords: soil water erosion, Mediterranean vineyards, rainfall

simulation, Structure from Motion, sediment connectivity.

Corresponding Author: Mr. Massimo Prosdocimi,

Corresponding Author's Institution: Land, Environment, Agriculture and Forestry, University of Padova

First Author: Massimo Prosdocimi

Order of Authors: Massimo Prosdocimi; Maria Burguet; Simone Di Prima; Giulia Sofia; Enric Terol Esparza; Jesús Rodrigo Comino; Artemi Cerdà; Paolo Tarolli

Abstract: Soil water erosion is a serious problem, especially in agricultural lands. Among these, vineyards deserve attention, because they constitute for the Mediterranean areas a type of land use affected by high soil losses. A significant problem related to the study of soil water erosion in these areas consists in the lack of a standardized procedure of collecting data and reporting results, mainly due to a variability among the measurement methods applied. Given this issue and the seriousness of soil water erosion in Mediterranean vineyards, this works aims to quantify the soil losses caused by simulated rainstorms, and compare them with each other depending on two different

methodologies: (i) rainfall simulation and (ii) surface elevation changebased, relying on high-resolution Digital Elevation Models (DEMs) derived from a photogrammetric technique (Structure-from-Motion or SfM). The experiments were carried out in a typical Mediterranean vineyard, located in eastern Spain, at very fine scales. SfM data were obtained from one reflex camera and a smartphone built-in camera. An index of sediment connectivity was also applied to evaluate the potential effect of connectivity within the plots. DEMs derived from the smartphone and the reflex camera were comparable with each other in terms of accuracy and capability of estimating soil loss. Furthermore, soil loss estimated with the surface elevation change-based method resulted to be of the same order of magnitude of that one obtained with rainfall simulation, as long as the sediment connectivity within the plot was considered. Highresolution topography derived from SfM revealed to be essential in the sediment connectivity analysis and, therefore, in the estimation of eroded materials, when comparing them to those derived from the rainfall simulation methodology. The fact that smartphones built-in cameras could produce as much satisfying results as those derived from reflex cameras is a high value added for using SfM.

Response to Reviewers: First of all, we wish to thank the Editor and two reviewers for their comments on the manuscript, and their constructive 
suggestions. The reviewers underlined some minor issues. In this revised version of the paper, we did our best to follow all the comments raised and to incorporate the reviewers' recommendations. Here a detailed response to each point raised. We also added two co-authors for their contributions during the field surveys and review stage.

\section{Reviewer\# 1}

We really wish to thank Reviewer\# 1 for his/her review of our manuscript. Reviewer\#1 raised useful comments and advices that helped us to improve and clarify the work.

We have done our best to incorporate as much of the Reviewer\#l 's suggestions.

Below we report the replies to each general comment:

The rainfall simulation techniques are generally adopted for the analysis of the potential risk of erosion at microscale (0.25 $\mathrm{m} 2$ in this work). Conversely a real time monitoring (e.g. the post event analysis) could be based on the analysis of data from digital cameras with specific surface elevation change-based methods. The authors agree with this statement when they write that the smartphones are easily available for farmers/researchers and could be adopted for "fast and cheap post-event analyses" (conclusions - row 508). Nevertheless, it is not clear how this specific use could be implemented on the base of a work that proposes only a field test for a very small piece of a vineyard. Therefore, I think that this work should analyse the problems that limit the feasibility of the scale-up from experimental plots $(0.25 \mathrm{~m} 2)$ to the whole vineyard and discuss if and how these problems can be overcome. This request is crucial because the deduction of a reader of the present version is that the scale-up is almost automatic while in my opinion it is far from immediate with the proposed technology. In other terms the abovementioned "Conclusion 2" must be corroborated in an effective way.

We thank the reviewer for this comment. In our work, we stated that our analyses were carried out at very-fine scales and that SfM confirmed to be a useful approach to quantify topographic changes at these spatial scales. The final statement we reported in the conclusion (lines 508-511) gives, in our opinion, a general overview of the likely future uses of smartphones for these kind of analyses, without alluding in detail to specific spatial scales. Considering the reviewer comment, we enhanced the above-mentioned 'Conclusion 2' also following Reviewer\#2's suggestions. Please refer to pag. 22, lines 520-532.

In order to easily understand the characteristics of climate and soils of the experimental site I suggest to report (maybe in the supplementary material):

- results of a chemical-physical analysis of the soil of the vineyard with the main variables (texture, organic matter and so on).

- table with monthly mean values of temperature, precipitation amount and number of rainy days 
- climogram of Bagnouls - Gaussen (alias Walter - Lieth) useful to easily see thermal and precipitation regime and the length of the dry period.

All the information we have about the soil and parent material of the study area, are reported at pag. 8, lines 191-197. We corrected the texture of the soil from sandy to sandy loam according to USDA classification by adding the percentages of clay, silt and sand. About the second and third request, we reported only the Walter-Lieth climate diagram (Figure 3 in the revised version of the paper) because we strongly think we already reported exhaustive information about the study area. The data used to compute the climate diagram derive from the Ontinyent climate station which is the one with the longest records closest to our study site. We specified this in the text (please refer to pag. 9 line 200). For further information, readers can refer to http://www.globalbioclimatics.org/ (pag 9, line 206).

Below we report the replies to each specific comment:

Abstract: please specify the country and the site of the experimental activities

Done. Please refer to pag. 2, line 39.

Row 97: "high intensity rainfall events, mainly concentrated in spring and autumn, which characterize the Mediterranean climate". The Mediterranean is characterized by rainfall concentrated in the winter semester (october-march). This was stated for example by Koeppen which classified as Mediterranean the climates with more than $70 \%$ of the total yearly precipitation concentrated in winter semester.

Reviewer\#1 is right and we added the winter as season (pag. 4, line 100). However, we also left spring because the authors we reported as references gave evidence of the occurrence of extreme events in this season too. These events characterize the Mediterranean climate as well.

Row 108: the authors speak of "catch crops" that are fast-growing crops that are grown between successive plantings of a main crop. For this work this is senseless because vineyard is a permanent crop. More interesting should be to speak of "cover crops" which are a "state of art" approach to the anti-erosion management of vineyard (see for example Ingels C.A., Bugg R.L., McGourty G.T., Christensen L.P. - 1998. Cover crops in vineyards: a grower's handbook, University of California, publication $3338,154 \mathrm{pp})$.

Reviewer\#1 is right. We corrected it with 'cover crops' (pag. 5, line 113)

Row 122. I suggest a wrap after "C) stable isotopes".

To be clearer, we considered appropriate to simply write "carbon stable isotopes" (pag. 6, line 130).

Row 179: for the effects on the structure of the soil it is important to know the farm implement adopted for soil cultivation (e.g.: tooth harrow, disc arrow, mouldboard plough)

Tooth arrow. Information added in the text (pag. 9 line 184). 
Row 191: "and bulk density (1.109 g cm-3)" please change in something like "and low bulk density (1.109 g cm-3)"

Done.

Row 416: it is preferable to speak of "net eroded sediments" and "net deposited sediments" because an observed deposition or erosion is always the result of the balance between intakes and losses.

Done.

Reviewer\#2

We really wish to thank Reviewer\#2 for his/her review of our manuscript. Reviewer\#2 raised useful comments and advices that helped us to improve and clarify the work. Furthermore, he recognized the novelty of our work. We have done our best to incorporate as much of the Reviewer\#2's suggestions.

Below we report the replies to his/her comments:

The paper is written in a concise and understandable way. It would be interesting to also shortly elaborate on the possible deployment of the technology. What are the best channels to deploy tool use? What training is required? What do you expect about the uptake?

We thank the reviewer for this suggestion. We incorporated it in pag. 22, lines 520-532.

A side note - strictly, tillage is not a soil conservation technique. Zero till is a soil conservation technique. No till is not per se chemical weeding. Please review these concepts. I recommend Amir Kassam's literature.

We thank the reviewer for this comment. In a recent review, Maetens et al. (2012) included in the soil and water conservation techniques (SWCTs) the crop and vegetation management (i.e. cover crops, mulching etc.), the soil management (i.e. no-tillage, reduced tillage, deep tillage etc.) and mechanical methods (i.e. terraces, contour bounds etc.). To be more precise, we substituted soil conservation techniques with soil management techniques. Furthermore, we wrote 'no tillage (where the weeds are usually removed chemically)'. Please refer to pag. 5, lines 102-105.

References

Maetens, W., Poesen, J., Vanmaercke, M., 2012. How effective are soil conservation techniques in reducing plot runoff and soil loss in Europe and the Mediterranean? Earth Sci. Rev. 115, 21-36. 


\section{DEPARTMENT of LAND, ENVIRONMENT, AGRICULTURE and FORESTRY}

\section{AGRIPOLIS}

Viale dell'Università 16

35020 LEGNARO (Padova), Italy

Tel. +390498272684-+390498272685

Fax 0498272686

P.IVA 00742430283

Legnaro (PD), $5^{\text {th }}$ September 2016

Dear Editor,

we are submitting herein the revision version of the paper entitled "Rainfall simulation and Structure-from-Motion photogrammetry for the analysis of soil water erosion in Mediterranean vineyards" by Massimo Prosdocimi, Maria Burguet, Simone Di Prima, Giulia Sofia, Enric Terol Esparza, Jesús Rodrigo Comino, Artemi Cerdà and Paolo Tarolli to be considered for publication in Science of the Total Environment.

We included two co-authors for their contributions during the field surveys and review stage, and fixed all the critical issues raised by the reviewers.

We look forward to hearing from you.

Best regards,

Massimo Prosdocimi

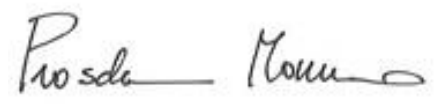




\title{
Response to Editor and reviewers' comments
}

\author{
on the manuscript $n^{\circ}$ : STOTEN-S-16-04026
Rainfall simulation and Structure-from-Motion photogrammetry for the analysis of soil water erosion in Mediterranean vineyards.

revised for publication in

Science of the Total Environment

by

\begin{abstract}
Massimo Prosdocimi, Maria Burguet, Simone Di Prima, Giulia Sofia, Enric Terol Esparza, Jesús Rodrigo Comino, Artemi Cerdà and Paolo Tarolli
\end{abstract}

First of all, we wish to thank the Editor and two reviewers for their comments on the manuscript, and their constructive suggestions. The reviewers underlined some minor issues. In this revised version of the paper, we did our best to follow all the comments raised and to incorporate the reviewers' recommendations. Here a detailed response to each point raised. We also added two co-authors for their contributions during the field surveys and review stage.

\section{Reviewer\#1}

We really wish to thank Reviewer\#1 for his/her review of our manuscript. Reviewer\#1 raised useful comments and advices that helped us to improve and clarify the work.

We have done our best to incorporate as much of the Reviewer\#1's suggestions.

Below we report the replies to each general comment:

The rainfall simulation techniques are generally adopted for the analysis of the potential risk of erosion at microscale (0.25 $\mathrm{m} 2$ in this work). Conversely a real time monitoring (e.g. the post event analysis) could be based on the analysis of data from digital cameras with specific surface elevation change-based methods. The authors agree with this statement when they write that the smartphones are easily available for farmers/researchers and could be adopted for "fast and cheap post-event analyses" (conclusions - row 508). Nevertheless, it is not clear how this specific use could be implemented on the base of a work that proposes only a field test for a very small piece of a vineyard. Therefore, I think that this work should analyse the problems that limit the feasibility of the scale-up from experimental plots $(0.25 \mathrm{~m} 2)$ to the whole vineyard and discuss if and how these problems can be overcome. This request is crucial because the deduction of a reader of the present version is that the scale-up is almost automatic while in my opinion it is far from immediate with the proposed technology. In other terms the abovementioned "Conclusion 2" must be corroborated in an effective way.

We thank the reviewer for this comment. In our work, we stated that our analyses were carried out at very-fine scales and that SfM confirmed to be a useful approach to quantify topographic changes at these spatial scales. The final statement we reported in the conclusion (lines 508-511) gives, in our opinion, a general overview of the likely future uses of smartphones for these kind of analyses, without alluding in detail to specific spatial scales. Considering the reviewer comment, we enhanced the above-mentioned 'Conclusion 2' also following Reviewer\#2's suggestions. Please refer to pag. 22, lines 520-532. 
In order to easily understand the characteristics of climate and soils of the experimental site I suggest to report (maybe in the supplementary material):

- results of a chemical-physical analysis of the soil of the vineyard with the main variables (texture, organic matter and so on).

- table with monthly mean values of temperature, precipitation amount and number of rainy days

- climogram of Bagnouls - Gaussen (alias Walter - Lieth) useful to easily see thermal and precipitation regime and the length of the dry period.

All the information we have about the soil and parent material of the study area, are reported at pag. 8, lines 191-197. We corrected the texture of the soil from sandy to sandy loam according to USDA classification by adding the percentages of clay, silt and sand.

About the second and third request, we reported only the Walter-Lieth climate diagram (Figure 3 in the revised version of the paper) because we strongly think we already reported exhaustive information about the study area. The data used to compute the climate diagram derive from the Ontinyent climate station which is the one with the longest records closest to our study site. We specified this in the text (please refer to pag. 9 line 200). For further information, readers can refer to http://www.globalbioclimatics.org/ (pag 9, line 206).

Below we report the replies to each specific comment:

Abstract: please specify the country and the site of the experimental activities

Done. Please refer to pag. 2, line 39.

Row 97: "high intensity rainfall events, mainly concentrated in spring and autumn, which characterize the Mediterranean climate". The Mediterranean is characterized by rainfall concentrated in the winter semester (october-march). This was stated for example by Koeppen which classified as Mediterranean the climates with more than $70 \%$ of the total yearly precipitation concentrated in winter semester.

Reviewer\#1 is right and we added the winter as season (pag. 4, line 100). However, we also left spring because the authors we reported as references gave evidence of the occurrence of extreme events in this season too. These events characterize the Mediterranean climate as well.

Row 108: the authors speak of "catch crops" that are fast-growing crops that are grown between successive plantings of a main crop. For this work this is senseless because vineyard is a permanent crop. More interesting should be to speak of "cover crops" which are a "state of art" approach to the anti-erosion management of vineyard (see for example Ingels C.A., Bugg R.L., McGourty G.T., Christensen L.P. - 1998. Cover crops in vineyards: a grower's handbook, University of California, publication 3338, 154 pp).

Reviewer\#1 is right. We corrected it with 'cover crops' (pag. 5, line 113)

Row 122. I suggest a wrap after "C) stable isotopes".

To be clearer, we considered appropriate to simply write "carbon stable isotopes" (pag. 6, line 130).

Row 179: for the effects on the structure of the soil it is important to know the farm implement adopted for soil cultivation (e.g.: tooth harrow, disc arrow, mouldboard plough) 
Tooth arrow. Information added in the text (pag. 9 line 184).

Row 191: "and bulk density (1.109 g cm-3)" please change in something like "and low bulk density (1.109 g cm-3)"

Done.

Row 416: it is preferable to speak of "net eroded sediments" and "net deposited sediments" because an observed deposition or erosion is always the result of the balance between intakes and losses.

Done.

\section{Reviewer\#2}

We really wish to thank Reviewer\#2 for his/her review of our manuscript. Reviewer\#2 raised useful comments and advices that helped us to improve and clarify the work. Furthermore, he recognized the novelty of our work.

We have done our best to incorporate as much of the Reviewer\#2's suggestions.

Below we report the replies to his/her comments:

The paper is written in a concise and understandable way. It would be interesting to also shortly elaborate on the possible deployment of the technology. What are the best channels to deploy tool use? What training is required? What do you expect about the uptake?

We thank the reviewer for this suggestion. We incorporated it in pag. 22, lines 520-532.

A side note - strictly, tillage is not a soil conservation technique. Zero till is a soil conservation technique. No till is not per se chemical weeding. Please review these concepts. I recommend Amir Kassam's literature.

We thank the reviewer for this comment. In a recent review, Maetens et al. (2012) included in the soil and water conservation techniques (SWCTs) the crop and vegetation management (i.e. cover crops, mulching etc.), the soil management (i.e. no-tillage, reduced tillage, deep tillage etc.) and mechanical methods (i.e. terraces, contour bounds etc.). To be more precise, we substituted soil conservation techniques with soil management techniques. Furthermore, we wrote 'no tillage (where the weeds are usually removed chemically)'. Please refer to pag. 5, lines 102-105.

\section{References}

Maetens, W., Poesen, J., Vanmaercke, M., 2012. How effective are soil conservation techniques in reducing plot runoff and soil loss in Europe and the Mediterranean? Earth Sci. Rev. 115, 21-36. 


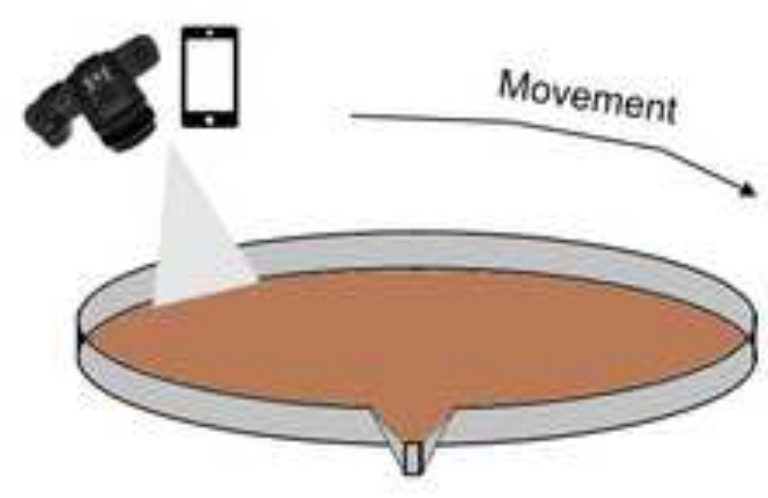

Pre-event pictures

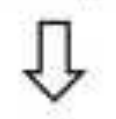

Pre-event Digital Elevation

Model (DEM)
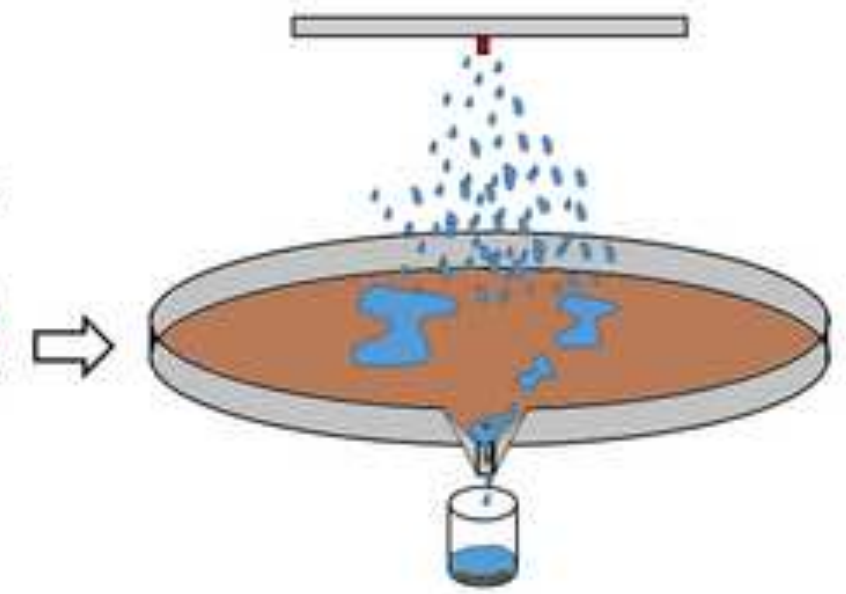

Rainfall simulation

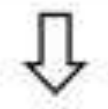

Soil loss

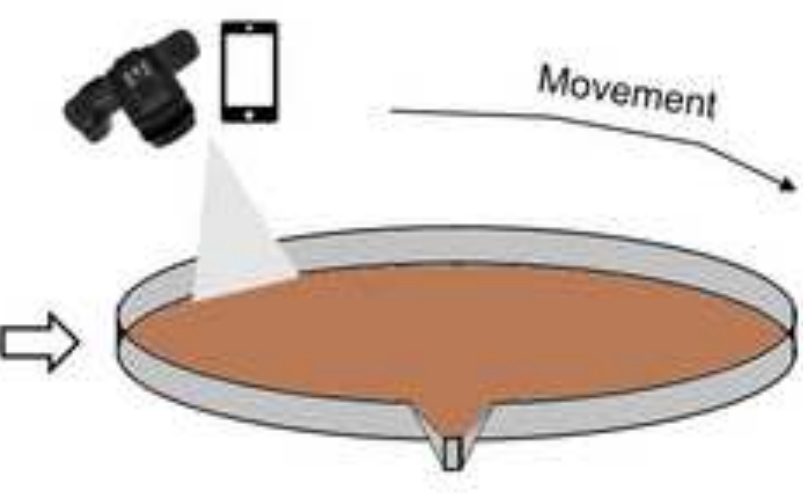

Post-event pictures

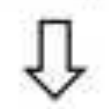

Post-event Digital Elevation Model (DEM)

Post-event DEM - Pre-event DEM

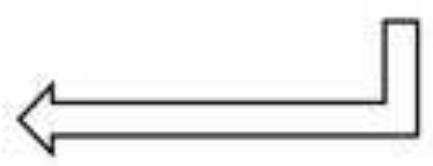


Highlights of the paper "Rainfall simulation and Structure-from-Motion photogrammetry for the analysis of soil water erosion in Mediterranean vineyards"

The core findings of this paper are synthesized as follows:

- Structure-from-Motion is able to detect topographic changes at very fine scales

- Smartphones can be used to obtain reliable image datasets for Structure-fromMotion

- Sediment connectivity plays a key role in estimating eroded materials 
Rainfall simulation and Structure-from-Motion photogrammetry for the analysis of soil water erosion in Mediterranean vineyards

Massimo Prosdocimi ${ }^{a}$, Maria Burguet $^{b}$, Simone Di Prima ${ }^{b}$ Prima $^{c}$, Giulia Sofia ${ }^{a}$, Enric Terol Esparza ${ }^{d}$, Jesús Rodrigo Comino ${ }^{\mathrm{e}, \mathrm{f}}$, Artemi Cerdà $^{\mathrm{b}, \mathrm{g}}$, Paolo Tarollia $^{\mathrm{a}}$

${ }^{a}$ Department of Land, Environment, Agriculture and Forestry, University of Padova, Agripolis, Viale dell'Università 16, 35020 Legnaro (PD), Italy. massimo.prosdocimi@studenti.unipd.it.

bSoil Erosion and Degradation Research Group, Department of Geography, University of Valencia, Blasco Ibáñez, 28, 46010, Valencia, Spain. artemio.cerda@uv.es.artemio.cerda@uv.es.

'Dipartimento di Agraria, Università degli Studi di Sassari, Viale Italia 39, $\underline{07100 \text { Sassari, Italy. }}$
Style Definition: Heading 1: Font: 10 $\mathrm{pt}$

Style Definition: Heading 2: Font: 10 $\mathrm{pt}$

Style Definition: Heading 3: Font: 10 $\mathrm{pt}$, (none)

Style Definition: Heading 4: Font: 10 pt, (none)

Style Definition: Heading 5: Font: 10 pt, (none)

Style Definition: Heading 6: Font: 10 pt, (none)

Style Definition: Heading 7: Font: 10 pt, (none)

Style Definition: Heading 8: (none)

Style Definition: Heading 9: (none)

Style Definition: Comment Subject: Font: (Default) Cambria, (none)

Style Definition: Title: Font: $10 \mathrm{pt}$ Style Definition: Caption

Formatted: Font: 12 pt Formatted

Formatted: Hyperlink, English

(United Kingdom), Highlight 
dDepartment of Cartographic Engineering, Geodesy and Photogrammetry,

Universitat Politècnica de València, Camino de Vera, s/n 46022, Valencia, Spain.

ePhysical Geography, Trier University, 54286 Trier, Germany.

Instituto de Geomorfología y Suelos, University of Málaga, 29071, Málaga, Spain.

${ }^{9}$ Soil Physics and Land Management Group, Wageningen University, Droevendaalsesteeg 4, 6708PB Wageningen, The Netherlands. artemio.cerdabolinches@wur.nl.

Correspondence to: Massimo Prosdocimi (massimo.prosdocimi@studenti.unipd.it), +39 0498272700 (Italy)

\section{Abstract}

Soil water erosion is a serious problem, especially in agricultural lands. Among these, vineyards deserve attention, because they constitute for the Mediterranean areas; a type of land use affected by high soil losses. A significant problem related to the study of soil water erosion in these areas consists in the lack of a standardized procedure of collecting data and reporting results, mainly due to a variability among the measurement methods applied. Given this issue and the seriousness of soil water erosion in Mediterranean vineyards, this works aims to quantify the soil losses caused by simulated rainstorms, and compare them with each other depending on two different methodologies: (i) rainfall simulation and (ii) surface elevation change-based, relying on high-resolution Digital Elevation Models (DEMs) derived from a photogrammetric technique (Structure-from-Motion or SfM). The experiments 
were carried out in a typical Mediterranean vineyard, located in eastern Spain, at very fine scales. SfM data were obtained from one standalone digital-reflex camera and a smartphone built-in camera. An index of sediment connectivity was also applied to evaluate the potential effect of connectivity within the plots. DEMs derived from the smartphone and the reflex camera were comparable with each other in terms of accuracy and capability of estimating soil loss. Furthermore, soil loss estimated with the surface elevation change-based method resulted to be of the same order of magnitude of that one obtained with rainfall simulation, as long as the sediment connectivity within the plot was considered. High-resolution topography derived from SfM revealed to be essential in the sediment connectivity analysis and, therefore, in the estimation of eroded materials, if comparedwhen comparing them to those derived from the rainfall simulation methodology. The fact that smartphones built-in cameras could produce as much satisfying results as those derived from reflex cameras is a high value added to the use offor using SfM.

.

Formatted: Font color: Black, English (United Kingdom)

Formatted: Left

Formatted: Font color: Black, English

(United Kingdom), Not Highlight 
Keywords: soil water erosion, Mediterranean vineyards, rainfall simulation, Structure from Motion, sediment connectivity. 
4 1. Introduction,

Throughout the world, soil erosion by water is a serious problem, especially in semi-arid and semi-humid areas (Barton et al., 2004; Bhatt and Khera, 2006; Cerdà et al., 2009, 2015; Cerdan et al., 2010; Dregne, 1992; García-Ruiz, 2010; Lal, 1995, 2000; SadeghiLigonja and Shrestha, 2015; Novara et al., 2016;Taguas et al., 2015a,b; Zheng, 20062015; Rodrígo Comino et al., 2016a). Although soil erosion by water consists of physical processes that vary significantly in severity and frequency according to when and where they occur, they are also strongly influenced by anthropic factors such as land-use changes on large scales and unsustainable farming practices (Boardman $\underline{\text { Cerdà, 2000; }}$ León et al., 1990; Cerdà 1994; Lal, 19842015; López Vicente et al., 2015; Ochoa-Cueva et al., 2015; Montgomery, 2007; Mwango et al., 2016; Nanko et al., 2015; Tarolli et al., 2014; Tebrügge and Düring, 1999). This has led to the definition of 'accelerated' soil erosion as being the result of human impact on the landscape (Tarolli and Sofia, 2016) and this is found in all the continents (Borrelli et al., 2015, Cao et al., 2015; Gessesse et al., 2015); Rodrigo Comino et al., 2016b).

The impact of soil erosion on modern society has required to set threshold values against which to assess the monitoring of soil data, especially in agriculture (Montgomery, 2007). Among the cultivated lands, vineyards merit a particular attention, because, aside from representing one of the most important crops in terms of income and employment(Anderson and Nelgen, 2011),, they also constitute, for the Mediterranean areas, a form of agricultural land use that causes the highest soil losses (Cerdà and Doerr, 2007; Cerdan et al., 2002,
Formatted: Normal

Formatted: Heading 1 Char, Font: 12 pt, Font color: Auto

Formatted: Heading 1 Char, Font color: Auto 
2010; García-Ruiz, 2010; Garcia-Ruiz et al., 2010; Kosmas et al., 19972010;

Martìnez- Casasnovas and Sànchez-Bosch, 2000; Prosdocimi et al., 2016a;

Raclot et al., 2009; Rodrigo Comino et al., 2015; Rodrigo Comino et al., 2016c).

One of the main reasons for this is the bare soil under the vines that is exposed

to high intensity rainfall events, mainly concentrated in spring-and autumn $\underline{\text { and }}^{2}$

winter, which characterize the Mediterranean climate (Arnáez et al., 2007;

Borga et al., 2011; García-Ruiz, 2010; Prosdocimi et al., 2016a). In factFor this

cultivation, the two most common soil conservationmanagement techniques

(SCTs) are considered to be tillage (mechanical weeding), where the weeds are

usually removed mechanically, and no-tillage-(chemical weeding), where the

weeds are usually removed chemically (Novara et al., 2011; Raclot et al., 2009),

and both of them generally turn out in bare soil management during the whole

year-(Lasanta and Sobrón, 1998)... Extreme rainfall events that occur in the

Mediterranean area are able to cause significant soil water erosion processes,

especially when no protective material covers the soil (Figure 1) (Bisantino et

|al., 2015; Keesstra et al., 2016; Novara et al., 2016).; Prosdocimi et al., 2016c).

However, to reduce the high soil erosion rates, more conservation-minded soil

management practices have also been used such as mulching (Cerdà et al.,

2015; Costantini et al., 2015; Jordán et al., 2011; Prosdocimi et al., 2016b),

catch,c), cover crops (Novara et al., 2011), rock fragments (Blavet et al., 2009),

natural grassing (Grimaldi et al., 2015; Mekonnen et al., 2015a; Mekuria et al..,

2016; Raclot et al., 2009) and geotextiles (Giménez-Morera et al., 2010;

Mekonnen et al., 2015b; Mengistu et al., 2016). Furthermore, new approaches

to evaluate incentives for the adoption of agri-environment measures in

degraded and eroded vineyards have been implemented (Galati et al., 


\section{5).2015) and mulching is one of those successful strategies (Prosdocimi et}

al., 2016c).

Another issue related to soil water erosion in Mediterranean vineyards is the lack of a standardized procedure of collecting data and reporting results, mainly due to a great variability among the measurement methods applied to quantify it (Prosdocimi et al., 2016a; García-Ruiz et al., 2015). This induces difficulties in comparing data coming from different studies and obtained with different methodologies. Based on the paper review of Prosdocimi et al. (2016a), six different methodologies to assess soil water erosion in vineyards have been identified: (i) experimental plot stations under simulated or natural rainfalls, (ii) erosion markers, (iii) models, (iv) the surface elevation change-based methods, (v) geochemical methods, and (vi) carbon (C)-stable isotopes. This works focuses on the use of plot stations under simulated rainfall and on the surface elevation change-based method. Rainfall simulation has become a very effective technique for assessing soil erosion, particle detachment and overland flow at very fine scales (Arnáez et al., 2007; Cerdà et al., 1997; Iserloh et al., 2013; Rodrigo Comino et al., 2016; Tossel et al., 1987).2016b). Several types and designs of rainfall simulators have been realized to meet the objectives of | researchers (Iserloh et al., 2013; Lassu et al., 2015; Tossel et al., 1987)..). In particular, the advantages of using a portable rainfall simulator are: i) its versatility, ii) low cost and easy operation-(Walsh et al., 1998), and iii) capability of obtaining data under controlled conditions and over relatively short periods of time-(Navas et al., 1990)... The surface elevation change-based method is able to detect the topographic changes over time. It relies on Digital Elevation Models (DEMs) that can be used as basic topographic information to derive 
morphometric attributes and quantify soil erosion and deposition rates

(Martínez-Casasnovas and Sánchez-Bosch, 2000; Martínez-Casasnovas et al., 2002; Prosdocimi et al., 2015). Remote-sensing technologies have proven to facilitate significantly the creation of high-resolution DEMs (Farolli, 2014; Tarolli et al., 2015):Aucelli et al., 2016; Tarolli, 2014; Tarolli et al., 2015), and the availability of DEMs at multiple scales in terms of resolution but also temporal coverage is becoming essential to the understanding of global issues, such sediment production and anthropogenic changes to the Earth system, among others (Sofia et al., 2016). The recent development of the photogrammetric technique 'Structure-from-Motion' (SfM) has confirmed to represent a valid and cheaper alternative to the established airborne and terrestrial lidar (Light Detection and Ranging) technology for measuring soil surface changes in different environments (Dandois and Ellis, 2013; Eltner et al., 2015; James and Robson, 2012; Masiero et al., 2015; Piermattei et al., 2016; Westoby et al., 2012; Whitehead et al., 2013; Woodget et al., 2014)-2015). All this information can shed light into the connectivity within the soil and water losses (LópezVicente et al., 2016; Marchamalo et al., 2016; Masselink et al., 2016). The growing interest for SfM has been enhanced by the fact that it is a userfriendly technique, and that it can also rely on smartphone built-in cameras (Masiero and Vettore, 2016; Micheletti et al., 2014; Prosdocimi et al., 2015) and on the diffusion of unmanned aerial vehicles (UAVs) (Chen et al., 2015;

Colomina and Molina, 2014).

Given the seriousness of soil water erosion in Mediterranean agricultural lands and the issue of putting data obtained with different methodologies in relation to each other, this works intends to quantify the soil losses caused by simulated 
rainstorms, and compare them with each other depending on two different methodologies used: (i) rainfall simulation and (ii) surface elevation changebased, relying on high-resolution DEMs derived from SfM. Furthermore, this work aims to compare the results obtained from SfM with each other, depending on the type of camera used. The objectives are pursued by carrying out the experiments in a typical Mediterranean vineyard, under tillage conditions, located within the province of Valencia (Spain), at very fine scales $\left(0.25 \mathrm{~m}^{2}\right)$.

\section{Material and Methods}

\subsection{Study area}

The study area consists in a 25-year-old vineyard, located at El Celler del Roure in Les Alcusses de Moixent, within the Canyoles river watershed in the province of Valencia (La Costera District, eastern Spain) (38 $48^{\prime} 33.12^{\prime \prime} \mathrm{N}, 0^{\circ} 49^{\prime} 3.27^{\prime \prime}$ O). Vines are located parallel to the contour lines and the inter-rows, which are 
about $2.5 \mathrm{~m}$ wide, are artificially maintained bare during the whole year through tillage operations carried out with a Landini Rex 95 tractor- which adopts a tooth arrow as farm implement. The portion affected by the tractor wheel tracks results to be about $36 \%$ of the total inter-row area (Figure 2). Climate is typically Mediterranean with 3-5 months of summer drought (June-September). Mean annual rainfall is about $350 \mathrm{~mm} \mathrm{yr}^{-1}$. Rainfall is distributed amongst autumn, winter and spring, with maximum peak rainfall intensities during the autumn season, where values higher of $200 \mathrm{~mm} \mathrm{day}^{-1}$ were recorded during the last 50 years. Mean annual temperature is about $13.8^{\circ} \mathrm{C}$ while the hottest month (August) has average temperatures of about $23^{\circ} \mathrm{C}$. The parent materials in this area belong to Cretaceous limestones and Tertiary Marly deposits that develop Typic Xerothent soils (Soil Survey Staff, 1998). The soils are characterized by low levels of soil organic matter $(<1 \%)$ due to the millennia of agricultural use and soil disturbance (ploughing), basic pH (8) (Prosdocimi et al., 2016b), sandy loam soil textures, (clay $19.3 \%$, silt $13.4 \%$ and sand $67.3 \%$ ), and low bulk density $\left(1.109 \mathrm{~g} \mathrm{~cm}^{-3}\right)$.

$\underline{\text { To better characterize the climate of our study site, Walter-Lieth climate }}$ diagram (Walter and Lieth, 1960) has been obtained using data derived from Ontinyent climate station as it is the one with the longest records (29 years) closest to the study site (about $17 \mathrm{~km}$ ) (Figure 3). The diagram displays monthly averages for temperature and precipitation over a year. When the precipitation 
curve undercuts the temperature curve, the area in between them indicates dry

season. When the precipitation curve supersedes the temperature curve, the

area in between them indicates moist season. For further information, readers

may refer to http://www.globalbioclimatics.org/.

\subsection{Experimental plot design}

Formatted: Font: $12 \mathrm{pt}$

Four circular steel plots $\left(0.25 \mathrm{~m}^{2}\right)$ were located in the bare inter-rows of the vines managed with conventional tillage, and are referred to in the text as 1,2 , 3 and 4 . Each plot was placed in a different inter-row and had an outlet, which allowed to converge and collect the surface runoff samples during the runoff simulation experiments. For each plot, five targets (SfM-targets), made of black and white polythene squares, were used: four $(5.5 \mathrm{~cm} \times 5.5 \mathrm{~cm})$ were placed outside the circular plots and one $(2.5 \mathrm{~cm} \times 2.5 \mathrm{~cm})$ inside the plot (Figure 34). SfM-targets centroids were surveyed using a Topcon GRS-1 rover receiver running in real time kinematic (RTK) mode. In addition, other thirteen groundcontrol points (GCPs) were surveyed in the immediate neighborhood of each plot.

\subsection{Rainfall simulation}

A one-nozzle (Hardi-1553-12) rainfall simulator was used to reproduce seven rainstorms at $55 \mathrm{~mm} \mathrm{~h}^{-1}$ rainfall intensity for one hour on the 4 circular plots of $0.25 \mathrm{~m}^{2}$. For plots 1,2 and 3 , a single rainfall experiment was carried out, while for plot 4 , four rainfall experiments were carried out during four consecutive days, and are referred to in the text as $4 A, 4 B, 4 C$ and $4 \mathrm{D}$. Storms similar to the ones simulated have a return period of 10 years in the study area (Cerdà, 1996; 
Prosdocimi et al., 2016b). The rainfall simulator used was the one described by Cerdà et al. (1997) because it revealed to be effective in rugged terrain conditions proving to give good results in semi-arid environments. Its basic components are a nozzle, a structure that holds the nozzle, the connection with the water supply, the pumping system and a tarpaulin to protect the rainfall simulation from wind. As the nozzle was kept at about $2 \mathrm{~m}$ height over a plane surface, the $0.25 \mathrm{~m}^{2}$ plots were established at the centre of the $1 \mathrm{~m}^{2}$ sprinkling area, to avoid border interference. Readers are referred to Cerdà et al. (1997) and Iserloh et al. (2013) for a further description of the rainfall simulator used and Cerdà (1996; 1997) for more information about the distribution of rainfall parameters. Surface runoff from the plots were collected and measured at 1min intervals during each simulated rainfall event. Every tenth 1-min runoff sample was collected for laboratory analysis in order to determine sediment concentration, that was obtained after the desiccation of the samples in the laboratory. Then, runoff rates and sediment concentration were used to calculate the soil loss, runoff, runoff coefficient, and erosion rates.

\subsection{Surface elevation changes through Structure-from-motion}

Photographs of each plot were taken using two different types of camera: (i) a standalone digital reflex camera (Nikon D3000 at $10.2 \mathrm{MP}$ resolution, set at a focal length of $35 \mathrm{~mm}$ ) and (ii) a smartphone, precisely a BQ Aquaris E5, built-in camera (13 MP resolution) with both automatic focusing and exposure enabled. The choice of using two cameras was due to test the effectiveness of SfM, also when it relies on an image dataset derived from a smartphone. Twenty photographs were taken before and after the rainfall simulation using each 
camera. A $1 \mathrm{~m}$ high support having two boxes, that were $0.3 \mathrm{~m}$ far from each other and capable of holding the cameras, was used to take the pictures (Figure 45). Photographs were taken inside the rainfall simulator covered by the tarpaulin to have a homogeneous light over the plots.

The SfM technique was then used to obtain three-dimensional (3D) georeferenced point clouds and to generate $0.01 \mathrm{~m}$ resolution DEMs for each plot. The thirteen points collected in the immediate neighborhood of each plot (see the previous chapter Experimental plot design) were used as GCPs to assess the accuracy and precision of the DEMs through the computation of the root-mean-square-error (RMSE), mean error, and standard deviation of error (SDE). The working principles of SfM are similar to those of stereoscopic photogrammetry, namely that the 3D model can be created from overlapping, offset images. However, unlike traditional photogrammetry, in which either the position of the camera or the positions of some points are known prior to scene reconstruction (Fonstad et al., 2013; Verhoeven et al., 2012; Westoby et al., 2012), in the SfM, matches are made between points across many photographs without prior knowledge of the camera position (Lowe, 2004).

The images acquired were processed using the commercial software Agisoft PhotoScan ${ }^{\circledR}$, as already successfully considered in different analyses (Doneus et al., 2011; Javernick et al., 2014; Piermattei et al., 2016; Prosdocimi et al., 2015; Verhoeven et al., 2012; Woodget et al., 2015). A custom algorithm similar to the Lowe's (2004) Scale Invariant Feature Transform (SIFT) object recognition system was used by the software to determine the 3D location of matching features in multiple images. Then, camera position was calculated by estimating the camera's intrinsic (focal length, principal point, and lens 
distortion) and extrinsic (projection centre location and the six exterior orientation parameters that define the image) orientation parameters. This was done by using a bundle-adjustment algorithm (Javernick et al., 2014; Robertson and Cipolla, 2009; Verhoeven et al., 2012). Afterwards, the software created a dense surface, usually referred to as mesh, by using these parameters and a dense multi-view stereo reconstruction (DMVR) (Agisoft, 2016). The mesh was generated in a relative 'image-space' coordinate system (Westoby et al., 2012), and therefore, it required to undergo a linear similarity transformation using seven parameters (three translation, three rotation, and one scaling), based on known GCPs, to be transformed to an absolute coordinate system. The GCPs corresponded to the SfM-targets centroids, whose the $x, y$ and $z$ coordinates were previously recorded with Topcon GRS-1. As the linear similarity transformation could not remove non-linear model misalignments (Woodget et al., 2015), an optimization transformation method was applied to minimize geometric distortions within the mesh (Agisoft, 2016). Thereafter the mesh was rebuilt and the 3D georeferenced point could be exported. The georeferenced point clouds are referred to in the text as GEOPre ${ }_{\mathrm{NKN}}$ and GEOPost $\mathrm{NKN}_{\mathrm{N}}$, for those derived from the Nikon camera before and after the rainfall simulation,

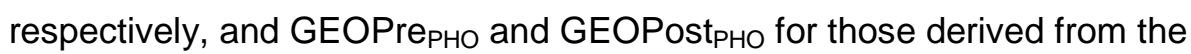
smartphone camera before and after the rainfall simulation, respectively. Furthermore, the number of the plot is also included $(1,2,3,4 \mathrm{~A}, 4 \mathrm{~B}, 4 \mathrm{C}$ and 4D).

Then, the SfM final point clouds were further manipulated using the open source program CloudCompare ${ }^{\circledR}$ (http://www.danielgm.net/cc/)GirardeauMontaut, 2015) to remove additional noise that typically affects these data 
(Javernick et al., 2014; Prosdocimi et al., 2015). In this case, given the small size of the plots, the noise removal was accomplished manually. Finally, the elevation points were interpolated by the natural neighboursneighbor method (Sibson, 1981) to generate $0.01 \mathrm{~m}$ resolution DEMs. The DEMs are referred to in the text as DEMPre ${ }_{N K N}$ and DEMPost ${ }_{N K N}$, for those derived from the Nikon camera before and after the rainfall simulation, respectively, and DEMPre $\mathrm{PHO}$ and DEMPost $\mathrm{PHO}_{\mathrm{O}}$ for those derived from the smartphone camera before and after the rainfall simulation, respectively. Furthermore, the number of the plot is also included (1, 2, 3, 4A, 4B, 4C and 4D). The DEMsPre NKN $_{\text {obtained for each }}$ plot are shown in Figure $5 \underline{6}$.

For the objectives of this work, all the analysis werewas based on the final DEMs, as done by Bangen et al. (2014), Calligaro et al. (2013), Javernick et al. (2014), Prosdocimi et al. (2015), Tarolli et al. (2015), and Wechsler (2007). The DEMs derived from the smartphone were then directly compared to the DEMs derived from the camera, by assuming a normal distribution and using robust statistical methods (Höhle and Höhle, 2009; Prosdocimi et al., 2015). This entailed the computation of the mean error, SDE, RSME, median, and normalized median absolute deviation (NMAD).

\subsection{Computation of soil loss}

Soil loss was computed for both rainfall simulation and surface elevation change-based methodologies. For rainfall simulation methodology, the runoff samples were used to determine the sediment concentration and, then, the runoff rates and sediment concentration were used to calculate the total soil loss (g). For the surface elevation change-based methodology, SfM was applied 
to obtain high-resolution DEMs before (DEMsPre) and after (DEMsPost) the rainfall simulation. Then, the so-called morphological method (Ashmore and Church, 1998) was used to estimate the soil loss. The morphological method consists in carrying out repeated topographic surveys from which DEMs can be obtained and differenced to produce DEMs of difference (DoDs). The volumes of eroded materials $\left(\mathrm{cm}^{3}\right)$ were computed by considering the DEMsPre and DEMsPost for each plot and for each camera by using the Geomorphic Change Detection (GCD) 6.1.14 toolbar embedded in an ESRI® add-in for ArcGIS 10.X that is freely downloadable from http://gcd.joewheaton.org/downloads. Then, the volumes of eroded materials were turned into soil loss expressed in grams, by knowing the bulk density. The GCD allows to compute the volumes of deposited materials too, but, for this work, only eroded materials have been considered, to make a comparison with the soil loss derived from the rainfall simulation methodology. The DoDs are referred to in the text as DoDs NKN $_{\text {and }}$ and

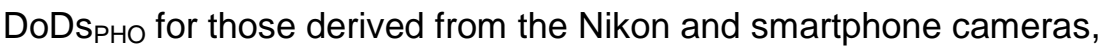
respectively. DEMs' uncertainty in DoDs has also been considered (Brasington et al., 2000; Lane et al., 1994; Lane, 1998; Lane et al., 2003; Prosdocimi et al., 2015; Wheaton, 2008; Wheaton et al., 2010). In this case, DEMs' uncertainties were evaluated according to a probabilistic thresholding that can be carried out with a user-defined confidence interval (Brasington et al., 2003; Lane et al., 2003; Taylor, 1997):

$$
U_{\text {crit }}=t\left(\sqrt{S D E_{\text {new }}^{2}+S D E_{\text {old }}^{2}}\right)
$$

where $U_{\text {crit }}$ is the critical threshold error propagated in the DoD and $S D E_{\text {new }}$ and $S D E_{\text {old }}$ are the individual standard deviation errors in $\mathrm{DEM}_{\text {new }}$ (post-event) and 


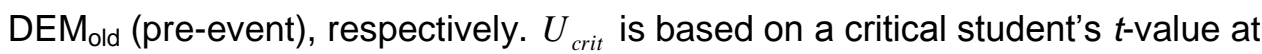
a chosen confidence interval where:

$$
t=\frac{\left|z_{\text {DEMnew }}-z_{\text {DEMold }}\right|}{\delta u_{D o D}}
$$

where $\left|z_{\text {DEMnew }}-z_{\text {DEMOld }}\right|$ is simply the absolute value of the DoD. The probability of a DoD predicted elevation change occurring due the uncertainty can then be calculated by relating the $t$-statistic to its cumulative distribution function. In this work, we used the $95 \%$ confidence interval as a threshold, as also suggested by Wheaton et al. (2010).

\subsection{Sediment connectivity}

Formatted: Font: $12 \mathrm{pt}$

Sediment connectivity is defined as the connected transfer of sediment from a source to a sink in a system through processes of sediment detachment and transport (Bracken et al., 2015). The concept of connectivity ishas increasingly been used in quantitative process-based sediment dynamics research, especially at catchment scales (Ali et al., 2014; Baartman et al., 2013; Bracken and Croke, 2007; Bracken et al., 2015; Brierley et al., 2006; Cavalli et al., 2013; Fryirs et al., 2007; Heckmann and Schwanghart, 2013; Lexartza-Artza and Wainwright, 2011; López-Vicente et al., 2013; Wainwright et al., 2011). Geomorphology has been considered as a major driver on determining sediment connectivity (Heckmann and Schwanghart, 2013; Theler et al., 2010), and geomorphometric indices have increasingly been developed to assess it (Borselli et al., 2008; Cavalli et al., 2013; López-Vicente et al., 2013; Reid et al., 2007; Sougnez et al., 2011). In this study we applied the index of connectivity (IC) as proposed by Cavalli et al. (2013) based on the work of Borselli et al. 
(2008), to evaluate the potential effect of sediment connectivity within the plots.

The reasons for this choice relied on the facts that the IC (i) is a distributed geomorphometric index that can be easily derived from a DEM, (ii) can be computed with reference to specific target features, and (iii) has been adapted for high-resolution DEMs. The IC has been developed as a ToolBox for ArcGis 10.1 or as stand-alone application based on Python scripting with bindings for processing geographical datasets. It uses functionalities and algorithms available in TauDEM 5.2 tool (Tarboton 2013) and it is freely downloadable from http://www.sedalp.eu/download/tools.shtml. This index mainly focuses on the influence of topography on sediment connectivity, and takes into account the characteristics of the drainage area (upslope component, $D_{\text {up }}$ ) and the flow path length that a particle has to travel to arrive at the nearest sink (downslope component, $\left.D_{d n}\right)$.

The IC is computed as follows:

$$
I C=\log _{10}\left(\frac{D_{u p}}{D_{d n}}\right)=\log _{10}\left(\frac{\bar{W} \bar{S} \sqrt{A}}{\sum_{i} \frac{d_{i}}{W_{i} S_{i}}}\right)
$$

where $\bar{W}$ is the average weighting factor of the upslope contributing area (dimensionless), $\bar{S}$ is the average slope gradient of the upslope contributing area $(\mathrm{m} / \mathrm{m}), A$ is the upslope contributing area $\left(\mathrm{m}^{2}\right), d_{i}$ is the length of the flow path along the $i^{\text {th }}$ cell according to the steepest downslope direction (m), $W_{i}$ and $S_{i}$ are the weighting factor and the slope gradient of the $i^{\text {th }}$ cell, respectively. IC can assume values ranging from $-\infty$ to $+\infty$, with connectivity increasing for larger IC values. 


\section{Results and discussion}

\subsection{Nikon and smartphone built-in cameras comparisons}

Regarding the comparisons between the Nikon and smartphone built-in cameras, the georeferentiation errors (RMSE) calculated by the Agisoft PhotoScan ${ }^{\circledR}$ software along the $x, y$ and $z$-axes for each SfM point cloud are reported (Table 1). The SfM point clouds show an average error of the order of about $0.01 \mathrm{~m}$ along the $\mathrm{x}$-axis, and an even lower order error along the $\mathrm{y}$ and $\mathrm{z}$ axes. These good results support the choice of setting the DEMs resolution equal to $0.01 \mathrm{~m}$ and can be explained by the fact that: (i) the plots were very small, (ii) the 5 SfM-targets were well distributed over each plot, and (iii) the pictures were taken in a correct way, thanks to the support used, the expedient of shooting photographs inside the tarpaulin, and the short distance between the position of the cameras and the plots (about $1 \mathrm{~m}$ ). Furthermore, differences

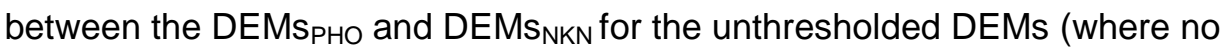
uncertainty analysis was carried out) were also evaluated with accuracy measures assuming a normal distribution and more robust parameters too (Table 2). From Table 2, emerges that all the DEMs PHO $_{\text {are comparable to }}$ $D_{\text {DEM }}$ NKN. Mean values are of the order of about $0.0001 \mathrm{~m}$ and SDE values of the order of about $0.001 \mathrm{~m}$. Skewness and kurtosis confirm the fact that the elevation differences do not follow normal distributions (Höhle and Höhle, 2009; Sofia et al., 2013), and this supports the choice of considering more robust 
parameters too such as NMAD and median. However, also when considering

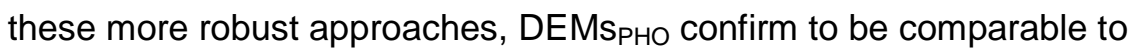
DEMs $_{\text {NKN }}$, showing NMAD and median values of the order of about 0.001 and $0.001 \mathrm{~m}$, respectively.

\subsection{Soil loss}

Figure $6 \underline{7}$ shows the DoDs derived from SfM, by considering the DEMsPre ${ }_{\mathrm{NKN}}$ and DEMsPost ${ }_{N K N}$ for each plot, thresholded according to the probabilistic thresholding with a $95 \%$ confidence interval. The fact that, the thresholding of DoDs entails a loss of information, is expected and occurs at the expense of a better geomorphic plausibility (Wheaton et al., 2010). Elevation differences range from negative values (red colour), to which correspond net eroded sediments, to positive values (blue colour), to which correspond net deposited sediments. From Figure $6 \underline{7}$ emerges that plots $1,2,3$ and $4 \mathrm{~A}$ mainly show negative elevation differences. This means that the single simulated rainfall event caused more erosion than deposition, and this can be explained by the fact that the plots, at the beginning, have more material which is prone to be washed away. In contrast, plots 4B, 4C and 4D show greater elevation differences. This suggests that, as rainfall events follow one another, the soil particles, that are susceptible to be eroded, diminish, and therefore, the soil shows elevation differences which are closer to zero values, where zero corresponds exactly to no difference at all between before and after the rainstorm.

Figure $7 \underline{8}$ shows the soil loss data, expressed in grams, derived from both the methodologies applied. For the surface elevation change-based method, the data coming from the DoDs obtained with both the Nikon and smartphone 
cameras are reported. From Figure $7 \underline{8}$ emerges how the soil loss data estimated with the two methodologies are not comparable with each other, especially for the plots $1,2,3$ and $4 \mathrm{~A}$, where only a single rainstorm was artificially reproduced. On the contrary, soil loss data derived from the same methodology, namely surface elevation change-based, are comparable with each other, independently from the type of camera used. Soil loss derived from the surface elevation change-based method result to be of two orders of magnitude greater than the one obtained with rainfall simulation. However, this discrepancy is in line with the processes that are involved and analysed with the two different methodologies. Rainfall simulation accounts for splash and initial inter-rill erosion processes and allows to study the impact of rain drops on sediment detachment, transport and runoff initiation. However, when it rains the water is able to disintegrate some of the soil aggregates, leading to the collapse of micro-pores and to the surface seal formation. Furthermore, the water that infiltrates makes also the soil heavier, causing a lowering of the soil surface, which is the process that DoDs are able to detect. To overcome this discrepancy between the two methodologies, sediment connectivity within the plots has been taken into consideration too.

\subsection{Sediment connectivity analysis}

Other than rainfall intensity and kinetic energy, also micro-topography plays a key role in the collection of eroded materials, especially when the experiments are carried out at very fine scales, as in our case. To prove this, Figure $8 \underline{9}$ shows the maps of the connectivity index calculated with regard to the plots outlets, by considering, as inputs, the DEMsPre ${ }_{\mathrm{NKN}}$. As no reference theory exists for the partitioning of the connectivity index into classes, we relied on the 
same classification provided by Tarolli and Sofia (2016), in which they proposed to adopt a relative classification into four classes (High, Medium-High, MediumLow and Low) by considering break points that best grouped similar values and maximized the differences between classes (natural breaks).

From Figure $8 \underline{9}$ emerges how (i) each plot has different patterns of sediment connectivity, which vary whether or not consecutive rainstorms occur (Figure $8 d 9 d, e, f$ and $g$ ), and (ii) not all the soil within the plots is connected to the outlet. This proves the fact that the placement of the plots in the field is extremely important because micro-reliefs with their roughness can facilitate sediment dis-connectivity. The portions of soil that are more connected to the outlet are those that are closer to it. Therefore, these portions, which correspond to the Medium-High and High classes of the connectivity index maps, are reasonably those that will be more prone to erosion, once the rainstorm occurs. As a consequence, by masking the elevation differences maps (Figure 67) with the Medium-High and High classes of the connectivity index maps (Figure 89), we re-computed the soil loss derived from the surface elevation change-based method, considering both the Nikon (DoDs $\left.\mathrm{NKN}_{\mathrm{N}} \mathrm{IC}\right)$ and smartphone (DoDspHO IC) DoDs (Figure 910).

Differently from what emerged from Figure $7 \underline{8}$, Figure $9 \underline{10}$ illustrates that the soil loss data, estimated with the two methodologies, are of the same order of magnitude, as long as the sediment connectivity within the plot is taken into consideration. These results confirm the importance of micro-topography in the sediment connectivity and, consequently, in the estimation of eroded materials. 


\section{Conclusions}

In this work, we quantified the soil losses caused by water and compared them with each other, depending on two different methodologies applied: rainfall simulation and surface elevation change-based, relying on high-resolution DEMs derived from SfM. The experiments were carried out in a typical Mediterranean vineyard, under tillage conditions, at very fine scales. SfM data were derived from one standalone digital reflex camera and a smartphone builtin camera. We also applied an index of connectivity (IC) to evaluate the potential effect of sediment connectivity within the plots. Compared to the $D_{\text {DEMs }}$ NKN, we evaluated the DEMs $s_{\text {PHO }}$ in terms of (i) accuracy, and (ii) capability to estimate soil loss with regard to the results derived from the rainfall

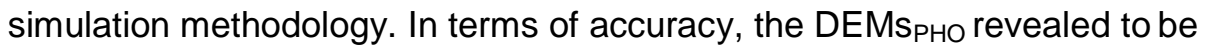
comparable with the DEMs $\mathrm{NKN}_{\mathrm{N}}$, by assuming a normal distribution of errors and with more robust parameters too. Also regarding the estimation of soil losses, caused by the rainstorms artificially reproduced, through the surface elevation change-based methodology, the results between the two different types of cameras used were comparable with each other. What they differed from was the soil losses data estimated with the rainfall simulation. However, this discrepancy was overcome when the sediment connectivity within the plot was taken into consideration by computing the IC index. In conclusion, highresolution topography derived from SfM revealed to be essential in the sediment connectivity analysis and, therefore, this, proved to play a key role in the estimation of eroded materials, if compared them to those derived from 
another methodology such as the rainfall simulation. SfM confirmed to be a useful approach to quantify topographic changes in agricultural lands, also at very fine scales, and revealed to be capable of detecting the more random changes, less easily traceable, induced by the rainstorms. In addition, the fact that smartphones built-in cameras can produce as much satisfying results as those derived from standalone digital reflex cameras is undoubtedly a high value added. Nowadays, smartphones are commonly available for anyone, from farmers to researchers, and will become increasingly important for fast and cheap post-event analyses, as long as they are provided with a high-resolution camera. The increasing development of computer vision technologies and digital camera sensors makes the process of taking good pictures quite easy. A farmer would require few hours of training to learn how to take good pictures of a specific case study, i.e. a rill process, located in its own land. Afterwards, he would be completely independent during the whole field survey, and then he could send the pictures taken to a researcher for further analyses. In this way, the famer could easily keep monitoring some of the erosion processes that occur in his land and the researcher could provide him quantitative information about net erosion and deposition rates. However, it also should be said that the spatial scale plays a fundamental role in the feasibility of using smartphones for post-event analyses. For erosion processes that occur at field or catchment scales, the use of aerial photogrammetry, supported by the increasing diffusion of UAVs, is more recommended. 


\section{Acknowledgements}

The research leading to these results has received funding from the Research

Formatted: Spanish (Spain,

International Sort)

project 60A08-5455/15 of University of Padova (Italy), entitled "The analysis of the topographic signature of anthropic processes" and from the European Union

Formatted: Spanish (Spain, Seventh Framework Programme (FP7/2007-2013) under grant agreement $\mathrm{n}^{\circ}$ 603498 (RECARE project).

The authors also thank the M.Sc. student Nicoletta Pradetto Sordo to help to carry out the photogrammetric surveys and the rainfall simulation experiments, and Enric Terol Esparza to provide techincal support for the photogrammetric surveys. 


\section{References}

Agisoft., 20152016. Agisoft PhotoScan User Manual: Professional Edition.

Version 1.0. http://www.agisoft.ru/products/photoscan/professional/ [duneSeptember 2016].

Ali, G., Birkel, C., Tetzlaff, D., Soulsby, C., McDonnell, J.J., Tarolli, P., 2014. A comparison of wetness indices for the prediction of connected saturated areas under contrasted conditions. Earth Surface Processes and Landforms 39, 399-413.

Anderson, K., Nelgen, D., 2011. Global wine markets, 1961 to 2009: a statistical compendium, Adelaide: University of Adelaide Press. ISBN 978-0$9870730-1-3$

Arnáez, J., Lasanta, T., Ruiz-Flaño, P., Ortigosa, L., 2007. Factors affecting runoff and erosion under simulated rainfall in Mediterranean vineyards. Soil \& Tillage Research 93, 324-334.

Ashmore, P.E., Church, M., 1998. Sediment transport and river morphology: a paradigm for study, in: Klingeman, P.C., Beschta, R.L., Komar, P.D., Bradley, J.B. (Eds), Gravelbed Rivers in the Environment, Water Resources Publications: Highlands Ranch, CO, pp. 115-148. Aucelli, P.P.C., Conforti, M., Della Seta, M., Del Monte, M., D'uva, L., Rosskopf, C.M., Vergari, F., 2016. Multi-Temporal Digital Photogrammetric Analysis for Quantitative Assessment of Soil Erosion Rates in the Landola 


\section{Catchment of the Upper Orcia Valley (Tuscany, Italy). Land Degradation}

and Development 27 (4), 1075-1092. doi:10.1002/ldr.2324.

Baartman, J.E.M., Messelink, R., Keesstra, S.D., Temme, A.J.M., 2013. Linking landscape morphological complexity and sediment connectivity. Earth Surface Processes and Landforms 38, 1457-1471.

Bangen, S., Wheaton, J., Bouwes, N., Jordan, C., Volk, C., Ward, M.B., 2014.

Crew variability in topographic surveys for monitoring wadeable streams: a case study from the Columbia River Basin. Earth Surface Processes and Landforms 39(15), 2070 - 2086.

Barton, A.P., Fullen, M.A., Mitchell, D.J., Hocking, T.J., Liu, L., Bo, Z.W., Zheng Y, Xia, Z.Y. 2004. Effects of soil conservation measures on erosion rates and crop productivity on subtropical Ultisols in Yunnan Province, China. Agriculture, Ecosystems and Environment 104, 343-357.

Bhatt, R., Khera, K.L., 2006. Effect of tillage and mode of straw mulch application on soil erosion in the submontaneous tract of Punjab, India. Soil \& Tillage Research 88, 107-115.

Bisantino, T., Bingner, R., Chouaib, W., Gentile, F., Trisorio Liuzzi, G., - 2015. Estimation of runoff, peak discharge and sediment load at the event scale in a medium-size mediterranean watershed using the annagnps model. Land Degradation and Development 26 (4), 340-355. DOI: 10.1002/ldr.2213

Blavet, D., De Noni, G., Le Bissonnais, Y., Leonard, M., Maillo, L., Laurent, J.Y., Asseline, J., Leprun, J.C., Arshad, M.A., Roose, E., 2009. Effect of land use and management on the early stages of soil water erosion in French Mediterranean vineyards. Soil Tillage Res. 106, 124 - 136. 
Boardman, J., Foster, I.D.L., Dearing, J.A., 1990. Soil Erosion on Agricultural Land. John Wiley and Sons Ltd., Chichester.

Borga, M., Anagnostou, E.N., Bloschl, G., Creutin, J.D., 2011. Flash flood forecasting, warning and risk management: the HYDRATE project. Environmental Science \& Policy 14 (7), 834-844.

Borrelli, P., Märker, M., Schütt, B., 2015. Modelling Post-Tree-Harvesting soil erosion and sediment deposition potential in the Turano river basin (Italian central Apennine). Land Degradation and Development 26 (4), 356-366. DOI: 10. 1002/ldr. 2214.

Borselli, L., Cassi, P., Torri, D., 2008. Prolegomena to sediment and flow connectivity in the landscape: a GIS and field numerical assessment. Catena 75, 268-277.

Bracken, J., Turnbull, L., Wainwright, J., Bogaart, P., 2015. Sediment connectivity: a framework for understanding sediment transfer at multiple scales. Earth Surface Processes and Landforms 40, 177-188.

Bracken, L.J., Croke, J., 2007. The concept of hydrological connectivity and its contribution to understanding runoff-dominated geomorphic systems. Hydrological Processes 21, 1749-1763.

Brasington, J., Langham, J., Rumsby, B., 2003. Methodological sensitivity of morphometric estimates of coarse fluvial sediment transport. Geomorphology 53(3-4), 299-316.

Brasington, J., Rumsby, B.T., Mcvey, R.A., 2000. Monitoring and modelling morphological change in a braided gravel-bed river using high resolution GPS-based survey. Earth Surface Processes and Landforms 25(9), 973990. 
Brierley, G., Fryirs, K., Jain, V., 2006. Landscape connectivity: the geographic basis of geomorphic applications. Area 38, 165-174.

Calligaro, S., Sofia, G., Prosdocimi, M., Dalla Fontana, G., Tarolli, P., 2013.

Terrestrial laser scanner data to support coastal erosion analysis: the

Conero case study. International Archives of the Photogrammetry, Remote

Sensing and Spatial Information Sciences 40(5W3), 125-129. DOI.

10.5194/isprsarchives-XL-5-W3-125-2013.

Cao, L., Zhang, K., Dai, H., Liang, Y., 2015. Modeling Interrill Erosion on Unpaved Roads in the Loess Plateau of China. Land Degradation and Development 26 (8), 825-832. DOI: 10. 1002/ldr. 2253.

Cavalli, M., Trevisani, S., Comiti, F., Marchi, L., 2013. Geomorphometric assessment of spatial sediment connectivity in small Alpine catchments. Geomorphology 188, 31-41.

Cerdà, A., 1994. The response of abandoned terraces to simulated rain, in: Rickson, R.J., (Ed.), Conserving Soil Resources: European Perspective, GAB International, Wallingford, pp. 44-55.

Gerdà, A., 1996. Seasonal variability of infiltration rates under contrasting slope Formatted: Italian (Italy) conditions in Southeast Spain. Geoderma 69, 217-232.

Cerdà, A., 1997. Soil erosion after land abandonment in a semiarid environment of Southeastern Spain. Arid Soil Research and Rehabilitation 11, 163176.

Cerdà, A., 2000. Aggregate Stability Against Water Forces Under Different

Climates on Agriculture Land and Scrubland in Southern Bolivia. Soil and Tillage Research 57 (3), 159-166. doi:10.1016/S0167-1987(00)00155-0. 


\section{portable rainfall simulator for rugged terrain. Soil Technol. 11, 161-170.}

Cerdà, A., Doerr, S.H., 2007. Soil wettability, runoff and erodibility of major dry-

Mediterranean land use types on calcareous soils. Hydrological Processes 21, 2325-2336,_doi: 10.1016/j.catena.2008.03.010.

Cerdà, A., Flanagan, D.C., Le Bissonnais, Y., Boardman, J., 2009. Soil erosion and agriculture. Soil \& Tillage Research 106, 107-108.

Cerdà, A., González-Pelayo, O., Giménez-Morera, A., Jordán, A., Pereira, P., Novara, A., Brevik, E.C., Prosdocimi, M., Mahmoodabadi, M., Keesstra, S., García Orenes, F., Ritsema, C., 2015. The use of barley straw residues to avoid high erosion and runoff rates on persimmon plantations in Eastern Spain under low frequency - high magnitude simulated rainfall events. Soil Research 54(2), 154-165.

Cerdà, A., Ibàñez, S., Calvo, A., 1997. Design and operation of a small and portable rainfall simulator for rugged terrain. Soil Technol. 11, 161-170.

Cerdan, O., Govers, G., Le Bissonnais, Y., Van Oost, K., Poesen, J., Saby, N., Gobin, A., Vacca, A., Quinton, J., Auerwald, K., Klik, A., Kwaad, F.J.P.M., Raclot, D., lonita, I., Rejman, J., Rousseva, S., Muxart, T., Roxo, M.J., Dostal, T., 2010. Rates and spatial variations of soil erosion in Europe: A study based on erosion plot data. Geomorphology 122, 167177.

Gerdan, O., Le Bissonnais, Y., Couturier, A., Saby, N., 2002. Modelling interrill erosion in small cultivated catchments. Hydrological Processes 16, 3215 3226.
Formatted: Italian (Italy) 
Chen, J., Li, K., Chang, K.-J., Sofia, G., Tarolli, P., 2015. Open-pit mining geomorphic feature characterisation. Int. J. Appl. Earth Obs. Geoinf. 42, 76-86.

Colomina, I., Molina, P., 2014. Unmanned aerial systems for photogrammetry and remote sensing: a review. ISPRS Journal of Photogrammetry and Remote Sensing 92, 79-97.

Costantini, E.A.C., Agnelli, A.E., Fabiani, A., Gagnarli, E., Mocali, S., Priori, S., Simoni, S., Valboa, G., 2015. Short-term recovery of soil physical, chemical, micro and mesobiological functions in a new vineyard under organic farming. Soil 1, 443-457. http://dx.doi.org/10.5194/soil-1-4432015.

Dandois, J.P., Ellis, E.C., 2013. High spatial resolution three-dimensional mapping of vegetation spectral dynamics using computer vision. Remote Sensing of Environment 136, 259-276.

Doneus, M., Verhoeven, G., Fera, M., Briese, C., Kucera, M., Neubauer, W., 2011. From deposit to point cloud - a study of low cost computer vision approaches for the straightforward documentation of archeological excavations. Proceedings of the XXIIIrd International CIPA Symposium, Prague.

Dregne, H.E., 1992. Erosion and soil productivity in Asia. Journal of Soil and Water Conservation 47(1), 8-13.

Eltner, A., Kaiser, A., Castillo, C., Rock, G., Neugirg, F., Abellán, A., 2015. Image-based surface reconstruction in geomorphometry - merits, limits and developments, Earth Surf. Dynam., 4, 359-389. doi:10.5194/esurf-4359-2016. 
Fonstad, M.A., Dietrich, J.T., Courville, B.C., Jensen, J.L., Carbonneau, P.E., 2013. Topographic structure from motion: a new development in photogrammetric measurement. Earth Surface Processes and Landforms 38, 421-430.

Fryirs, K.A., Brierley, G.J., Preston, N.J., Kasai, M., 2007. Buffers, barriers and blankets: the (dis)connectivity of catchment-scale sediment cascades. Catena 70, 49-67.

Galati, A., Gristina, L., Crescimanno, M., Barone, E., Novara, A., 2015. Towards More Efficient Incentives for Agri-environment Measures in Degraded and Eroded Vineyards. Land Degrad. Dev. 26, 557-564.

Garcì-Ruiz, J.M., 2010. The effects of land uses on soil erosion in Spain: A review. Catena 81, 1-11.

García-Ruiz, J.M., Beguería, S., Nadal-Romero, E., Gonzalez-Hidalgo, J.C., Lana-Renault, N., Sansjuan, Y., 2015. A meta-analysis of soil erosion rates across the world. Geomorphology 239, 160-173.

Garcìa-Ruiz, J.M., Lana-Renault, N., Beguerìa, S., Lasanta, T., Regués, D., Nadal-Romero, E., Serrano-Muela, P., Lòpez-Moreno, J.l., Alvera, B., Martì-Bono, C., Alatorre, L.C., 2010. From plot to regional scales: interactions of slope and catchment hydrology and geomorphic processes in the Spanish Pyrenees. Geomorphology 120, 248-257.

Gessesse, B., Bewket, W., Bräuning, A., 2015. Model-Based Characterization and Monitoring of Runoff and Soil Erosion in Response to Land Use/land Cover Changes in the Modjo Watershed, Ethiopia. Land Degradation and Development 26 (7), 711-724. DOI: 10. 1002/ldr. 2276. 
Giménez Morera, A., Ruiz Sinoga, J.D., Cerdà, A., 2010. The impact of cotton geotextiles on soil and water losses in Mediterranean rainfed agricultural land. Land Degrad. Dev. 21, 210-217.

Girardeau-Montaut, D., 2015. CloudCompare (version 2.7) [GPL software]. Retrieved from http://www.cloudcompare.org/.

Grimaldi, S., Angeluccetti, I., Coviello, V., Vezza, P., 2015. Cost-Effectiveness of Soil and Water Conservation Measures on the Catchment Sediment Budget-the Laaba Watershed Case Study, Burkina Faso. Land Degradation and Development 26 (7), 737-747. doi:10.1002/ldr.2212.

Heckmann, T., Schwanghart, W., 2013. Geomorphic coupling and sediment connectivity in an alpine catchment - exploring sediment cascades using graph theory. Geomorphology 182, 89-103.

Höhle, J., Höhle, M., 2009. Accuracy assessment of digital elevation models by means of robust statistical methods. ISPRS Journal of Photogrammetry and Remote Sensing 64, 398-406.

Iserloh, T., Ries, J.B., Arnáez, J., Boix-Fayos, C., Butzen, V., Cerdà, A., Echeverría, M.T., Fernández-Gálvez, J., Fister, W., Geißler, C., Gómez, J.A., Gómez-Macpherson, H., Kuhn, N.J., Lázaro, R., León, F.J., Martínez-Mena, M., Martínez-Murillo, J.F., Marzen, M., Mingorance, M.D., Ortigosa, L., Peters, P., Regüés, D., Ruiz-Sinoga, J.D., Scholten, T., Seeger, M., Solé-Benet, A., Wengel, R., Wirtz, S., 2013. European small portable rainfall simulators: A comparison of rainfall characteristics.

Catena 110, 100-112. 
James, M.R., Robson, S., 2012. Straightforward reconstruction of 3D surfaces and topography with a camera: accuracy and geoscience application. Journal of Geophysical Research 117, F03017.

Javernick, L., Brasington, B., Caruso, B., 2014. Modeling the topography of shallow braided rivers using structure-from-motion photogramnmetry. Geomorphology 213, 166-182.

Jordán, A., Zavala, L.M., Muñoz-Rojas, M., 2011. Mulching, effects on soil physical properties. In: Gliński, J., Horabik, J., Lipiec, J. (Eds.), Encyclopedia of Agrophysics. Springer, Dordrecht, pp. 492-496.

Keesstra, S., Pereira, P., Novara, A., Brevik, E.C., Azorin-Molina, C., ParrasAlcántara, L., Jordán, A., Cerdà, A., 2016. Effects of soil management techniques on soil water erosion in apricot orchards. Science of the Total Environment 551-552, 357-366. DOI: 10.1016/j.scitotenv.2016.01.182. Kosmas, C., Danalatos, N., Cammeraat, L.H., Chabart, M., Diamantopoulos, J., Farand, R., Gutierrez, L., Jacob, A., Marques, H., Martínez-Fernandez, J., Mizara, A., Moustakas, N., Nicolau, J.M., Oliveros, C., Pinna, G., Puddu, R., Puigdefabregas, J., Roxo, M., Simao, A., Stamou, G., Tomasi, N., Usai, D., Vacca, A., 1997. The effect of land use on runoff and soil erosion rates under Mediterranean conditions. Catena 29, 45-59.

Lal, R., 1984. Mulch requirements for erosion control with the no-till system in the tropics: a review. Challenges in African Hydrology and Water Rerources. Proceedings of the Harare Symposium. IAHS Publ. no. 144. Lal, R., 1995 Global soil erosion by water and carbon dynamics. In: Lal R., Kimble J., Levine E., Stewart B.A. (Ed.), Advances in Soil Science, Soils and Global Change, pp. 131-143. 
Lal, R., 2000. Soil management in the developing countries. Soil Science 165(1): 57-72.

Lane, S.N., Chandler, J.H., Richards, K.S., 1994. Developments in monitoring and modeling small-scale river bed topography. Earth Surface Processes and Landforms 19(4), 349-368. DOI. 10.1002/esp.3290190406.

Lane, S.N., Westaway, R.M., Hicks, D.M., 2003. Estimation of erosion and deposition volumes in a large, gravel-bed, braided river using synoptic remote sensing. Earth Surface Processes and Landforms 28(3), 249271. DOI. $10.1002 /$ esp.483.

Lasanta, T., Sobròn, 1., 1988. Influencia de las pràcticas de laboreo en la evoluciòn hidromorfològica de suelos cultivados con vinedos. Cuadernos de Investigaciòn Geogràfica 14, 81-97.

Lassu, T., Seeger, M., Peters, P., Keesstra, S.D., 2015. The Wageningen Rainfall Simulator: Set-up and Calibration of an Indoor Nozzle-Type Rainfall Simulator for Soil Erosion Studies. Land Degradation and Development 26 (6), 604-612. DOI: 10. 1002/ldr. 2360.

León, J., Badía, D., Echeverría, M.T., 2015. Comparison of Different Methods to Measure Soil Erosion in the Central Ebro Valley. Cuadernos De Investigacion Geografica 41 (1), 165-180. doi:10.18172/cig.2703. Lexartza-Artza, I., Wainwright, J., 2011. Making connections: changing sediment sources and sinks in an upland catchment. Earth Surface Processes and Landforms 36, 1090-1104. Ligonja, P.J., Shrestha, R.P., 2015. Soil Erosion Assessment in Kondoa Eroded Area in Tanzania using Universal Soil Loss Equation, Geographic 
$\underline{\text { Information Systems and Socioeconomic Approach. Land Degradation }}$ and Development 26 (4): 367-379. doi:10.1002/ldr.2215.

López-Vicente, M., Poesen, J., Navas, A., Gaspar, L., 2013. Predicting runoff Formatted: English (United States) and sediment connectivity and soil erosion by water for different land use scenarios in the Spanish Pre-Pyrenees. Catena 102, 62-73.

López-Vicente, M., Quijano, L., Palazón, L., Gaspar, L., Navas, A., 2015.

Assessment of Soil Redistribution at Catchment Scale by Coupling a Soil

Erosion Model and a Sediment Connectivity Index (Central Spanish Pre-

Pyrenees). Cuadernos De Investigacion Geografica 41 (1), 127-147. doi:10.18172/cig.2649.

López-Vicente, M., Nadal-Romero, E., Cammeraat, E.L.H., 2016. Hydrological

Connectivity does Change Over 70Years of Abandonment and

Afforestation in the Spanish Pyrenees. Land Degradation and

Development. doi:10.1002/ldr.2531.

Lowe, D., 2004. Distinctive image features from scale-invariant keypoints. International Journal of Computer Vision 60, 91-110.

Marchamalo, M., Hooke, J.M., Sandercock, P.J., 2016. Flow and Sediment

Connectivity in Semi-Arid Landscapes in SE Spain: Patterns and Controls.

Land Degradation and Development 27 (4), 1032-1044. doi:10.1002/ldr.2352.

Martínez-Casasnovas, J.A., Ramos, M.C., Ribes-Dasi, M., 2002. Soil erosion caused by extreme rainfall events: mapping and quantification in agricultural plots from very detailed digital elevation models. Geoderma $105,125-140$ 
Martínez-Casasnovas, J.A., Sánchez-Bosch, I., 2000. Impact assessment of changes in land use/conservation practices on soil erosion in the Penedès-Anoia vineyard region (NE Spain). Soil and Tillage Research 57, 101-106.

Masiero, A., Guarnieri, A., Pirotti, F., and Vettore, A., 2015. Semi-automated detection of surface degradation on bridges based on a level set method. Int. Arch. Photogramm. Remote Sens. Spatial Inf. Sci., XL-3/W3, 15-21, doi:10.5194/isprsarchives-XL-3-W3-15-2015.

Masiero, A., Vettore, A., 2016. Improved feature matching for mobile devices with IMU. Sensors 16, 1243. doi:10.3390/s16081243.

Masselink, R.J.H., Keesstra, S.D., Temme, A.J.A.M., Seeger, M., Giménez, R., Casalí, J., 2016. Modelling Discharge and Sediment Yield at Catchment Scale using Connectivity Components. Land Degradation and Development 27 (4), 933-945. doi:10.1002/ldr.2512. Mekonnen, M., Keesstra, S.D., Baartman, J.E., Ritsema, C.J., Melesse, A.M., 2015a. Evaluating Sediment Storage Dams: Structural Off-Site Sediment $\underline{\text { Trapping Measures in Northwest Ethiopia. Cuadernos De Investigacion }}$ Geografica 41 (1), 7-22. doi:10.18172/cig.2643. Mekonnen, M., Keesstra, S.D., Stroosnijder, L., Baartman, J.E.M., Maroulis, J., 2015b. Soil Conservation through Sediment Trapping: A Review. Land Degradation and Development 26 (6), 544-556. doi:10.1002/ldr.2308. Mekuria, W., Langan, S., Noble, A., Johnston, R., 2016. Soil Restoration After Seven Years of Exclosure Management in Northwestern Ethiopia. Land Degradation and Development. doi:10.1002//dr.2527. 
Mengistu, D., Bewket, W., Lal, R., 2016. Conservation Effects on Soil Quality and Climate Change Adaptability of Ethiopian Watersheds. Land Degradation and Development 27 (6), 1603-1621. doi:10.1002/ldr.2376.

Micheletti, N., Chandler, J.H., Lane, S.N., 2014. Investigating the Formatted: English (United States) geomorphological potential of freely available and accessible structurefrom-motion photogrammetry using a smartphone. Earth Surface Processes and Landforms 40(4), 473-486. DOI. 10.1002/esp.3648.

Montgomery, D.R., 2007. Soil erosion and agricultural sustainability. PNAS 104, $13268-13272$.

Navas, A., Alberto, F., Machìn, J., Galàn, A., 1990. Design and operation of a fainfall simulator for field studies of runoff and soil erosion. Soil Technology 3: 385-397.

Mwango, S.B., Msanya, B.M., Mtakwa, P.W., Kimaro, D.N., Deckers, J., Poesen, J., 2016. Effectiveness OF Mulching Under Miraba in Controlling Soil Erosion, Fertility Restoration and Crop Yield in the Usambara Mountains, Tanzania. Land Degradation and Development 27 (4), 12661275. doi:10.1002/ldr.2332.

Nanko, K., Giambelluca, T.W., Sutherland, R.A., Mudd, R.G., Nullet, M.A., Ziegler, A.D., 2015. Erosion Potential under Miconia calvescens Stands on the Island of Hawai'i. Land Degradation and Development 26, 218-226. doi:10.1002/ldr.2200.

Novara, A., Gristina, L., Saladino, S.S., Santoro, A., Cerdà, A., 2011. Soil erosion assessment on tillage and alternative soil managements in a Sicilian vineyard. Soil \& Tillage Research 117, 140-147. 
Novara, A., Keesstra, S., Cerdà, A., Pereira, P., Gristina, L., 2016.

Understanding the role of soil erosion on $\mathrm{CO}_{2}$ - $\mathrm{C}$ loss using ${ }^{13} \mathrm{C}$ isotopic signatures in abandoned Mediterranean agricultural land. Science of the Total Environment 550, 330-336, 10.1016/j.scitotenv.2016.01.095, 2016.

Ochoa-Cueva P., Fries A., Montesinos P., Rodríguez-Díaz J. A., Boll J. 2015.

Spatial Estimation of Soil Erosion Risk by Land-cover Change in the

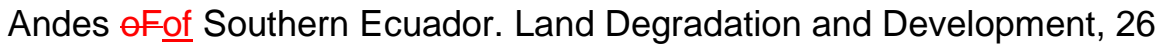
(6), 565-573. DOI: 10. 1002/ldr. 2219

Piermattei, L., Carturan, L., de Blasi, F., Tarolli, P., Dalla Fontana, G., Vettore, A., Pfeifer, N., 2016. Suitability of ground-based SfM-MVS for monitoring glacial and periglacial processes. Earth Surface Dynamics 4, 425-443.

Prosdocimi, M., Calligaro, S., Sofia, G., Dalla Fontana, G., Tarolli, P., 2015. Bank erosion in agricultural drainage networks: new challenges from structure-from-motion photogrammetry for post-event analysis. Earth Surface Processes and Landform 40, 1891-1906.

Prosdocimi, M., Cerdà, A., Tarolli, P., 2016a. Soil water erosion on Mediterranean vineyards: A review. Catena 141, 1-21.

Prosdocimi, M., Jordán, A., Tarolli, P., Keesstra, S., Novara, A., Cerdà, A., 2016b. The immediate effectiveness of barley straw mulch in reducing soil erodibility and surface runoff generation in Mediterranean vineyards. Science of the Total Environment 547, 323-330.

Prosdocimi, M., Tarolli, P., Cerdà, A. 2016c. Mulching practices for reducing soil water erosion: A review. Earth-Science Reviews 161, 191-203.

\section{DOI: 10.1016/..earscirev.2016.08.006.}


Raclot, D., Le Bissonnais, Y., Louchart, X., Andrieux, P., Moussa, R., Voltz, M., 2009. Soil tillage and scale effects on erosion from fields to catchment in a Mediterranean vineyard area. Agriculture, Ecosystems \& Environment $134,201-210$.

Reid, S.C., Lane, S.N., Montgomery, D.R., Brookes, C.J., 2007. Does hydrological connectivity improve modelling of coarse sediment delivery in upland environments? Geomorphology 90, 263-282.

Robertson, D.P., Cipolla, R., 2009. Structure from motion. In Practical Image Processing and Computer Vision, Varga M (ed.). John Wiley \& Sons: Chichester.

Rodrigo Comino, J., Brings, C., Lassu, T., Iserloh, T., Senciales, J.M., Martínez Murillo, J.F., Ruiz Sinoga, J.D., Seeger, M., Ries, J.B., 2015. Rainfall and human activity impacts on soil losses and rill erosion in vineyards (Ruwer Valley, Germany). Solid Earth 6, 823-837. http://dx.doi.org/10.5194/se-6823-2015.

Rodrigo Comino, J., Iserloh, T., Lassu, T., Cerdà, A., Keesstra, S.D.,

Prosdocimi, M., Brings, C., Marzen, M., Ramos, M.C., Senciales, J.M.,

$\underline{\text { Ruiz Sinoga, J.D., Seeger, M., Ries, J.B., 2016a. Quantitative comparison }}$ of initial soil erosion processes and runoff generation in Spanish and German vineyards. Sci. Total Environ. 565, 1165-1174.

\section{DOI:10.1016/i.scitotenv.2016.05.163.}

Rodrigo Comino, J., Iserloh, T., Morvan, X., Malam Issa, O., Naisse, C., Keesstra, S., Cerdà, A., Prosdocimi,M., Arnáez, J., Lasanta, T., Ramos, M.C., Marqués,M.J., Ruiz Colmenero, M., Bienes, R., Ruiz Sinoga, J.D., Seeger, M., Ries, J.B., 20162016b. Soil erosion processes in European 
vineyards: a qualitative comparison of rainfall simulation measurements in Germany, Spain and France. Hydrology 3 (6).

http://dx.doi.org/10.3390/hydrology3010006.

Sadeghi, S.H.R., Gholami, L., Homaee, M., Khaledi Darvishan, A., 2015a.

Reducing sediment concentration and soilloss using organic and inorganic amendments at plot scale. Soild Earth 6, 1-8.

Sadeghi, S.H.R., Gholami, L., Sharifi, E., Khaledi Darvishan, A., Homaee, M., 2015b. Scale effect on runoff and soill loss control using rice straw mulch under laboratory conditions. Soild Earth 6, 445-455.

Rodrigo Comino, J., Seeger, M., Senciales, J.M., Ruiz-Sinoga, J.D., Ries, J.B., 2016c. Spatial and Temporal Variation of Soil Hydrological Processes on Steep Slope Vineyards (Ruwel-Mosel Valley, Gemany). Cuadernos De Investigacion Geografica 42 (1), 281-306. doi:10.18172/cig.2934.

Sibson, R., 1981. A brief description of natural neighbor interpolation. In Interpreting Multivariate Data, Barnett V (ed.). John Wiley \& Sons: Chichester; chapter 2, 21-36.

Sofia, G., Pirotti, F., Tarolli, P., 2013. Variations in multiscale curvature distribution and signatures of lidar DEM errors. Earth Surface Processes and Landforms 38, 1116-1134.

Sofia, G., Hillier, J.K., Conway, S.J., 2016. Frontiers in Geomorphometry and Earth Surface Dynamics: Possibilities, Limitations and Perspectives, Earth Surf. Dynam., 4: 1-5. doi:10.5194/esurf-4-1-2016.

Soil Survey Staff, 1998. Keys of soil taxonomy, $8^{\text {th }}$ ed. USDA-NRCS, Washington DC. 
Sougnez, N., Van Wesemael, B., Vanacker, V., 2011. Low erosion rates measured for steep, sparsely vegetated catchments in southeast Spain. Catena 84, 1-11

Taguas, E.V., Guzmán, E., Guzmán, G., Vanwalleghem, T., Gómez, J.A., 2015. Characteristics and Importance of Rill and Gully Erosion: A Case Study in a Small Catchment of a Marginal Olive Grove. Cuadernos De Investigacion Geografica 41 (1), 107-126. doi:10.18172/cig.2644.

Tarboton, D.G., 2013. Taudem 5.1, Terrain Analysis Using Digital Elevation Models [online] Available from: http://hydrology.usu.edu/taudem/taudem5/

Tarolli, P., 2014. High-resolution topography for understanding Earth surface processes: opportunities and challenges. Geomorphology 216, 295-312.

Tarolli, P., Preti, F., Romano, N., 2014. Terraced landscapes: from an old best practice to a potential hazard for soil degradation due to land abandonment. Anthropocene 6, 10-25.

Tarolli, P., Sofia, G., 2016. Human topographic signatures and derived geomorphic processes across landscapes. Geomorphology 255, 140161.

Tarolli, P., Sofia, G., Calligaro, S., Prosdocimi, M., Preti, F., Dalla Fontana, G., 2015. Vineyards in terraced landscapes: new opportunities from lidar data. Land Degradation \& Development 26, 92-102.

Taylor, J., 1997. An Introduction to Error Analysis: the Study of Uncertainties in Physical Measurements, 2nd edn. University Science Books: Sausalito, CA. 
Tebrügge, F., Düring, R.-A., 1999. Reducing tillage intensity - a review of results from a long-term study in Germany. Soil \& Tillage Research 53, 15-28.

Theler, D., Reynard, E., Lambiel, C., Bardou, E., 2010. The contribution of geomorphological mapping to sediment transfer evaluation in small alpine catchments. Geomorphology 124, 113-123.

Tossel, R.W., Dickinson, W.T., Rudra, R.P., Wall, G.d., 1987. A portable rainfall simulator. Can. Agric. Eng. 29: 155-162.

Verhoeven, G., Doneus, M., Briese, C., Vermeulen, F., 2012. Mapping by

matching: a computer vision-based approach to fast and accurate georeferencing of archaeological aerial photographs. Journal of Archaeological Science 39, 2060-2070.

Wainwright, J., Turnbull, L., Ibrahim, T.G., Lexartza-Artza, I., Thornton, S.F., Brazier, R.E., 2011. Linking environmental regimes, space and time: interpretations of structural and functional connectivity. Geomorphology 126, 387-404.

Walsh, R.P.D., Coelho, C., Elmes, A., Ferreira, A.J.D., Goncalves, A.J.B., Shakesby, R.A., Ternan, J.L., Williams, A.G., 1998. Rainfall simulation plot experiments as a tool in overland flow and soil erosion assessment, north-central Portugal. Geoodynamik 19 (3/4), 139-152.

$\underline{\text { H. Walter, H., Lieth, H., 1960. Klimadiagramma-Weltatlas. G. Fischer Verlag, }}$ Jena.

Wechsler, S.P., 2007. Uncertainties associated with digital elevation models for hydrologic applications: a review. Hydrology and Earth System Sciences $11,1481-1500$. 
Westoby, M.J., Brasington, J., Glasser, N.F., Hambrey, M.J., Reynolds, J.M., 2012. 'Structure-from-Motion' photogrammetry: a low-cost, effective tool for geosciences applications. Geomorphology 17, 300-314.

Wheaton, J.M., 2008. Uncertainty in Morphological Sediment Budgeting of Rivers, Unpublished PhD thesis. University of Southampton; 412 pp. http://www.joewheaton.org/Home/research/projects-1/morphologicalsediment-budgeting/phdthesis.

Wheaton, J.M., Brasington, J., Darby, S.E., Sear, D.A., 2010. Accounting for uncertainty in DEMs from repeat topographic surveys: improved sediment budgets. Earth Surface Processes and Landforms 35, 136-156.

Whitehead, K., Moorman, B.J., Hugenholtz, C.H., 2013. Brief Communication: Low-cost, on-demand aerial photogrammetry for glaciological measurement. The Cryosphere 7, 1879-1884.

Woodget, A.S., Carbonneau, P.E., Visser, F., Maddock, I., 2015. Quantifying submerged fluvial topography using hyperspatial resolution UAS imagery and structure from motion photogrammetry. Earth Surface Processes and Landforms 40, 47-64. DOI. 10.1002/esp.3613.

Zheng, F.L., 2006. Effects of vegetation changes on soil erosion on the Loess Plateau. Pedosphere. 16, 420-427. 
Formatted: Font: $9 \mathrm{pt}$

Formatted: Indent: Left: $0 \mathrm{~cm}$, First line: $0 \mathrm{~cm}$, Line spacing: single, No widow/orphan control, Don't adjust space between Latin and Asian text, Don't adjust space between Asian text and numbers

\section{TABLES CAPTIONS}

Table 1 Georeferentiation errors (RMSE) calculated by Agisoft PhotoScan® along the $x, y$ and $z$-axes for each point cloud derived from SfM technique. GEOPre $_{\text {NKN }}$ and GEOPost ${ }_{N K N}$ refer to the point clouds derived from the Nikon camera before and after the rainfall simulation, respectively, and GEOPre ${ }_{\mathrm{PHO}}$ and GEOPost $t_{\mathrm{PHO}}$ for those derived from the smartphone camera before and after the rainfall simulation, respectively. The number of the plot is also included $(1,2,3,4 A, 4 B, 4 C$ and 4D).

Table 2 Accuracy measures of DEMs PHO $_{\text {checked by }}$ DEMs NKN $_{\text {with }}$ the assumption of normal distribution and more robust parameters too. DEMPre ${ }_{\mathrm{NKN}}$ and DEMPost $t_{\text {NKN }}$ refer to DEMs derived from the Nikon camera before and after the rainfall simulation, respectively, and DEMPre $\mathrm{PHO}_{\mathrm{P}}$ and DEMPost $\mathrm{PHO}_{\mathrm{H}}$ for those derived from the smartphone camera before and after the rainfall simulation, 
respectively. The number of the plot is also included $(1,2,3,4 \mathrm{~A}, 4 \mathrm{~B}, 4 \mathrm{C}$ and 4D). 


\section{FIGURE CAPTIONS}

Figure 1 Examples of soil water erosion processes caused by a $40 \mathrm{~mm}$ in 30 min thunderstorm occurred in mid-June 2015 in the study area. The white arrows point out a gully (a) and a rill (b).

Figure 2 Visual perspective of the tilled inter-rows where the tractor wheel tracks are well visible (black arrows) (a). The white arrows stress the soil sediments that were transported following the $40 \mathrm{~mm}$ in $30 \mathrm{~min}$ thunderstorm occurred in mid-June 2015.

Figure 3Figure 3 Walter-Lieth climate diagram (Walter and Lieth, 1960)

computed for the Ontinyent climate station as it is the one with the longest records (29 years) closest to our study site (about $17 \mathrm{~km}$ ). The information above the panel corresponds to station location, the period of years recorded, the mean annual temperature and the mean annual precipitation.

Figure 4 Localization of the study areas (a), that correspond to the four circular plots $(1,2,3$ and 4$)$ where the rainfall simulation and photogrammetric surveys were carried out. Views of the rainfall simulator (b) and of the rainfall simulation experiment in action (c) are also shown.

Figure $4 \underline{5}$ Two visual perspectives of the support used to take the pictures. The support consists in a main pole, $1 \mathrm{~m}$ high, with two boxes that stick out the main pole for $0.6 \mathrm{~m} \mathrm{(a)} \mathrm{and} \mathrm{are} 0.3 \mathrm{~m}$ far from each other (b). The boxes were designed to hold the cameras with the lens downwards facing. 
Figure $5 \underline{6}$ DEMsPre ${ }_{N K N}$ (0.01 m resolution) obtained for each plot: (a)

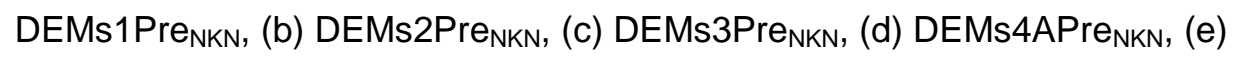

DEMs4BPre $_{\text {NKN }}$, (f) DEMs4CPre ${ }_{N K N}$, and (g) DEMs4DPre ${ }_{N K N}$.

Figure $6 \underline{7}$ DoDs derived from the Nikon dataset, thresholded according to the probabilistic thresholding with a 95\% confidence interval and obtained for each plot: (a) Plot 1, (b) Plot 2, (c) Plot 3, (d) Plot 4A, (e) Plot 4B, (f) Plot 4C, and (g) Plot 4D.

Figure $7 \underline{8}$ Soil loss data, expressed in grams, derived for each plot from both the methodologies applied: rainfall simulation and surface elevation change-

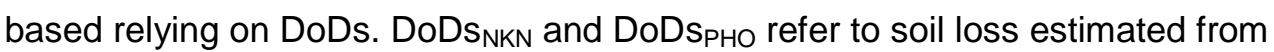
Nikon and smartphone cameras, respectively.

Figure 89 Connectivity index maps calculated with regard to the plots outlets, by considering, as inputs, the DEMsPre ${ }_{\mathrm{NKN}}$, for each plot: (a) Plot 1, (b) Plot 2, (c) Plot 3, (d) Plot 4A, (e) Plot 4B, (f) Plot 4C, and (g) Plot 4D.

Figure 910 Soil loss data, expressed in grams, derived for each plot from both the methodologies applied: rainfall simulation and surface elevation changebased relying on DoDs. DoDs $s_{N K N}$ and DoDs $s_{P H O}$ refer to soil loss estimated from Nikon and smartphone cameras, respectively. DoDs NKN IC $_{\text {I }}$ and DoDs PHO $_{\text {IC refer }}$ to soil loss estimated from Nikon and smartphone cameras, respectively, by considering the connectivity index computed according to the DEMsPre. 
Rainfall simulation and Structure-from-Motion photogrammetry for the analysis of soil water erosion in Mediterranean vineyards

3 Massimo Prosdocimi $^{\mathrm{a}}$, Maria Burguet ${ }^{\mathrm{b}}$, Simone Di Prima ${ }^{\mathrm{c}}$, Giulia Sofia ${ }^{\mathrm{a}}$, Enric

4 Terol Esparza $^{\mathrm{d}}$, Jesús Rodrigo Comino ${ }^{\mathrm{e}, \mathrm{f}}$, Artemi Cerdà $^{\mathrm{b}, \mathrm{g}}$, Paolo Tarolli ${ }^{\mathrm{a}}$ 07100 Sassari, Italy.

dDepartment of Cartographic Engineering, Geodesy and Photogrammetry, Universitat Politècnica de València, Camino de Vera, $s / n$

17 ePhysical Geography, Trier University, 54286 Trier, Germany. fInstituto de Geomorfología y Suelos, University of Málaga, 29071, Málaga, Spain.

${ }^{9}$ Soil Physics and Land Management Group, Wageningen University,

Netherlands. artemio.cerdabolinches@wur.nl.

24 Correspondence to: Massimo Prosdocimi

25 (massimo.prosdocimi@studenti.unipd.it), +39 0498272700 (Italy) 


\section{Abstract}

27 Soil water erosion is a serious problem, especially in agricultural lands. Among these, vineyards deserve attention, because they constitute for the Mediterranean areas a type of land use affected by high soil losses. A significant problem related to the study of soil water erosion in these areas consists in the lack of a standardized procedure of collecting data and reporting results, mainly due to a variability among the measurement methods applied. Given this issue and the seriousness of soil water erosion in Mediterranean vineyards, this works aims to quantify the soil losses caused by simulated rainstorms, and compare them with each other depending on two different methodologies: (i) rainfall simulation and (ii) surface elevation change-based, relying on high-resolution Digital Elevation Models (DEMs) derived from a photogrammetric technique (Structure-from-Motion or SfM). The experiments were carried out in a typical Mediterranean vineyard, located in eastern Spain, at very fine scales. SfM data were obtained from one reflex camera and a smartphone built-in camera. An index of sediment connectivity was also applied to evaluate the potential effect of connectivity within the plots. DEMs derived from the smartphone and the reflex camera were comparable with each other in terms of accuracy and capability of estimating soil loss. Furthermore, soil loss estimated with the surface elevation change-based method resulted to be of the same order of magnitude of that one obtained with rainfall simulation, as long as the sediment connectivity within the plot was considered. High-resolution topography derived from SfM revealed to be essential in the sediment connectivity analysis and, therefore, in the estimation of eroded materials, when comparing them to those derived from the rainfall simulation methodology. The 
51 fact that smartphones built-in cameras could produce as much satisfying results

52 as those derived from reflex cameras is a high value added for using SfM.

53

54

55

56

57

58

59

60

61

62

63

64

65

66

67

68

69

70

71

72

73

74 Keywords: soil water erosion, Mediterranean vineyards, rainfall simulation,

75 Structure from Motion, sediment connectivity. 
77 Throughout the world, soil erosion by water is a serious problem, especially in semi-arid and semi-humid areas (Cerdà et al., 2009, 2015; Cerdan et al., 2010; García-Ruiz, 2010; Ligonja and Shrestha, 2015; Novara et al., 2016;Taguas et al., 2015; Rodrígo Comino et al., 2016a). Although soil erosion by water consists of physical processes that vary significantly in severity and frequency according to when and where they occur, they are also strongly influenced by anthropic factors such as land-use changes on large scales and unsustainable farming practices (Cerdà, 2000; León et al., 2015; López Vicente et al., 2015; Ochoa-Cueva et al., 2015; Montgomery, 2007; Mwango et al., 2016; Nanko et al., 2015; Tarolli et al., 2014). This has led to the definition of 'accelerated' soil erosion as being the result of human impact on the landscape (Tarolli and Sofia, 2016) and this is found in all the continents (Borrelli et al., 2015, Cao et al., 2015; Gessesse et al., 2015; Rodrigo Comino et al., 2016b).

The impact of soil erosion on modern society has required to set threshold values against which to assess the monitoring of soil data, especially in agriculture (Montgomery, 2007). Among the cultivated lands, vineyards merit a particular attention, because, aside from representing one of the most important crops in terms of income and employment, they also constitute, for the Mediterranean areas, a form of agricultural land use that causes the highest soil losses (Cerdà and Doerr, 2007; Cerdan et al., 2010; Martìnez- Casasnovas and

97 Sànchez-Bosch, 2000; Prosdocimi et al., 2016a; Raclot et al., 2009; Rodrigo

98 Comino et al., 2015; Rodrigo Comino et al., 2016c). One of the main reasons for this is the bare soil under the vines that is exposed to high intensity rainfall events, mainly concentrated in spring, autumn and winter, which characterize 
101 the Mediterranean climate (Arnáez et al., 2007; Borga et al., 2011; García-Ruiz, 102 2010; Prosdocimi et al., 2016a). For this cultivation, the two most common soil 103 management techniques are considered to be tillage, where the weeds are 104 usually removed mechanically, and no-tillage, where the weeds are usually 105 removed chemically (Novara et al., 2011; Raclot et al., 2009), and both of them 106 generally turn out in bare soil management during the whole year. Extreme 107 rainfall events that occur in the Mediterranean area are able to cause significant 108 soil water erosion processes, especially when no protective material covers the soil (Figure 1) (Bisantino et al., 2015; Keesstra et al., 2016; Novara et al., 2016;

110 Prosdocimi et al., 2016c). However, to reduce the high soil erosion rates, more 111 conservation-minded soil management practices have also been used such as 112 mulching (Cerdà et al., 2015; Costantini et al., 2015; Jordán et al., 2011;

113 Prosdocimi et al., 2016b,c), cover crops (Novara et al., 2011), rock fragments 114 (Blavet et al., 2009), natural grassing (Grimaldi et al., 2015; Mekonnen et al., 115 2015a; Mekuria et al., 2016; Raclot et al., 2009) and geotextiles (Giménez116 Morera et al., 2010; Mekonnen et al., 2015b; Mengistu et al., 2016).

117 Furthermore, new approaches to evaluate incentives for the adoption of agri118 environment measures in degraded and eroded vineyards have been 119 implemented (Galati et al., 2015) and mulching is one of those successful 120 strategies (Prosdocimi et al., 2016c).

121 Another issue related to soil water erosion in Mediterranean vineyards is the 122 lack of a standardized procedure of collecting data and reporting results, mainly 123 due to a great variability among the measurement methods applied to quantify it 124 (Prosdocimi et al., 2016a; García-Ruiz et al., 2015). This induces difficulties in 125 comparing data coming from different studies and obtained with different 
methodologies. Based on the paper review of Prosdocimi et al. (2016a), six

127 different methodologies to assess soil water erosion in vineyards have been

128 identified: (i) experimental plot stations under simulated or natural rainfalls, (ii)

129 erosion markers, (iii) models, (iv) the surface elevation change-based methods,

130 (v) geochemical methods, and (vi) carbon stable isotopes. This works focuses

131 on the use of plot stations under simulated rainfall and on the surface elevation

132 change-based method. Rainfall simulation has become a very effective

133 technique for assessing soil erosion, particle detachment and overland flow at very fine scales (Arnáez et al., 2007; Cerdà et al., 1997; Iserloh et al., 2013;

135 Rodrigo Comino et al., 2016b). Several types and designs of rainfall simulators

136 have been realized to meet the objectives of researchers (Iserloh et al., 2013;

137 Lassu et al., 2015). In particular, the advantages of using a portable rainfall 138 simulator are: i) its versatility, ii) low cost and easy operation, and iii) capability

139 of obtaining data under controlled conditions and over relatively short periods of

140 time. The surface elevation change-based method is able to detect the

141 topographic changes over time. It relies on Digital Elevation Models (DEMs) that

142 can be used as basic topographic information to derive morphometric attributes

143 and quantify soil erosion and deposition rates (Martínez-Casasnovas and

Sánchez-Bosch, 2000; Martínez-Casasnovas et al., 2002; Prosdocimi et al.,

145 2015). Remote-sensing technologies have proven to facilitate significantly the

146 creation of high-resolution DEMs (Aucelli et al., 2016; Tarolli, 2014; Tarolli et al.,

147 2015), and the availability of DEMs at multiple scales in terms of resolution but

148 also temporal coverage is becoming essential to the understanding of global

149 issues, such sediment production and anthropogenic changes to the Earth

150 system, among others (Sofia et al., 2016). The recent development of the 
151 photogrammetric technique 'Structure-from-Motion' (SfM) has confirmed to

152 represent a valid and cheaper alternative to the established airborne and

153 terrestrial lidar (Light Detection and Ranging) technology for measuring soil

154 surface changes in different environments (Dandois and Ellis, 2013; Eltner et

155 al., 2015; James and Robson, 2012; Masiero et al., 2015; Piermattei et al.,

156 2016; Westoby et al., 2012; Whitehead et al., 2013; Woodget et al., 2015). All

157 this information can shed light into the connectivity within the soil and water

158 losses (López-Vicente et al., 2016; Marchamalo et al., 2016; Masselink et al.,

159 2016).

160 The growing interest for SfM has been enhanced by the fact that it is a user-

161 friendly technique, and that it can also rely on smartphone built-in cameras

162 (Masiero and Vettore, 2016; Micheletti et al., 2014; Prosdocimi et al., 2015) and

163 on the diffusion of unmanned aerial vehicles (UAVs) (Chen et al., 2015;

164 Colomina and Molina, 2014).

165 Given the seriousness of soil water erosion in Mediterranean agricultural lands

166 and the issue of putting data obtained with different methodologies in relation to

167 each other, this works intends to quantify the soil losses caused by simulated

168 rainstorms, and compare them with each other depending on two different

169 methodologies used: (i) rainfall simulation and (ii) surface elevation change-

170 based, relying on high-resolution DEMs derived from SfM. Furthermore, this

171 work aims to compare the results obtained from SfM with each other, depending

172 on the type of camera used. The objectives are pursued by carrying out the

173 experiments in a typical Mediterranean vineyard, under tillage conditions,

174 located within the province of Valencia (Spain), at very fine scales $\left(0.25 \mathrm{~m}^{2}\right)$. 


\section{Material and Methods}

\subsection{Study area}

178 The study area consists in a 25-year-old vineyard, located at El Celler del Roure 179 in Les Alcusses de Moixent, within the Canyoles river watershed in the province 180 of Valencia (La Costera District, eastern Spain) (38 48' 33.12" N, 0 49' 3.27"

181 O). Vines are located parallel to the contour lines and the inter-rows, which are 182 about $2.5 \mathrm{~m}$ wide, are artificially maintained bare during the whole year through 183 tillage operations carried out with a Landini Rex 95 tractor which adopts a tooth 184 arrow as farm implement. The portion affected by the tractor wheel tracks 185 results to be about $36 \%$ of the total inter-row area (Figure 2 ). Climate is typically 186 Mediterranean with 3-5 months of summer drought (June-September). Mean annual rainfall is about $350 \mathrm{~mm} \mathrm{yr}^{-1}$. Rainfall is distributed amongst autumn, winter and spring, with maximum peak rainfall intensities during the autumn season, where values higher of $200 \mathrm{~mm}_{\text {day }}{ }^{-1}$ were recorded during the last 50 years. Mean annual temperature is about $13.8^{\circ} \mathrm{C}$ while the hottest month

191 (August) has average temperatures of about $23^{\circ} \mathrm{C}$. The parent materials in this 192 area belong to Cretaceous limestones and Tertiary Marly deposits that develop Typic Xerothent soils (Soil Survey Staff, 1998). The soils are characterized by

194 low levels of soil organic matter $(<1 \%)$ due to the millennia of agricultural use and soil disturbance (ploughing), basic pH (8) (Prosdocimi et al., 2016b), sandy

196 loam soil textures (clay $19.3 \%$, silt $13.4 \%$ and sand $67.3 \%$ ), and low bulk 197 density $\left(1.109 \mathrm{~g} \mathrm{~cm}^{-3}\right)$.

198 To better characterize the climate of our study site, Walter-Lieth climate 199 diagram (Walter and Lieth, 1960) has been obtained using data derived from 
200 Ontinyent climate station as it is the one with the longest records (29 years)

201 closest to the study site (about $17 \mathrm{~km}$ ) (Figure 3). The diagram displays monthly

202 averages for temperature and precipitation over a year. When the precipitation

203 curve undercuts the temperature curve, the area in between them indicates dry

204 season. When the precipitation curve supersedes the temperature curve, the

205 area in between them indicates moist season. For further information, readers

206 may refer to http://www.globalbioclimatics.org/.

207

\subsection{Experimental plot design}

208 Four circular steel plots $\left(0.25 \mathrm{~m}^{2}\right)$ were located in the bare inter-rows of the

209 vines managed with conventional tillage, and are referred to in the text as 1,2 ,

2103 and 4 . Each plot was placed in a different inter-row and had an outlet, which

211 allowed to converge and collect the surface runoff samples during the runoff

212 simulation experiments. For each plot, five targets (SfM-targets), made of black

213 and white polythene squares, were used: four $(5.5 \mathrm{~cm} \times 5.5 \mathrm{~cm})$ were placed

214 outside the circular plots and one $(2.5 \mathrm{~cm} \times 2.5 \mathrm{~cm})$ inside the plot (Figure 4).

215 SfM-targets centroids were surveyed using a Topcon GRS-1 rover receiver

216 running in real time kinematic (RTK) mode. In addition, other thirteen ground-

217 control points (GCPs) were surveyed in the immediate neighborhood of each 218 plot.

\subsection{Rainfall simulation}

220 A one-nozzle (Hardi-1553-12) rainfall simulator was used to reproduce seven 221 rainstorms at $55 \mathrm{~mm} \mathrm{~h}^{-1}$ rainfall intensity for one hour on the 4 circular plots of $2220.25 \mathrm{~m}^{2}$. For plots 1,2 and 3 , a single rainfall experiment was carried out, while 
223 for plot 4, four rainfall experiments were carried out during four consecutive

224 days, and are referred to in the text as $4 \mathrm{~A}, 4 \mathrm{~B}, 4 \mathrm{C}$ and $4 \mathrm{D}$. Storms similar to the 225 ones simulated have a return period of 10 years in the study area (Cerdà, 1996;

226 Prosdocimi et al., 2016b). The rainfall simulator used was the one described by

227 Cerdà et al. (1997) because it revealed to be effective in rugged terrain

228 conditions proving to give good results in semi-arid environments. Its basic

229 components are a nozzle, a structure that holds the nozzle, the connection with

230 the water supply, the pumping system and a tarpaulin to protect the rainfall

231 simulation from wind. As the nozzle was kept at about $2 \mathrm{~m}$ height over a plane

232 surface, the $0.25 \mathrm{~m}^{2}$ plots were established at the centre of the $1 \mathrm{~m}^{2}$ sprinkling

233 area, to avoid border interference. Readers are referred to Cerdà et al. (1997)

234 and Iserloh et al. (2013) for a further description of the rainfall simulator used

235 and Cerdà $(1996 ; 1997)$ for more information about the distribution of rainfall

236 parameters. Surface runoff from the plots were collected and measured at 1-

237 min intervals during each simulated rainfall event. Every tenth 1-min runoff

238 sample was collected for laboratory analysis in order to determine sediment

239 concentration, that was obtained after the desiccation of the samples in the

240 laboratory. Then, runoff rates and sediment concentration were used to

241 calculate the soil loss, runoff, runoff coefficient, and erosion rates.

243 Photographs of each plot were taken using two different types of camera: (i) a 244 standalone digital reflex camera (Nikon D3000 at 10.2 MP resolution, set at a 245 focal length of $35 \mathrm{~mm}$ ) and (ii) a smartphone, precisely a BQ Aquaris E5, built-in 246 camera (13 MP resolution) with both automatic focusing and exposure enabled. 
247 The choice of using two cameras was due to test the effectiveness of SfM, also

248 when it relies on an image dataset derived from a smartphone. Twenty

249 photographs were taken before and after the rainfall simulation using each

250 camera. A $1 \mathrm{~m}$ high support having two boxes, that were $0.3 \mathrm{~m}$ far from each

251 other and capable of holding the cameras, was used to take the pictures (Figure

252 5). Photographs were taken inside the rainfall simulator covered by the tarpaulin

253 to have a homogeneous light over the plots.

254 The SfM technique was then used to obtain three-dimensional (3D)

255 georeferenced point clouds and to generate $0.01 \mathrm{~m}$ resolution DEMs for each

256 plot. The thirteen points collected in the immediate neighborhood of each plot

257 (see the previous chapter Experimental plot design) were used as GCPs to

258 assess the accuracy and precision of the DEMs through the computation of the

259 root-mean-square-error (RMSE), mean error, and standard deviation of error

260 (SDE). The working principles of SfM are similar to those of stereoscopic

261 photogrammetry, namely that the 3D model can be created from overlapping,

262 offset images. However, unlike traditional photogrammetry, in which either the

263 position of the camera or the positions of some points are known prior to scene

264 reconstruction (Fonstad et al., 2013; Verhoeven et al., 2012; Westoby et al.,

265 2012), in the SfM, matches are made between points across many photographs

266 without prior knowledge of the camera position (Lowe, 2004).

267 The images acquired were processed using the commercial software Agisoft

268 PhotoScan $\AA$, as already successfully considered in different analyses (Doneus

269 et al., 2011; Javernick et al., 2014; Piermattei et al., 2016; Prosdocimi et al.,

270 2015; Verhoeven et al., 2012; Woodget et al., 2015). A custom algorithm similar

271 to the Lowe's (2004) Scale Invariant Feature Transform (SIFT) object 
272 recognition system was used by the software to determine the 3D location of

273 matching features in multiple images. Then, camera position was calculated by

274 estimating the camera's intrinsic (focal length, principal point, and lens

275 distortion) and extrinsic (projection centre location and the six exterior

276 orientation parameters that define the image) orientation parameters. This was

277 done by using a bundle-adjustment algorithm (Javernick et al., 2014; Robertson

278 and Cipolla, 2009; Verhoeven et al., 2012). Afterwards, the software created a

279 dense surface, usually referred to as mesh, by using these parameters and a

280 dense multi-view stereo reconstruction (DMVR) (Agisoft, 2016). The mesh was

281 generated in a relative 'image-space' coordinate system (Westoby et al., 2012),

282 and therefore, it required to undergo a linear similarity transformation using

283 seven parameters (three translation, three rotation, and one scaling), based on

284 known GCPs, to be transformed to an absolute coordinate system. The GCPs

285 corresponded to the SfM-targets centroids, whose $x, y$ and $z$ coordinates were

286 previously recorded with Topcon GRS-1. As the linear similarity transformation

287 could not remove non-linear model misalignments (Woodget et al., 2015), an

288 optimization transformation method was applied to minimize geometric

289 distortions within the mesh (Agisoft, 2016). Thereafter the mesh was rebuilt and

290 the 3D georeferenced point could be exported. The georeferenced point clouds

291 are referred to in the text as GEOPre ${ }_{\text {NKN }}$ and GEOPost NKN $_{\text {, for those derived }}$

292 from the Nikon camera before and after the rainfall simulation, respectively, and

293 GEOPre $_{\mathrm{PHO}}$ and GEOPost $\mathrm{PHO}_{\mathrm{HO}}$ for those derived from the smartphone camera

294 before and after the rainfall simulation, respectively. Furthermore, the number of

295 the plot is also included (1, 2, 3, 4A, 4B, 4C and 4D). 
296 Then, the SfM final point clouds were further manipulated using the open 297 source program CloudCompare® (Girardeau-Montaut, 2015) to remove 298 additional noise that typically affects these data (Javernick et al., 2014;

299 Prosdocimi et al., 2015). In this case, given the small size of the plots, the noise 300 removal was accomplished manually. Finally, the elevation points were 301 interpolated by the natural neighbor method (Sibson, 1981) to generate $0.01 \mathrm{~m}$ 302 resolution DEMs. The DEMs are referred to in the text as DEMPre ${ }_{\mathrm{NKN}}$ and 303 DEMPost $_{N K N}$, for those derived from the Nikon camera before and after the 304 rainfall simulation, respectively, and DEMPre $\mathrm{PHO}_{\mathrm{P}}$ and DEMPostPHO for those 305 derived from the smartphone camera before and after the rainfall simulation, 306 respectively. Furthermore, the number of the plot is also included $(1,2,3,4 \mathrm{~A}$, $3074 \mathrm{~B}, 4 \mathrm{C}$ and 4D). The DEMsPre ${ }_{\mathrm{NKN}}$ obtained for each plot are shown in Figure 6. 308 For the objectives of this work, all the analysis was based on the final DEMs, as 309 done by Bangen et al. (2014), Calligaro et al. (2013), Javernick et al. (2014), 310 Prosdocimi et al. (2015), Tarolli et al. (2015), and Wechsler (2007). The DEMs

311 derived from the smartphone were then directly compared to the DEMs derived 312 from the camera, by assuming a normal distribution and using robust statistical 313 methods (Höhle and Höhle, 2009; Prosdocimi et al., 2015). This entailed the 314 computation of the mean error, SDE, RSME, median, and normalized median 315 absolute deviation (NMAD).

\subsection{Computation of soil loss}

317 Soil loss was computed for both rainfall simulation and surface elevation 318 change-based methodologies. For rainfall simulation methodology, the runoff 319 samples were used to determine the sediment concentration and, then, the 
320 runoff rates and sediment concentration were used to calculate the total soil

321 loss (g). For the surface elevation change-based methodology, SfM was applied

322 to obtain high-resolution DEMs before (DEMsPre) and after (DEMsPost) the

323 rainfall simulation. Then, the so-called morphological method (Ashmore and

324 Church, 1998) was used to estimate the soil loss. The morphological method

325 consists in carrying out repeated topographic surveys from which DEMs can be 326 obtained and differenced to produce DEMs of difference (DoDs). The volumes

327 of eroded materials $\left(\mathrm{cm}^{3}\right)$ were computed by considering the DEMsPre and

328 DEMsPost for each plot and for each camera by using the Geomorphic Change

329 Detection (GCD) 6.1.14 toolbar embedded in an ESRI® add-in for ArcGIS 10.X

330 that is freely downloadable from http://gcd.joewheaton.org/downloads. Then,

331 the volumes of eroded materials were turned into soil loss expressed in grams,

332 by knowing the bulk density. The GCD allows to compute the volumes of

333 deposited materials too, but, for this work, only eroded materials have been

334 considered, to make a comparison with the soil loss derived from the rainfall

335 simulation methodology. The DoDs are referred to in the text as DoDs $s_{\text {NKN }}$ and

336 DoDs sHo for those derived from the Nikon and smartphone cameras,

337 respectively. DEMs' uncertainty in DoDs has also been considered (Brasington

338 et al., 2000; Lane et al., 1994; Lane, 1998; Lane et al., 2003; Prosdocimi et al.,

339 2015; Wheaton, 2008; Wheaton et al., 2010). In this case, DEMs' uncertainties

340 were evaluated according to a probabilistic thresholding that can be carried out

341 with a user-defined confidence interval (Brasington et al., 2003; Lane et al.,

342 2003; Taylor, 1997):

$$
U_{\text {crit }}=t\left(\sqrt{S D E_{\text {new }}^{2}+S D E_{\text {old }}^{2}}\right)
$$


344 where $U_{c r i t}$ is the critical threshold error propagated in the DoD and $S D E_{\text {new }}$ and

$345 S D E_{\text {old }}$ are the individual standard deviation errors in $\mathrm{DEM}_{\text {new }}$ (post-event) and

346 DEM old (pre-event), respectively. $U_{c r i t}$ is based on a critical student's $t$-value at

347 a chosen confidence interval where:

348

$$
t=\frac{\left|z_{\text {DEMnew }}-z_{\text {DEMold }}\right|}{\delta u_{D o D}}
$$

349 where $\left|z_{\text {DEMnew }}-z_{\text {DEMold }}\right|$ is simply the absolute value of the DoD. The probability 350 of a DoD predicted elevation change occurring due the uncertainty can then be 351 calculated by relating the $t$-statistic to its cumulative distribution function. In this 352 work, we used the 95\% confidence interval as a threshold, as also suggested 353 by Wheaton et al. (2010).

\subsection{Sediment connectivity}

355 Sediment connectivity is defined as the connected transfer of sediment from a 356 source to a sink in a system through processes of sediment detachment and 357 transport (Bracken et al., 2015). The concept of connectivity has increasingly 358 been used in quantitative process-based sediment dynamics research, 359 especially at catchment scales (Ali et al., 2014; Baartman et al., 2013; Bracken 360 and Croke, 2007; Bracken et al., 2015; Brierley et al., 2006; Cavalli et al., 2013;

361 Fryirs et al., 2007; Heckmann and Schwanghart, 2013; Lexartza-Artza and 362 Wainwright, 2011; López-Vicente et al., 2013; Wainwright et al., 2011).

363 Geomorphology has been considered as a major driver on determining 364 sediment connectivity (Heckmann and Schwanghart, 2013; Theler et al., 2010), 365 and geomorphometric indices have increasingly been developed to assess it 366 (Borselli et al., 2008; Cavalli et al., 2013; López-Vicente et al., 2013; Reid et al., 
367 2007; Sougnez et al., 2011). In this study we applied the index of connectivity

368 (IC) as proposed by Cavalli et al. (2013) based on the work of Borselli et al.

369 (2008), to evaluate the potential effect of sediment connectivity within the plots.

370 The reasons for this choice relied on the facts that the IC (i) is a distributed

371 geomorphometric index that can be easily derived from a DEM, (ii) can be

372 computed with reference to specific target features, and (iii) has been adapted

373 for high-resolution DEMs. The IC has been developed as a ToolBox for ArcGis

37410.1 or as stand-alone application based on Python scripting with bindings for

375 processing geographical datasets. It uses functionalities and algorithms

376 available in TauDEM 5.2 tool (Tarboton 2013) and it is freely downloadable from

377 http://www.sedalp.eu/download/tools.shtml. This index mainly focuses on the

378 influence of topography on sediment connectivity, and takes into account the

379 characteristics of the drainage area (upslope component, $D_{\text {up }}$ ) and the flow path

380 length that a particle has to travel to arrive at the nearest sink (downslope

381 component, $\left.D_{d n}\right)$.

382 The IC is computed as follows:

383

$$
I C=\log _{10}\left(\frac{D_{u p}}{D_{d n}}\right)=\log _{10}\left(\frac{\overline{W S} \sqrt{A}}{\sum_{i} \frac{d_{i}}{W_{i} S_{i}}}\right)
$$

384 where $\bar{W}$ is the average weighting factor of the upslope contributing area

385 (dimensionless), $\bar{S}$ is the average slope gradient of the upslope contributing

386 area $(\mathrm{m} / \mathrm{m}), A$ is the upslope contributing area $\left(\mathrm{m}^{2}\right), d_{i}$ is the length of the flow

387 path along the $i^{\text {th }}$ cell according to the steepest downslope direction (m), $W_{i}$ and

$388 S_{i}$ are the weighting factor and the slope gradient of the $i^{\text {th }}$ cell, respectively. IC 
can assume values ranging from $-\infty$ to $+\infty$, with connectivity increasing for 390 larger IC values.

\section{Results and discussion}

\subsection{Nikon and smartphone built-in cameras comparisons}

393 Regarding the comparisons between the Nikon and smartphone built-in

394 cameras, the georeferentiation errors (RMSE) calculated by the Agisoft

395 PhotoScan $\AA^{\circledR}$ software along the $\mathrm{x}, \mathrm{y}$ and $\mathrm{z}$-axes for each SfM point cloud are 396 reported (Table 1). The SfM point clouds show an average error of the order of about $0.01 \mathrm{~m}$ along the $\mathrm{x}$-axis, and an even lower order error along the $\mathrm{y}$ and $\mathrm{z}$ axes. These good results support the choice of setting the DEMs resolution equal to $0.01 \mathrm{~m}$ and can be explained by the fact that: (i) the plots were very small, (ii) the $5 \mathrm{SfM}$-targets were well distributed over each plot, and (iii) the pictures were taken in a correct way, thanks to the support used, the expedient of shooting photographs inside the tarpaulin, and the short distance between the position of the cameras and the plots (about $1 \mathrm{~m}$ ). Furthermore, differences

404 between the DEMs PHO $_{\text {and }} \mathrm{DEMs}_{\mathrm{NKN}}$ for the unthresholded DEMs (where no 405 uncertainty analysis was carried out) were also evaluated with accuracy measures assuming a normal distribution and more robust parameters too

407 (Table 2). From Table 2, emerges that all the DEMs 408 DEMs $\mathrm{SKN}_{\mathrm{N}}$. Mean values are of the order of about $0.0001 \mathrm{~m}$ and SDE values of 409 the order of about $0.001 \mathrm{~m}$. Skewness and kurtosis confirm the fact that the 410 elevation differences do not follow normal distributions (Höhle and Höhle, 2009;

411 Sofia et al., 2013), and this supports the choice of considering more robust 412 parameters too such as NMAD and median. However, also when considering 


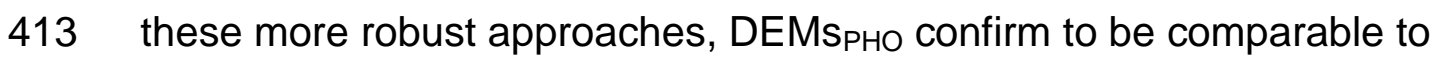

$414 D_{\text {DEMS }}$, showing NMAD and median values of the order of about 0.001 and

$4150.001 \mathrm{~m}$, respectively.

\subsection{Soil loss}

417 Figure 7 shows the DoDs derived from SfM, by considering the DEMsPre ${ }_{N K N}$ 418 and DEMsPost NKN $_{\text {for }}$ each plot, thresholded according to the probabilistic 419 thresholding with a 95\% confidence interval. The fact that, the thresholding of 420 DoDs entails a loss of information, is expected and occurs at the expense of a 421 better geomorphic plausibility (Wheaton et al., 2010). Elevation differences 422 range from negative values (red colour), to which correspond net eroded 423 sediments, to positive values (blue colour), to which correspond net deposited 424 sediments. From Figure 7 emerges that plots 1, 2, 3 and 4A mainly show 425 negative elevation differences. This means that the single simulated rainfall 426 event caused more erosion than deposition, and this can be explained by the 427 fact that the plots, at the beginning, have more material which is prone to be 428 washed away. In contrast, plots $4 \mathrm{~B}, 4 \mathrm{C}$ and $4 \mathrm{D}$ show greater elevation 429 differences. This suggests that, as rainfall events follow one another, the soil 430 particles, that are susceptible to be eroded, diminish, and therefore, the soil 431 shows elevation differences which are closer to zero values, where zero 432 corresponds exactly to no difference at all between before and after the 433 rainstorm.

434 Figure 8 shows the soil loss data, expressed in grams, derived from both the 435 methodologies applied. For the surface elevation change-based method, the 436 data coming from the DoDs obtained with both the Nikon and smartphone 437 cameras are reported. From Figure 8 emerges how the soil loss data estimated 
438 with the two methodologies are not comparable with each other, especially for

439 the plots 1, 2, 3 and $4 \mathrm{~A}$, where only a single rainstorm was artificially

440 reproduced. On the contrary, soil loss data derived from the same methodology,

441 namely surface elevation change-based, are comparable with each other,

442 independently from the type of camera used. Soil loss derived from the surface

443 elevation change-based method result to be of two orders of magnitude greater

444 than the one obtained with rainfall simulation. However, this discrepancy is in

445 line with the processes that are involved and analysed with the two different

446 methodologies. Rainfall simulation accounts for splash and initial inter-rill

447 erosion processes and allows to study the impact of rain drops on sediment

448 detachment, transport and runoff initiation. However, when it rains the water is

449 able to disintegrate some of the soil aggregates, leading to the collapse of

450 micro-pores and to the surface seal formation. Furthermore, the water that

451 infiltrates makes also the soil heavier, causing a lowering of the soil surface,

452 which is the process that DoDs are able to detect. To overcome this

453 discrepancy between the two methodologies, sediment connectivity within the

454 plots has been taken into consideration too.

\subsection{Sediment connectivity analysis}

456 Other than rainfall intensity and kinetic energy, also micro-topography plays a 457 key role in the collection of eroded materials, especially when the experiments 458 are carried out at very fine scales, as in our case. To prove this, Figure 9 shows 459 the maps of the connectivity index calculated with regard to the plots outlets, by 460 considering, as inputs, the DEMsPre ${ }_{N K N}$. As no reference theory exists for the 461 partitioning of the connectivity index into classes, we relied on the same classification provided by Tarolli and Sofia (2016), in which they proposed to 
463 adopt a relative classification into four classes (High, Medium-High, Medium-

464 Low and Low) by considering break points that best grouped similar values and 465 maximized the differences between classes (natural breaks).

466 From Figure 9 emerges how (i) each plot has different patterns of sediment 467 connectivity, which vary whether or not consecutive rainstorms occur (Figure $4689 \mathrm{~d}, \mathrm{e}, \mathrm{f}$ and g), and (ii) not all the soil within the plots is connected to the outlet. 469 This proves the fact that the placement of the plots in the field is extremely 470 important because micro-reliefs with their roughness can facilitate sediment dis-

471 connectivity. The portions of soil that are more connected to the outlet are those

472 that are closer to it. Therefore, these portions, which correspond to the Medium-

473 High and High classes of the connectivity index maps, are reasonably those

474 that will be more prone to erosion, once the rainstorm occurs. As a 475 consequence, by masking the elevation differences maps (Figure 7) with the 476 Medium-High and High classes of the connectivity index maps (Figure 9), we

477 re-computed the soil loss derived from the surface elevation change-based

478 method, considering both the Nikon (DoDs $\left.s_{\mathrm{NKN}} \mathrm{IC}\right)$ and smartphone (DoDs $\mathrm{PHO}_{\mathrm{PHO}}$ 479 IC) DoDs (Figure 10).

480 Differently from what emerged from Figure 8, Figure 10 illustrates that the soil 481 loss data, estimated with the two methodologies, are of the same order of 482 magnitude, as long as the sediment connectivity within the plot is taken into 483 consideration. These results confirm the importance of micro-topography in the 484 sediment connectivity and, consequently, in the estimation of eroded materials. 485 


\section{Conclusions}

489 In this work, we quantified the soil losses caused by water and compared them

490 with each other, depending on two different methodologies applied: rainfall

491 simulation and surface elevation change-based, relying on high-resolution

492 DEMs derived from SfM. The experiments were carried out in a typical

493 Mediterranean vineyard, under tillage conditions, at very fine scales. SfM data

494 were derived from one standalone digital reflex camera and a smartphone built-

495 in camera. We also applied an index of connectivity (IC) to evaluate the

496 potential effect of sediment connectivity within the plots. Compared to the

497 DEMs $_{\text {NKN }}$, we evaluated the DEMs PHO $_{\text {in }}$ terms of (i) accuracy, and (ii) capability

498 to estimate soil loss with regard to the results derived from the rainfall

499 simulation methodology. In terms of accuracy, the DEMspHo revealed to be

500 comparable with the DEMs ${ }_{N K N}$, by assuming a normal distribution of errors and

501 with more robust parameters too. Also regarding the estimation of soil losses,

502 caused by the rainstorms artificially reproduced, through the surface elevation

503 change-based methodology, the results between the two different types of

504 cameras used were comparable with each other. What they differed from was

505 the soil losses data estimated with the rainfall simulation. However, this

506 discrepancy was overcome when the sediment connectivity within the plot was

507 taken into consideration by computing the IC index. In conclusion, high-

508 resolution topography derived from SfM revealed to be essential in the

509 sediment connectivity analysis and, therefore, this, proved to play a key role in

510 the estimation of eroded materials, if compared them to those derived from

511 another methodology such as the rainfall simulation. SfM confirmed to be a

512 useful approach to quantify topographic changes in agricultural lands, also at 
513 very fine scales, and revealed to be capable of detecting the more random

514 changes, less easily traceable, induced by the rainstorms. In addition, the fact

515 that smartphones built-in cameras can produce as much satisfying results as

516 those derived from standalone digital reflex cameras is undoubtedly a high

517 value added. Nowadays, smartphones are commonly available for anyone, from

518 farmers to researchers, and will become increasingly important for fast and

519 cheap post-event analyses, as long as they are provided with a high-resolution

520 camera. The increasing development of computer vision technologies and

521 digital camera sensors makes the process of taking good pictures quite easy. A

522 farmer would require few hours of training to learn how to take good pictures of

523 a specific case study, i.e. a rill process, located in its own land. Afterwards, he

524 would be completely independent during the whole field survey, and then he

525 could send the pictures taken to a researcher for further analyses. In this way,

526 the famer could easily keep monitoring some of the erosion processes that

527 occur in his land and the researcher could provide him quantitative information

528 about net erosion and deposition rates. However, it also should be said that the

529 spatial scale plays a fundamental role in the feasibility of using smartphones for

530 post-event analyses. For erosion processes that occur at field or catchment

531 scales, the use of aerial photogrammetry, supported by the increasing diffusion

532 of UAVs, is more recommended.

533

534

535

536

537 


\section{Acknowledgements}

539 The research leading to these results has received funding from the Research

540 project $60 \mathrm{~A} 08-5455 / 15$ of University of Padova (Italy), entitled "The analysis of

541 the topographic signature of anthropic processes" and from the European Union

542 Seventh Framework Programme (FP7/2007-2013) under grant agreement $\mathrm{n}^{\circ}$

543603498 (RECARE project).

544 The authors also thank the M.Sc. student Nicoletta Pradetto Sordo to help to

545 carry out the photogrammetric surveys and the rainfall simulation experiments.

546

547

548

549

550

551

552

553

554

555

556

557

558

559

560

561

562 
References

564 Agisoft., 2016. Agisoft PhotoScan User Manual: Professional Edition. Version 1.0. http://www.agisoft.ru/products/photoscan/professional/ [September 2016].

Ali, G., Birkel, C., Tetzlaff, D., Soulsby, C., McDonnell, J.J., Tarolli, P., 2014. A comparison of wetness indices for the prediction of connected saturated areas under contrasted conditions. Earth Surface Processes and Landforms 39, 399-413.

571 Arnáez, J., Lasanta, T., Ruiz-Flaño, P., Ortigosa, L., 2007. Factors affecting runoff and erosion under simulated rainfall in Mediterranean vineyards. Soil \& Tillage Research 93, 324-334.

574 Ashmore, P.E., Church, M., 1998. Sediment transport and river morphology: a paradigm for study, in: Klingeman, P.C., Beschta, R.L., Komar, P.D., Bradley, J.B. (Eds), Gravelbed Rivers in the Environment, Water Resources Publications: Highlands Ranch, CO, pp. 115-148.

578 Aucelli, P.P.C., Conforti, M., Della Seta, M., Del Monte, M., D'uva, L., Rosskopf, C.M., Vergari, F., 2016. Multi-Temporal Digital Photogrammetric Analysis for Quantitative Assessment of Soil Erosion Rates in the Landola Catchment of the Upper Orcia Valley (Tuscany, Italy). Land Degradation

583 Baartman, J.E.M., Messelink, R., Keesstra, S.D., Temme, A.J.M., 2013. Linking landscape morphological complexity and sediment connectivity. Earth Surface Processes and Landforms 38, 1457-1471.

586 Bangen, S., Wheaton, J., Bouwes, N., Jordan, C., Volk, C., Ward, M.B., 2014. Crew variability in topographic surveys for monitoring wadeable streams: 

a case study from the Columbia River Basin. Earth Surface Processes and Landforms 39(15), 2070 - 2086.

590 Bisantino, T., Bingner, R., Chouaib, W., Gentile, F., Trisorio Liuzzi, G., 2015. Estimation of runoff, peak discharge and sediment load at the event scale in a medium-size mediterranean watershed using the annagnps model. Land Degradation and Development 26 (4), 340-355. DOI: $10.1002 / \mathrm{ldr} .2213$

Blavet, D., De Noni, G., Le Bissonnais, Y., Leonard, M., Maillo, L., Laurent, J.Y., 596 Asseline, J., Leprun, J.C., Arshad, M.A., Roose, E., 2009. Effect of land use and management on the early stages of soil water erosion in French Mediterranean vineyards. Soil Tillage Res. 106, 124 - 136.

599 Borga, M., Anagnostou, E.N., Bloschl, G., Creutin, J.D., 2011. Flash flood 600 forecasting, warning and risk management: the HYDRATE project. Environmental Science \& Policy 14 (7), 834-844.

602 Borrelli, P., Märker, M., Schütt, B., 2015. Modelling Post-Tree-Harvesting soil 603 erosion and sediment deposition potential in the Turano river basin 604 (Italian central Apennine). Land Degradation and Development 26 (4), 605 356-366. DOI: 10. 1002/ldr. 2214.

606 Borselli, L., Cassi, P., Torri, D., 2008. Prolegomena to sediment and flow 607 connectivity in the landscape: a GIS and field numerical assessment. $608 \quad$ Catena 75, 268-277.

609 Bracken, J., Turnbull, L., Wainwright, J., Bogaart, P., 2015. Sediment connectivity: a framework for understanding sediment transfer at multiple

611 scales. Earth Surface Processes and Landforms 40, 177-188. 
612 Bracken, L.J., Croke, J., 2007. The concept of hydrological connectivity and its 613 contribution to understanding runoff-dominated geomorphic systems. Hydrological Processes 21, 1749-1763.

615 Brasington, J., Langham, J., Rumsby, B., 2003. Methodological sensitivity of 616 morphometric estimates of coarse fluvial sediment transport.

617 Geomorphology 53(3-4), 299-316.

618 Brasington, J., Rumsby, B.T., Mcvey, R.A., 2000. Monitoring and modelling morphological change in a braided gravel-bed river using high resolution GPS-based survey. Earth Surface Processes and Landforms 25(9), 973990.

622 Brierley, G., Fryirs, K., Jain, V., 2006. Landscape connectivity: the geographic 623 basis of geomorphic applications. Area 38, 165-174.

624 Calligaro, S., Sofia, G., Prosdocimi, M., Dalla Fontana, G., Tarolli, P., 2013. Terrestrial laser scanner data to support coastal erosion analysis: the Conero case study. International Archives of the Photogrammetry, Remote Sensing and Spatial Information Sciences 40(5W3), 125-129. DOI. 10.5194/isprsarchives-XL-5-W3-125-2013.

Cao, L., Zhang, K., Dai, H., Liang, Y., 2015. Modeling Interrill Erosion on Unpaved Roads in the Loess Plateau of China. Land Degradation and

632 Cavalli, M., Trevisani, S., Comiti, F., Marchi, L., 2013. Geomorphometric assessment of spatial sediment connectivity in small Alpine catchments. Geomorphology 188, 31-41.

635 Cerdà, A., 1996. Seasonal variability of infiltration rates under contrasting slope 636 conditions in Southeast Spain. Geoderma 69, 217-232. 
637 Cerdà, A., 1997. Soil erosion after land abandonment in a semiarid environment of Southeastern Spain. Arid Soil Research and Rehabilitation 11, 163176.

Cerdà, A., 2000. Aggregate Stability Against Water Forces Under Different Climates on Agriculture Land and Scrubland in Southern Bolivia. Soil and Tillage Research 57 (3), 159-166. doi:10.1016/S0167-1987(00)00155-0.

Cerdà, A., Ibàñez, S., Calvo, A., 1997. Design and operation of a small and portable rainfall simulator for rugged terrain. Soil Technol. 11, 161-170.

Cerdà, A., Doerr, S.H., 2007. Soil wettability, runoff and erodibility of major dryMediterranean land use types on calcareous soils. Hydrological Processes 21, 2325-2336, doi: 10.1016/j.catena.2008.03.010.

648 Cerdà, A., Flanagan, D.C., Le Bissonnais, Y., Boardman, J., 2009. Soil erosion and agriculture. Soil \& Tillage Research 106, 107-108.

Cerdà, A., González-Pelayo, O., Giménez-Morera, A., Jordán, A., Pereira, P., Novara, A., Brevik, E.C., Prosdocimi, M., Mahmoodabadi, M., Keesstra, S., García Orenes, F., Ritsema, C., 2015. The use of barley straw residues to avoid high erosion and runoff rates on persimmon plantations in Eastern Spain under low frequency - high magnitude simulated rainfall

656 Cerdan, O., Govers, G., Le Bissonnais, Y., Van Oost, K., Poesen, J., Saby, N., 657 Gobin, A., Vacca, A., Quinton, J., Auerwald, K., Klik, A., Kwaad, 658 F.J.P.M., Raclot, D., Ionita, I., Rejman, J., Rousseva, S., Muxart, T., 659 Roxo, M.J., Dostal, T., 2010. Rates and spatial variations of soil erosion in Europe: A study based on erosion plot data. Geomorphology 122, 167177. 
662 Chen, J., Li, K., Chang, K.-J., Sofia, G., Tarolli, P., 2015. Open-pit mining geomorphic feature characterisation. Int. J. Appl. Earth Obs. Geoinf. 42, 76-86.

Colomina, I., Molina, P., 2014. Unmanned aerial systems for photogrammetry and remote sensing: a review. ISPRS Journal of Photogrammetry and Remote Sensing 92, 79-97.

Costantini, E.A.C., Agnelli, A.E., Fabiani, A., Gagnarli, E., Mocali, S., Priori, S., Simoni, S., Valboa, G., 2015. Short-term recovery of soil physical, chemical, micro and mesobiological functions in a new vineyard under organic farming. Soil 1, 443-457. http://dx.doi.org/10.5194/soil-1-443-

673 Dandois, J.P., Ellis, E.C., 2013. High spatial resolution three-dimensional mapping of vegetation spectral dynamics using computer vision. Remote Sensing of Environment 136, 259-276.

676 Doneus, M., Verhoeven, G., Fera, M., Briese, C., Kucera, M., Neubauer, W., 2011. From deposit to point cloud - a study of low cost computer vision approaches for the straightforward documentation of archeological excavations. Proceedings of the XXIIIrd International CIPA Symposium,

681 Eltner, A., Kaiser, A., Castillo, C., Rock, G., Neugirg, F., Abellán, A., 2015. 682 Image-based surface reconstruction in geomorphometry - merits, limits and developments, Earth Surf. Dynam., 4, 359-389. doi:10.5194/esurf-4359-2016.

685 Fonstad, M.A., Dietrich, J.T., Courville, B.C., Jensen, J.L., Carbonneau, P.E., 686 2013. Topographic structure from motion: a new development in 
photogrammetric measurement. Earth Surface Processes and Landforms 38, 421-430.

Fryirs, K.A., Brierley, G.J., Preston, N.J., Kasai, M., 2007. Buffers, barriers and blankets: the (dis)connectivity of catchment-scale sediment cascades. Catena 70, 49-67.

692 Galati, A., Gristina, L., Crescimanno, M., Barone, E., Novara, A., 2015. Towards 693 More Efficient Incentives for Agri-environment Measures in Degraded and Eroded Vineyards. Land Degrad. Dev. 26, 557-564.

Garcia-Ruiz, J.M., 2010. The effects of land uses on soil erosion in Spain: A review. Catena 81, 1-11.

697 García-Ruiz, J.M., Beguería, S., Nadal-Romero, E., Gonzalez-Hidalgo, J.C., 698 Lana-Renault, N., Sansjuan, Y., 2015. A meta-analysis of soil erosion 699 rates across the world. Geomorphology 239, 160-173.

700 Gessesse, B., Bewket, W., Bräuning, A., 2015. Model-Based Characterization 701 702 703 and Monitoring of Runoff and Soil Erosion in Response to Land Use/land Cover Changes in the Modjo Watershed, Ethiopia. Land Degradation and Development 26 (7), 711-724. DOI: 10. 1002//dr. 2276.

704 Giménez Morera, A., Ruiz Sinoga, J.D., Cerdà, A., 2010. The impact of cotton 705 geotextiles on soil and water losses in Mediterranean rainfed agricultural land. Land Degrad. Dev. 21, 210-217.

707 Girardeau-Montaut, D., 2015. CloudCompare (version 2.7) [GPL software]. 708 Retrieved from http://www.cloudcompare.org/.

709 Grimaldi, S., Angeluccetti, I., Coviello, V., Vezza, P., 2015. Cost-Effectiveness of Soil and Water Conservation Measures on the Catchment Sediment 
Budget-the Laaba Watershed Case Study, Burkina Faso. Land Degradation and Development 26 (7), 737-747. doi:10.1002/ldr.2212.

713 Heckmann, T., Schwanghart, W., 2013. Geomorphic coupling and sediment connectivity in an alpine catchment - exploring sediment cascades using graph theory. Geomorphology 182, 89-103.

716 Höhle, J., Höhle, M., 2009. Accuracy assessment of digital elevation models by 717 means of robust statistical methods. ISPRS Journal of Photogrammetry $718 \quad$ and Remote Sensing 64, 398-406.

719 Iserloh, T., Ries, J.B., Arnáez, J., Boix-Fayos, C., Butzen, V., Cerdà, A., 720 Echeverría, M.T., Fernández-Gálvez, J., Fister, W., Geißler, C., Gómez, J.A., Gómez-Macpherson, H., Kuhn, N.J., Lázaro, R., León, F.J., Martínez-Mena, M., Martínez-Murillo, J.F., Marzen, M., Mingorance, M.D., Ortigosa, L., Peters, P., Regüés, D., Ruiz-Sinoga, J.D., Scholten, T., Seeger, M., Solé-Benet, A., Wengel, R., Wirtz, S., 2013. European small

James, M.R., Robson, S., 2012. Straightforward reconstruction of 3D surfaces 728 and topography with a camera: accuracy and geoscience application. Journal of Geophysical Research 117, F03017.

730 Javernick, L., Brasington, B., Caruso, B., 2014. Modeling the topography of shallow braided rivers using structure-from-motion photogramnmetry. Geomorphology 213, 166-182.

Jordán, A., Zavala, L.M., Muñoz-Rojas, M., 2011. Mulching, effects on soil physical properties. In: Gliński, J., Horabik, J., Lipiec, J. (Eds.), Encyclopedia of Agrophysics. Springer, Dordrecht, pp. 492-496. 
736 Keesstra, S., Pereira, P., Novara, A., Brevik, E.C., Azorin-Molina, C., ParrasAlcántara, L., Jordán, A., Cerdà, A., 2016. Effects of soil management techniques on soil water erosion in apricot orchards. Science of the Total Environment 551-552, 357-366. DOI: 10.1016/j.scitotenv.2016.01.182.

Lane, S.N., Chandler, J.H., Richards, K.S., 1994. Developments in monitoring and modeling small-scale river bed topography. Earth Surface Processes and Landforms 19(4), 349-368. DOI. 10.1002/esp.3290190406.

Lane, S.N., Westaway, R.M., Hicks, D.M., 2003. Estimation of erosion and deposition volumes in a large, gravel-bed, braided river using synoptic remote sensing. Earth Surface Processes and Landforms 28(3), 249271. DOI. 10.1002/esp.483.

Lassu, T., Seeger, M., Peters, P., Keesstra, S.D., 2015. The Wageningen Rainfall Simulator: Set-up and Calibration of an Indoor Nozzle-Type Rainfall Simulator for Soil Erosion Studies. Land Degradation and Development 26 (6), 604-612. DOI: 10. 1002/ldr. 2360.

León, J., Badía, D., Echeverría, M.T., 2015. Comparison of Different Methods to Measure Soil Erosion in the Central Ebro Valley. Cuadernos De Investigacion Geografica 41 (1), 165-180. doi:10.18172/cig.2703.

Lexartza-Artza, I., Wainwright, J., 2011. Making connections: changing sediment sources and sinks in an upland catchment. Earth Surface Processes and Landforms 36, 1090-1104.

Ligonja, P.J., Shrestha, R.P., 2015. Soil Erosion Assessment in Kondoa Eroded Area in Tanzania using Universal Soil Loss Equation, Geographic Information Systems and Socioeconomic Approach. Land Degradation and Development 26 (4): 367-379. doi:10.1002/ldr.2215. 
761

762

763

764

765

766

767

768

769

770

771

772

773

774

775

776

777

778

779

780

781

782

783

784

López-Vicente, M., Poesen, J., Navas, A., Gaspar, L., 2013. Predicting runoff and sediment connectivity and soil erosion by water for different land use scenarios in the Spanish Pre-Pyrenees. Catena 102, 62-73.

López-Vicente, M., Quijano, L., Palazón, L., Gaspar, L., Navas, A., 2015.

Assessment of Soil Redistribution at Catchment Scale by Coupling a Soil Erosion Model and a Sediment Connectivity Index (Central Spanish PrePyrenees). Cuadernos De Investigacion Geografica 41 (1), 127-147. doi:10.18172/cig.2649.

López-Vicente, M., Nadal-Romero, E., Cammeraat, E.L.H., 2016. Hydrological Connectivity does Change Over 70Years of Abandonment and Afforestation in the Spanish Pyrenees. Land Degradation and Development. doi:10.1002/ldr.2531.

Lowe, D., 2004. Distinctive image features from scale-invariant keypoints. International Journal of Computer Vision 60, 91-110.

Marchamalo, M., Hooke, J.M., Sandercock, P.J., 2016. Flow and Sediment Connectivity in Semi-Arid Landscapes in SE Spain: Patterns and Controls. Land Degradation and Development 27 (4), 1032-1044. doi:10.1002/ldr.2352.

Martínez-Casasnovas, J.A., Ramos, M.C., Ribes-Dasi, M., 2002. Soil erosion caused by extreme rainfall events: mapping and quantification in agricultural plots from very detailed digital elevation models. Geoderma $105,125-140$.

Martínez-Casasnovas, J.A., Sánchez-Bosch, I., 2000. Impact assessment of changes in land use/conservation practices on soil erosion in the 
Penedès-Anoia vineyard region (NE Spain). Soil and Tillage Research 57, 101-106.

Masiero, A., Guarnieri, A., Pirotti, F., and Vettore, A., 2015. Semi-automated detection of surface degradation on bridges based on a level set method. Int. Arch. Photogramm. Remote Sens. Spatial Inf. Sci., XL-3/W3, 15-21, doi:10.5194/isprsarchives-XL-3-W3-15-2015.

Masiero, A., Vettore, A., 2016. Improved feature matching for mobile devices 792 with IMU. Sensors 16, 1243. doi:10.3390/s16081243.

793

Masselink, R.J.H., Keesstra, S.D., Temme, A.J.A.M., Seeger, M., Giménez, R., 794 795 Casalí, J., 2016. Modelling Discharge and Sediment Yield at Catchment

Mekonnen, M., Keesstra, S.D., Baartman, J.E., Ritsema, C.J., Melesse, A.M., 798 Scale using Connectivity Components. Land Degradation and

Mekonnen, M., Keesstra, S.D., Stroosnijder, L., Baartman, J.E.M., Maroulis, J., 802 2015b. Soil Conservation through Sediment Trapping: A Review. Land 803 Degradation and Development 26 (6), 544-556. doi:10.1002/ldr.2308.

804

Mekuria, W., Langan, S., Noble, A., Johnston, R., 2016. Soil Restoration After 805 806 Seven Years of Exclosure Management in Northwestern Ethiopia. Land Degradation and Development. doi:10.1002//dr.2527.

807 Mengistu, D., Bewket, W., Lal, R., 2016. Conservation Effects on Soil Quality 808 and Climate Change Adaptability of Ethiopian Watersheds. Land Degradation and Development 27 (6), 1603-1621. doi:10.1002/ldr.2376. 
810 Micheletti, N., Chandler, J.H., Lane, S.N., 2014. Investigating the geomorphological potential of freely available and accessible structurefrom-motion photogrammetry using a smartphone. Earth Surface Processes and Landforms 40(4), 473-486. DOI. 10.1002/esp.3648.

814 Montgomery, D.R., 2007. Soil erosion and agricultural sustainability. PNAS 104, $13268-13272$.

816 Mwango, S.B., Msanya, B.M., Mtakwa, P.W., Kimaro, D.N., Deckers, J., Poesen, J., 2016. Effectiveness OF Mulching Under Miraba in Controlling Soil Erosion, Fertility Restoration and Crop Yield in the Usambara Mountains, Tanzania. Land Degradation and Development 27 (4), 12661275. doi:10.1002/ldr.2332.

Nanko, K., Giambelluca, T.W., Sutherland, R.A., Mudd, R.G., Nullet, M.A., 822 Ziegler, A.D., 2015. Erosion Potential under Miconia calvescens Stands on the Island of Hawai'i. Land Degradation and Development 26, 218-226. doi:10.1002/ldr.2200.

825 Novara, A., Gristina, L., Saladino, S.S., Santoro, A., Cerdà, A., 2011. Soil 826 erosion assessment on tillage and alternative soil managements in a 827 Sicilian vineyard. Soil \& Tillage Research 117, 140-147.

828 Novara, A., Keesstra, S., Cerdà, A., Pereira, P., Gristina, L., 2016. Understanding the role of soil erosion on $\mathrm{CO}_{2}-\mathrm{C}$ loss using ${ }^{13} \mathrm{C}$ isotopic signatures in abandoned Mediterranean agricultural land. Science of the Total Environment 550, 330-336, 10.1016/j.scitotenv.2016.01.095, 2016.

832 Ochoa-Cueva P., Fries A., Montesinos P., Rodríguez-Díaz J. A., Boll J. 2015. 833 Spatial Estimation of Soil Erosion Risk by Land-cover Change in the 
Andes of Southern Ecuador. Land Degradation and Development, 26 (6), 565-573. DOI: 10. 1002/ldr. 2219

836 Piermattei, L., Carturan, L., de Blasi, F., Tarolli, P., Dalla Fontana, G., Vettore, A., Pfeifer, N., 2016. Suitability of ground-based SfM-MVS for monitoring glacial and periglacial processes. Earth Surface Dynamics 4, 425-443.

839 Prosdocimi, M., Calligaro, S., Sofia, G., Dalla Fontana, G., Tarolli, P., 2015. Bank erosion in agricultural drainage networks: new challenges from structure-from-motion photogrammetry for post-event analysis. Earth Surface Processes and Landform 40, 1891-1906.

843 Prosdocimi, M., Cerdà, A., Tarolli, P., 2016a. Soil water erosion on Mediterranean vineyards: A review. Catena 141, 1-21.

845 Prosdocimi, M., Jordán, A., Tarolli, P., Keesstra, S., Novara, A., Cerdà, A., 2016b. The immediate effectiveness of barley straw mulch in reducing soil erodibility and surface runoff generation in Mediterranean vineyards. Science of the Total Environment 547, 323-330.

849 Prosdocimi, M., Tarolli, P., Cerdà, A. 2016c. Mulching practices for reducing soil water erosion: A review. Earth-Science Reviews 161, 191-203. DOI: 10.1016/j.earscirev.2016.08.006.

852 Raclot, D., Le Bissonnais, Y., Louchart, X., Andrieux, P., Moussa, R., Voltz, M., 853 2009. Soil tillage and scale effects on erosion from fields to catchment in a

856 Reid, S.C., Lane, S.N., Montgomery, D.R., Brookes, C.J., 2007. Does hydrological connectivity improve modelling of coarse sediment delivery in upland environments? Geomorphology 90, 263-282. 
859 Robertson, D.P., Cipolla, R., 2009. Structure from motion. In Practical Image 860 Processing and Computer Vision, Varga M (ed.). John Wiley \& Sons:

$861 \quad$ Chichester.

862 Rodrigo Comino, J., Brings, C., Lassu, T., Iserloh, T., Senciales, J.M., Martínez 863 Murillo, J.F., Ruiz Sinoga, J.D., Seeger, M., Ries, J.B., 2015. Rainfall and 864 865 human activity impacts on soil losses and rill erosion in vineyards (Ruwer Valley, Germany). Solid Earth 6, 823-837. http://dx.doi.org/10.5194/se-6-

866 823-2015.

867 Rodrigo Comino, J., Iserloh, T., Lassu, T., Cerdà, A., Keesstra, S.D., 868 869 Prosdocimi, M., Brings, C., Marzen, M., Ramos, M.C., Senciales, J.M., Ruiz Sinoga, J.D., Seeger, M., Ries, J.B., 2016a. Quantitative comparison

Rodrigo Comino, J., Iserloh, T., Morvan, X., Malam Issa, O., Naisse, C., of initial soil erosion processes and runoff generation in Spanish and German vineyards. Sci. Total Environ. 565, 1165-1174. DOI:10.1016/j.scitotenv.2016.05.163. Keesstra, S., Cerdà, A., Prosdocimi,M., Arnáez, J., Lasanta, T., Ramos, M.C., Marqués,M.J., Ruiz Colmenero, M., Bienes, R., Ruiz Sinoga, J.D., Seeger, M., Ries, J.B., 2016b. Soil erosion processes in European vineyards: a qualitative comparison of rainfall simulation measurements in Germany, Spain and France. Hydrology 3 (6). http://dx.doi.org/10.3390/hydrology3010006.

Rodrigo Comino, J., Seeger, M., Senciales, J.M., Ruiz-Sinoga, J.D., Ries, J.B., 2016c. Spatial and Temporal Variation of Soil Hydrological Processes on Steep Slope Vineyards (Ruwel-Mosel Valley, Gemany). Cuadernos De Investigacion Geografica 42 (1), 281-306. doi:10.18172/cig.2934. 
884 Sibson, R., 1981. A brief description of natural neighbor interpolation. In

885

886

887

888

889

890

891

892

893

894

895

896

897

898

899

900

901

902

903

904

905

906 Interpreting Multivariate Data, Barnett V (ed.). John Wiley \& Sons: Chichester; chapter 2, 21-36.

Sofia, G., Pirotti, F., Tarolli, P., 2013. Variations in multiscale curvature distribution and signatures of lidar DEM errors. Earth Surface Processes and Landforms 38, 1116-1134.

Sofia, G., Hillier, J.K., Conway, S.J., 2016. Frontiers in Geomorphometry and Earth Surface Dynamics: Possibilities, Limitations and Perspectives, Earth Surf. Dynam., 4: 1-5. doi:10.5194/esurf-4-1-2016.

Soil Survey Staff, 1998. Keys of soil taxonomy, $8^{\text {th }}$ ed. USDA-NRCS, Washington DC.

Sougnez, N., Van Wesemael, B., Vanacker, V., 2011. Low erosion rates measured for steep, sparsely vegetated catchments in southeast Spain. Catena $84,1-11$

Taguas, E.V., Guzmán, E., Guzmán, G., Vanwalleghem, T., Gómez, J.A., 2015. Characteristics and Importance of Rill and Gully Erosion: A Case Study in a Small Catchment of a Marginal Olive Grove. Cuadernos De Investigacion Geografica 41 (1), 107-126. doi:10.18172/cig.2644.

Tarboton, D.G., 2013. Taudem 5.1, Terrain Analysis Using Digital Elevation Models [online] Available from: http://hydrology.usu.edu/taudem/taudem5/

Tarolli, P., 2014. High-resolution topography for understanding Earth surface processes: opportunities and challenges. Geomorphology 216, 295-312. 
907 Tarolli, P., Preti, F., Romano, N., 2014. Terraced landscapes: from an old best practice to a potential hazard for soil degradation due to land abandonment. Anthropocene 6, 10-25.

Tarolli, P., Sofia, G., 2016. Human topographic signatures and derived geomorphic processes across landscapes. Geomorphology 255, 140161.

913 Tarolli, P., Sofia, G., Calligaro, S., Prosdocimi, M., Preti, F., Dalla Fontana, G., 2015. Vineyards in terraced landscapes: new opportunities from lidar data. Land Degradation \& Development 26, 92-102.

916 Taylor, J., 1997. An Introduction to Error Analysis: the Study of Uncertainties in 917 Physical Measurements, 2nd edn. University Science Books: Sausalito, $918 \quad$ CA.

919 Theler, D., Reynard, E., Lambiel, C., Bardou, E., 2010. The contribution of 920 geomorphological mapping to sediment transfer evaluation in small 921 alpine catchments. Geomorphology 124, 113-123.

922 Verhoeven, G., Doneus, M., Briese, C., Vermeulen, F., 2012. Mapping by 923 matching: a computer vision-based approach to fast and accurate 924 georeferencing of archaeological aerial photographs. Journal of 925 Archaeological Science 39, 2060-2070.

926 Wainwright, J., Turnbull, L., Ibrahim, T.G., Lexartza-Artza, I., Thornton, S.F., 927 Brazier, R.E., 2011. Linking environmental regimes, space and time: 928 interpretations of structural and functional connectivity. Geomorphology $929 \quad 126,387-404$.

930 H. Walter, H., Lieth, H., 1960. Klimadiagramma-Weltatlas. G. Fischer Verlag, 931 Jena. 
932 Wechsler, S.P., 2007. Uncertainties associated with digital elevation models for hydrologic applications: a review. Hydrology and Earth System Sciences $11,1481-1500$.

Westoby, M.J., Brasington, J., Glasser, N.F., Hambrey, M.J., Reynolds, J.M., 2012. 'Structure-from-Motion' photogrammetry: a low-cost, effective tool for geosciences applications. Geomorphology 17, 300-314.

Wheaton, J.M., 2008. Uncertainty in Morphological Sediment Budgeting of Rivers, Unpublished PhD thesis. University of Southampton; 412 pp. http://www.joewheaton.org/Home/research/projects-1/morphologicalsediment-budgeting/phdthesis.

942 Wheaton, J.M., Brasington, J., Darby, S.E., Sear, D.A., 2010. Accounting for uncertainty in DEMs from repeat topographic surveys: improved sediment budgets. Earth Surface Processes and Landforms 35, 136-156.

Whitehead, K., Moorman, B.J., Hugenholtz, C.H., 2013. Brief Communication: Low-cost, on-demand aerial photogrammetry for glaciological measurement. The Cryosphere 7, 1879-1884.

948 Woodget, A.S., Carbonneau, P.E., Visser, F., Maddock, I., 2015. Quantifying submerged fluvial topography using hyperspatial resolution UAS imagery and structure from motion photogrammetry. Earth Surface Processes and Landforms 40, 47-64. DOI. 10.1002/esp.3613.

952

953

954 
959 Table 1 Georeferentiation errors (RMSE) calculated by Agisoft PhotoScan $\AA$

960 along the $x, y$ and $z$-axes for each point cloud derived from SfM technique.

961 GEOPre $_{\text {NKN }}$ and GEOPost ${ }_{\text {NKN }}$ refer to the point clouds derived from the Nikon

962 camera before and after the rainfall simulation, respectively, and GEOPre ${ }_{\mathrm{PHO}}$

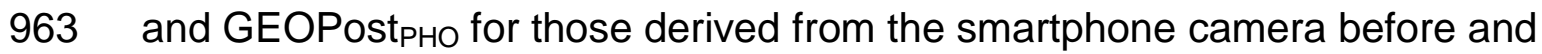

964 after the rainfall simulation, respectively. The number of the plot is also included

$965(1,2,3,4 A, 4 B, 4 C$ and 4D).

966 Table 2 Accuracy measures of DEMs PHO checked by DEMS $\mathrm{SKN}_{\mathrm{N}}$ with the

967 assumption of normal distribution and more robust parameters too. DEMPre ${ }_{\mathrm{NKN}}$

968 and DEMPost ${ }_{\text {NKN }}$ refer to DEMs derived from the Nikon camera before and after

969 the rainfall simulation, respectively, and DEMPre ${ }_{\mathrm{PHO}}$ and DEMPost $\mathrm{PHO}_{\mathrm{PHO}}$ for those

970 derived from the smartphone camera before and after the rainfall simulation,

971 respectively. The number of the plot is also included $(1,2,3,4 \mathrm{~A}, 4 \mathrm{~B}, 4 \mathrm{C}$ and

972 4D).

973

974 


\section{FIGURE CAPTIONS}

Figure 1 Examples of soil water erosion processes caused by a $40 \mathrm{~mm}$ in 30 min thunderstorm occurred in mid-June 2015 in the study area. The white arrows point out a gully (a) and a rill (b).

Figure 2 Visual perspective of the tilled inter-rows where the tractor wheel tracks are well visible (black arrows) (a). The white arrows stress the soil sediments that were transported following the $40 \mathrm{~mm}$ in 30 min thunderstorm occurred in mid-June 2015.

Figure 3 Walter-Lieth climate diagram (Walter and Lieth, 1960) computed for the Ontinyent climate station as it is the one with the longest records (29 years) closest to our study site (about $17 \mathrm{~km}$ ). The information above the panel corresponds to station location, the period of years recorded, the mean annual temperature and the mean annual precipitation.

Figure 4 Localization of the study areas (a), that correspond to the four circular plots (1, 2, 3 and 4) where the rainfall simulation and photogrammetric surveys were carried out. Views of the rainfall simulator (b) and of the rainfall simulation experiment in action (c) are also shown.

Figure 5 Two visual perspectives of the support used to take the pictures. The support consists in a main pole, $1 \mathrm{~m}$ high, with two boxes that stick out the main pole for $0.6 \mathrm{~m} \mathrm{(a)}$ and are $0.3 \mathrm{~m}$ far from each other (b). The boxes were designed to hold the cameras with the lens downwards facing. 
Figure 6 DEMsPre ${ }_{\text {NKN }}$ (0.01 m resolution) obtained for each plot: (a)

DEMs1Pre $_{\text {NKN, }}$ (b) DEMs2Pre ${ }_{\text {NKN, }}$ (c) DEMs3Pre NKN , (d) DEMs4APre NKN,$(e)$ DEMs4BPre $_{\text {NKN }}$, (f) DEMs4CPre ${ }_{\text {NKN }}$, and (g) DEMs4DPre ${ }_{N K N}$.

Figure 7 DoDs derived from the Nikon dataset, thresholded according to the probabilistic thresholding with a $95 \%$ confidence interval and obtained for each plot: (a) Plot 1, (b) Plot 2, (c) Plot 3, (d) Plot 4A, (e) Plot 4B, (f) Plot 4C, and (g) Plot 4D.

Figure 8 Soil loss data, expressed in grams, derived for each plot from both the methodologies applied: rainfall simulation and surface elevation change-based

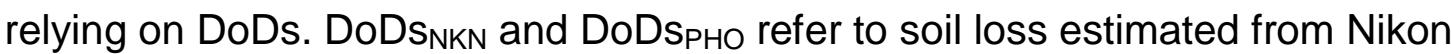
and smartphone cameras, respectively.

Figure 9 Connectivity index maps calculated with regard to the plots outlets, by considering, as inputs, the DEMsPre ${ }_{\text {NKN }}$, for each plot: (a) Plot 1, (b) Plot 2, (c) Plot 3, (d) Plot 4A, (e) Plot 4B, (f) Plot 4C, and (g) Plot 4D.

Figure 10 Soil loss data, expressed in grams, derived for each plot from both the methodologies applied: rainfall simulation and surface elevation change-

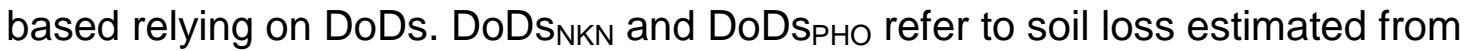
Nikon and smartphone cameras, respectively. DoDs $\mathrm{NKN}_{\mathrm{N}} \mathrm{IC}$ and DoDs PHO $_{\mathrm{IC}} \mathrm{IC}$ refer to soil loss estimated from Nikon and smartphone cameras, respectively, by considering the connectivity index computed according to the DEMsPre. 
1 Table 1 Georeferentiation errors (RMSE) calculated by Agisoft PhotoScan®

2 along the $x, y$ and $z$-axes for each point cloud derived from SfM technique.

3 GEOPre $_{\text {NKN }}$ and GEOPost NKN $_{\text {refer }}$ to the point clouds derived from the Nikon

4 camera before and after the rainfall simulation, respectively, and GEOPre $\mathrm{PHO}_{\mathrm{P}}$

5 and GEOPost $t_{\mathrm{PHO}}$ for those derived from the smartphone camera before and

6 after the rainfall simulation, respectively. The number of the plot is also included

$7 \quad(1,2,3,4 \mathrm{~A}, 4 \mathrm{~B}, 4 \mathrm{C}$ and 4D).

\begin{tabular}{|c|c|c|c|}
\hline & X Error $( \pm m)$ & Y Error $( \pm m)$ & Z Error $( \pm m)$ \\
\hline GEO1Pre $_{\text {NKN }}$ & 0.0119 & 0.0030 & 0.0038 \\
\hline GEO1Pre $_{\mathrm{PHO}}$ & 0.0119 & 0.0030 & 0.0041 \\
\hline GEO1Post $_{\text {NKN }}$ & 0.0113 & 0.0029 & 0.0045 \\
\hline GEO1Post ${ }_{P H O}$ & 0.0113 & 0.0029 & 0.0046 \\
\hline GEO2Pre $_{N K N}$ & 0.0123 & 0.0024 & 0.0043 \\
\hline GEO2Pre $_{\mathrm{PHO}}$ & 0.0125 & 0.0026 & 0.0071 \\
\hline GEO2Post $_{N K N}$ & 0.0126 & 0.0028 & 0.0034 \\
\hline GEO2Post & 0.0138 & 0.0017 & 0.0060 \\
\hline GEO3Pre $_{N K N}$ & 0.0085 & 0.0033 & 0.0105 \\
\hline GEO3Pre $_{\mathrm{PHO}}$ & 0.0074 & 0.0044 & 0.0094 \\
\hline GEO3Post $_{N K N}$ & 0.0093 & 0.0042 & 0.0120 \\
\hline GEO3Post $_{\mathrm{PHO}}$ & 0.0091 & 0.0042 & 0.0118 \\
\hline GEO4APre $_{N K N}$ & 0.0125 & 0.0062 & 0.0041 \\
\hline GEO4APre $_{\mathrm{PHO}}$ & 0.0131 & 0.0059 & 0.0044 \\
\hline GEO4APost $_{\mathrm{NKN}}$ & 0.0133 & 0.0079 & 0.0008 \\
\hline GEO4APost ${ }_{P H O}$ & 0.0142 & 0.0065 & 0.0010 \\
\hline GEO4BPre $_{N K N}$ & 0.0126 & 0.0083 & 0.0008 \\
\hline GEO4BPre ${ }_{\mathrm{PHO}}$ & 0.0127 & 0.0083 & 0.0009 \\
\hline GEO4BPost $_{\mathrm{NKN}}$ & 0.0129 & 0.0082 & 0.0006 \\
\hline GEO4BPost $_{\mathrm{PHO}}$ & 0.0130 & 0.0083 & 0.0006 \\
\hline GEO4CPre $_{N K N}$ & 0.0127 & 0.0083 & 0.0016 \\
\hline GEO4CPre $_{\mathrm{PHO}}$ & 0.0126 & 0.0083 & 0.0017 \\
\hline GEO4CPost $_{\text {NKN }}$ & 0.0128 & 0.0084 & 0.0011 \\
\hline
\end{tabular}




\begin{tabular}{llll} 
GEO4CPost $_{P H O}$ & 0.0127 & 0.0084 & 0.0011 \\
GEO4DPre $_{N K N}$ & 0.0128 & 0.0084 & 0.0011 \\
GEO4DPre $_{\mathrm{PHO}}$ & 0.0132 & 0.0085 & 0.0009 \\
GEO4DPost $_{\mathrm{NKN}}$ & 0.0132 & 0.0083 & 0.0011 \\
GEO4DPost $_{\mathrm{PHO}}$ & 0.0131 & 0.0085 & 0.0011 \\
\hline
\end{tabular}

8

9

10

11

12

13

14

15

16

17

18

19

20

21

22

23

24

25

26

27

28 
Table 2 Accuracy measures of DEMs PHO $_{\text {checked by DEMs }}$ NKN with the assumption of normal distribution and more robust parameters too. DEMPre ${ }_{N K N}$ and DEMPost ${ }_{N K N}$ refer to DEMs derived from the Nikon camera before and after the rainfall simulation, respectively, and DEMPre ${ }_{\mathrm{PHO}}$ and DEMPost $\mathrm{PHO}_{\mathrm{P}}$ for those derived from the smartphone camera before and after the rainfall simulation, respectively. The number of the plot is also included $(1,2,3,4 \mathrm{~A}, 4 \mathrm{~B}, 4 \mathrm{C}$ and $4 \mathrm{D})$.

\begin{tabular}{|c|c|c|c|c|c|c|c|c|}
\hline & $\begin{array}{l}\text { Minimum } \\
(\mathrm{m})\end{array}$ & $\begin{array}{l}\text { Maximum } \\
(\mathrm{m})\end{array}$ & $\begin{array}{l}\text { Mean } \\
(\mathrm{m})\end{array}$ & $\begin{array}{l}\text { SDE } \\
(\mathrm{m})\end{array}$ & Kurtosis & Skeweness & $\begin{array}{l}\text { NMAD } \\
(\mathrm{m})\end{array}$ & $\begin{array}{l}\text { Median } \\
\text { (m) }\end{array}$ \\
\hline DEM1Pre $_{\mathrm{PHO}}-\mathrm{DEM} 1 \mathrm{Pre}_{\mathrm{NKN}}$ & -0.0160 & 0.0210 & 0.0003 & 0.0022 & 12.5108 & 0.2772 & 0.0015 & 0.0003 \\
\hline DEM1Post $_{\mathrm{PHO}}-$ - DEM1Post ${ }_{\mathrm{NKN}}$ & -0.0344 & 0.0336 & -0.0002 & 0.0026 & 88.9927 & -1.3843 & 0.0010 & -0.0002 \\
\hline DEM2Pre $_{\mathrm{PHO}}-$ DEM2Pre $_{\mathrm{NKN}}$ & -0.0135 & 0.0142 & 0.0015 & 0.0031 & 4.1464 & -0.2322 & 0.0024 & 0.0017 \\
\hline DEM2Post $_{\mathrm{PHO}}-\mathrm{DEM}_{2} \mathrm{Post}_{\mathrm{NKN}}$ & -0.0063 & 0.0173 & 0.0049 & 0.0029 & 3.9343 & -0.0287 & 0.0022 & 0.0049 \\
\hline DEM3Pre $_{\mathrm{PHO}}-\mathrm{DEM} \mathrm{Pre}_{\mathrm{NKN}}$ & -0.0062 & 0.0054 & -0.0002 & 0.0019 & 2.5106 & 0.1547 & 0.0016 & -0.0003 \\
\hline DEM3PostPHO - DEM3Post ${ }_{N K N}$ & -0.0056 & 0.0059 & -0.0003 & 0.0010 & 6.3428 & 0.1691 & 0.0007 & -0.0003 \\
\hline DEM4APre $_{P H O}-D_{E M} 4 A P_{N K N}$ & -0.0139 & 0.0168 & -0.0009 & 0.0026 & 8.5218 & 0.6003 & 0.0018 & -0.0009 \\
\hline DEM4APost $_{P H O}-$ DEM4APost $_{N K N}$ & -0.0201 & 0.0242 & -0.0012 & 0.0043 & 5.6034 & 0.3439 & 0.0031 & -0.0015 \\
\hline DEM4BPre $_{\mathrm{PHO}}-$ DEM4BPre $_{\mathrm{NKN}}$ & -0.0193 & 0.0239 & 0.0003 & 0.0046 & 4.9291 & 0.0854 & 0.0034 & 0.0002 \\
\hline DEM4BPost $_{P H O}-$ DEM4BPost $_{N K N}$ & -0.0067 & 0.0078 & -0.0001 & 0.0014 & 6.2354 & 0.0027 & 0.0010 & -0.0002 \\
\hline DEM4CPre $_{\mathrm{PHO}}-\mathrm{DEM}$ 4CPre ${ }_{\mathrm{NKN}}$ & -0.0057 & 0.0061 & 0.0001 & 0.0012 & 5.3686 & -0.1376 & 0.0009 & 0.0002 \\
\hline DEM4CPost $_{P H O}-$ DEM4CPost ${ }_{N K N}$ & -0.0117 & 0.0128 & 0.0002 & 0.0028 & 5.6941 & 0.2353 & 0.0020 & 0.0002 \\
\hline DEM4DPre $_{\mathrm{PHO}}-\mathrm{DEM} \mathrm{DPre} \mathrm{NKN}_{\mathrm{N}}$ & -0.0068 & 0.0092 & -0.0001 & 0.0017 & 5.7170 & 0.5328 & 0.0012 & -0.0002 \\
\hline DEM4DPost $_{P H O}-$ DEM4DPost $_{N K N}$ & -0.0104 & 0.0115 & 0.0000 & 0.0023 & 5.8356 & 0.2322 & 0.0016 & -0.0001 \\
\hline
\end{tabular}


Click here to download high resolution image
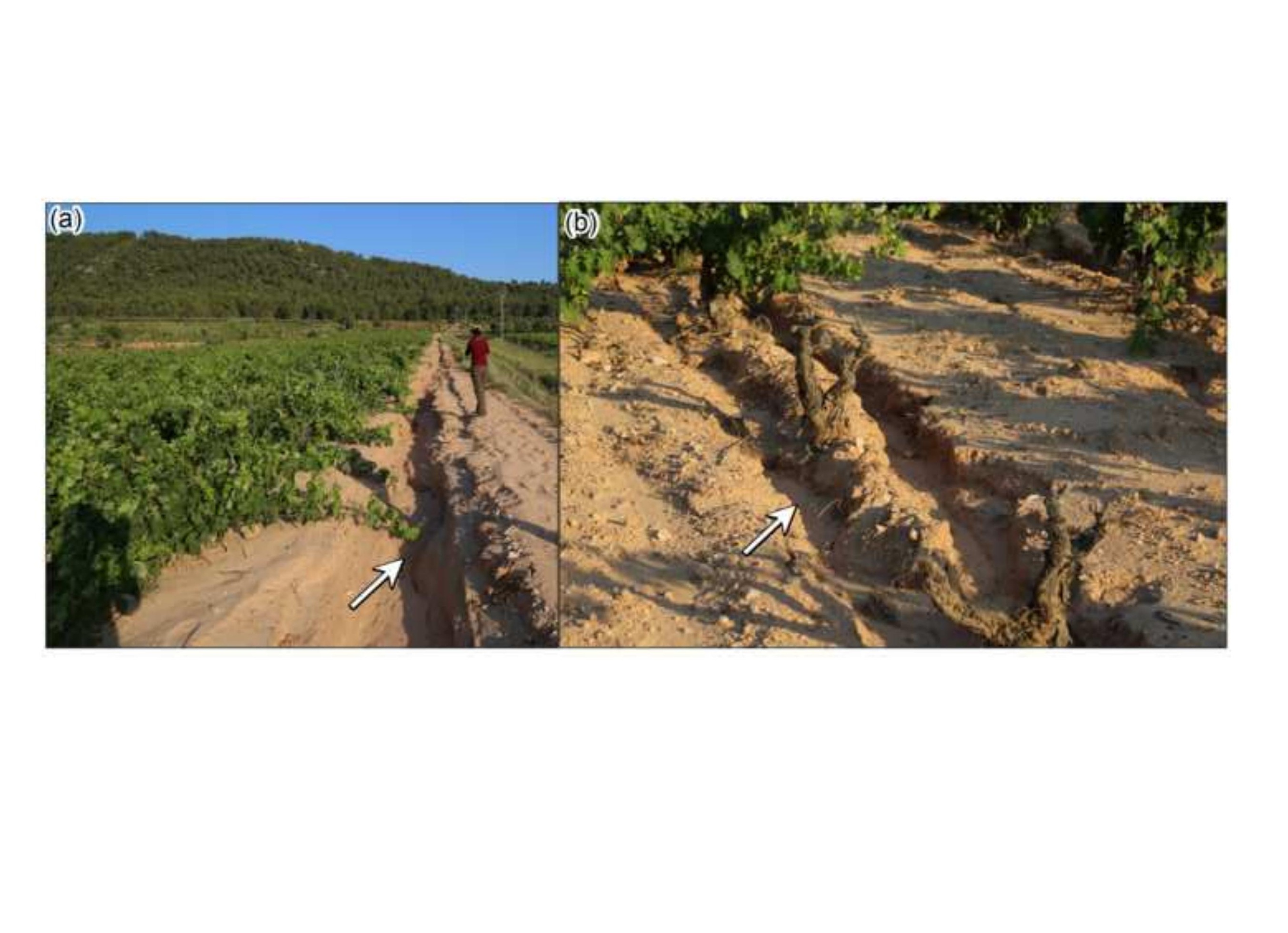
(a)
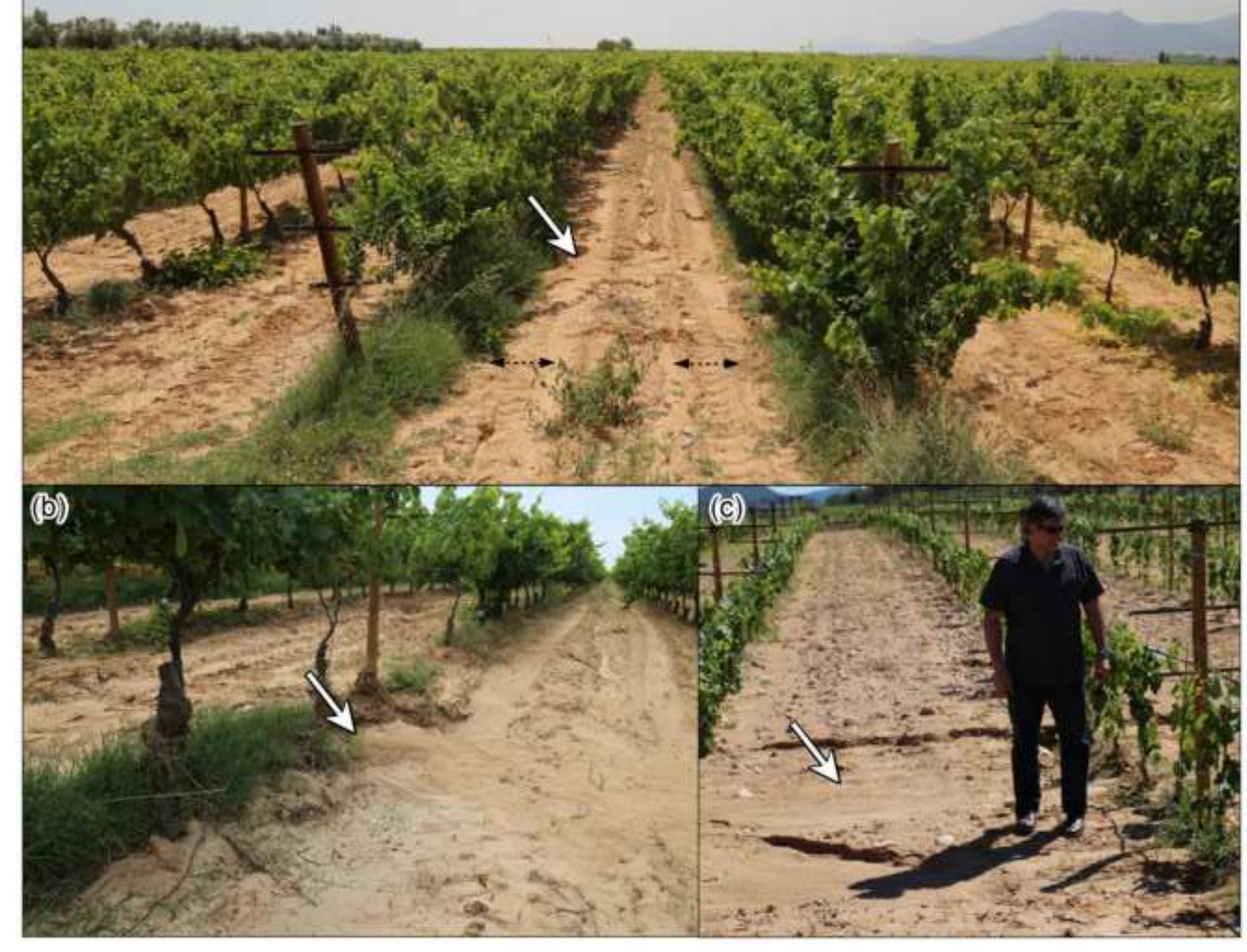
Ontinyent (Valencia, Spain)

Coordinates: $\mathrm{N} 38^{\circ} 49^{\prime}, \mathrm{W} \mathrm{O}{ }^{\circ} 36^{\prime}$

Elevation: $350 \mathrm{~m}$ a.s.I.

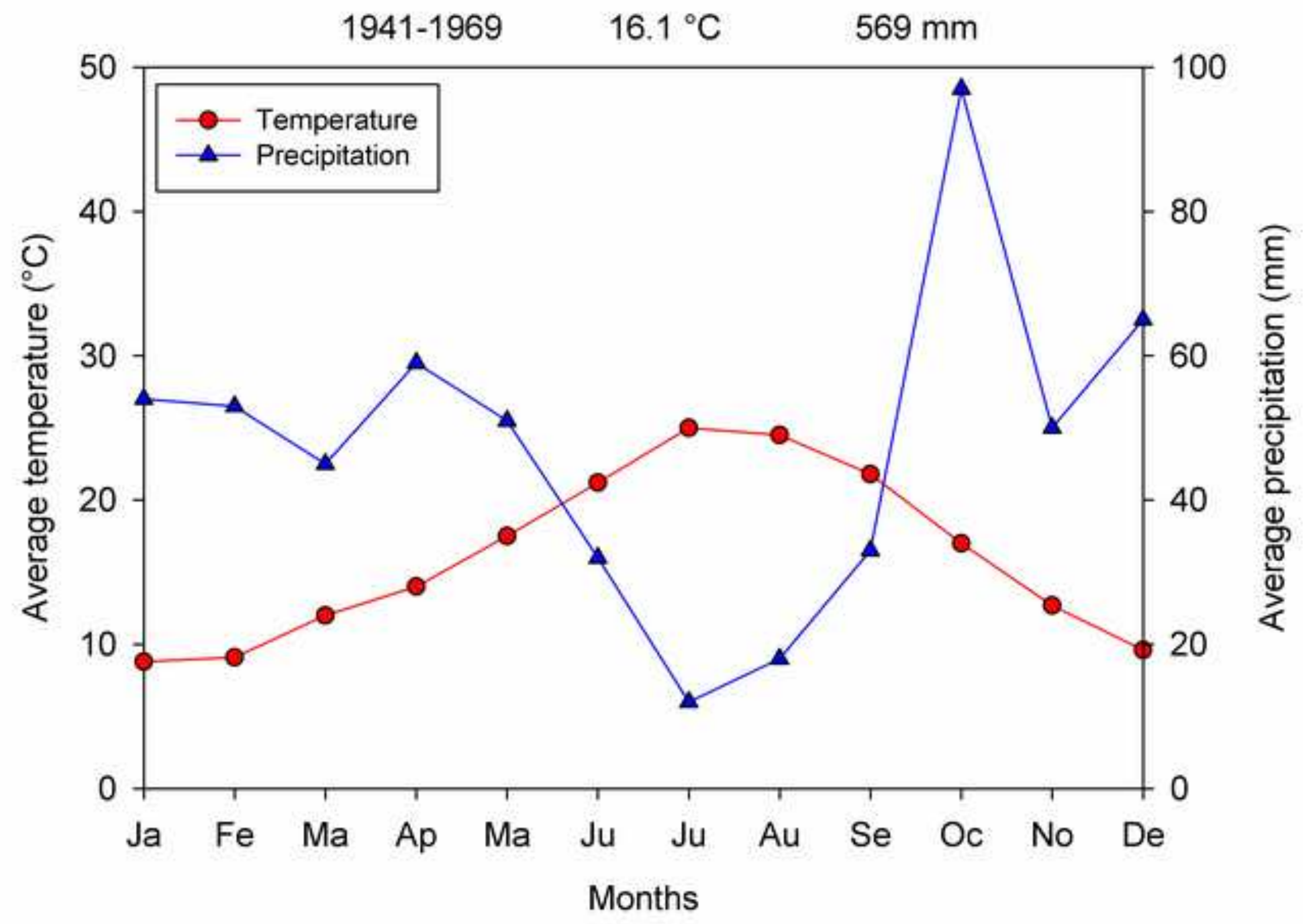


Click here to download high resolution image
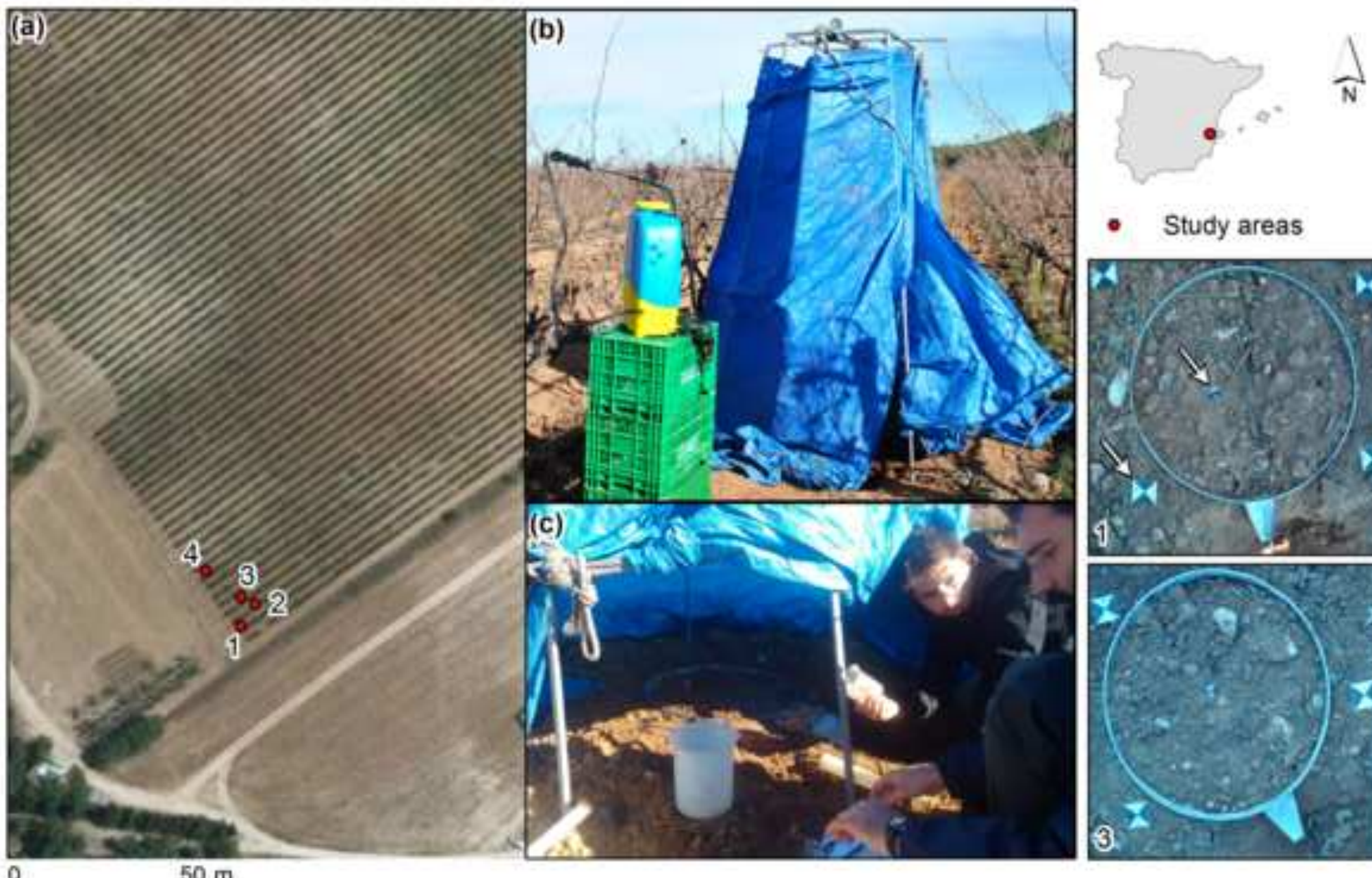

- Study areas
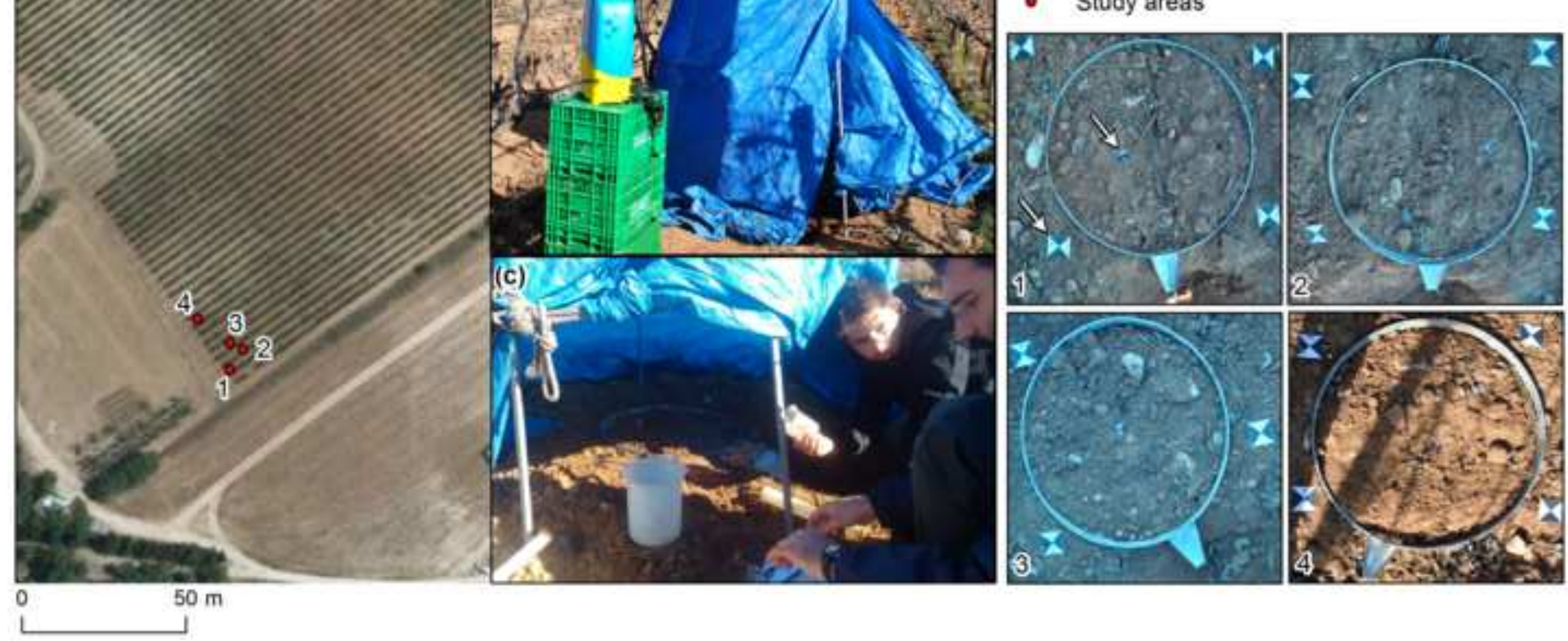

$\frac{1}{N}$ (n)

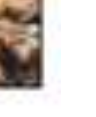
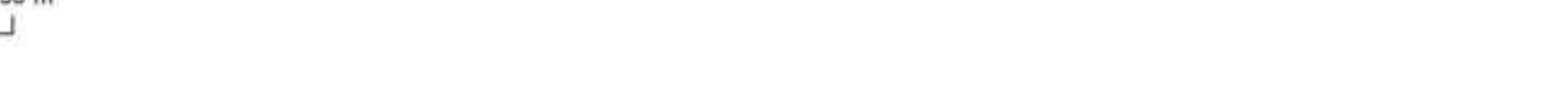
Click here to download high resolution image

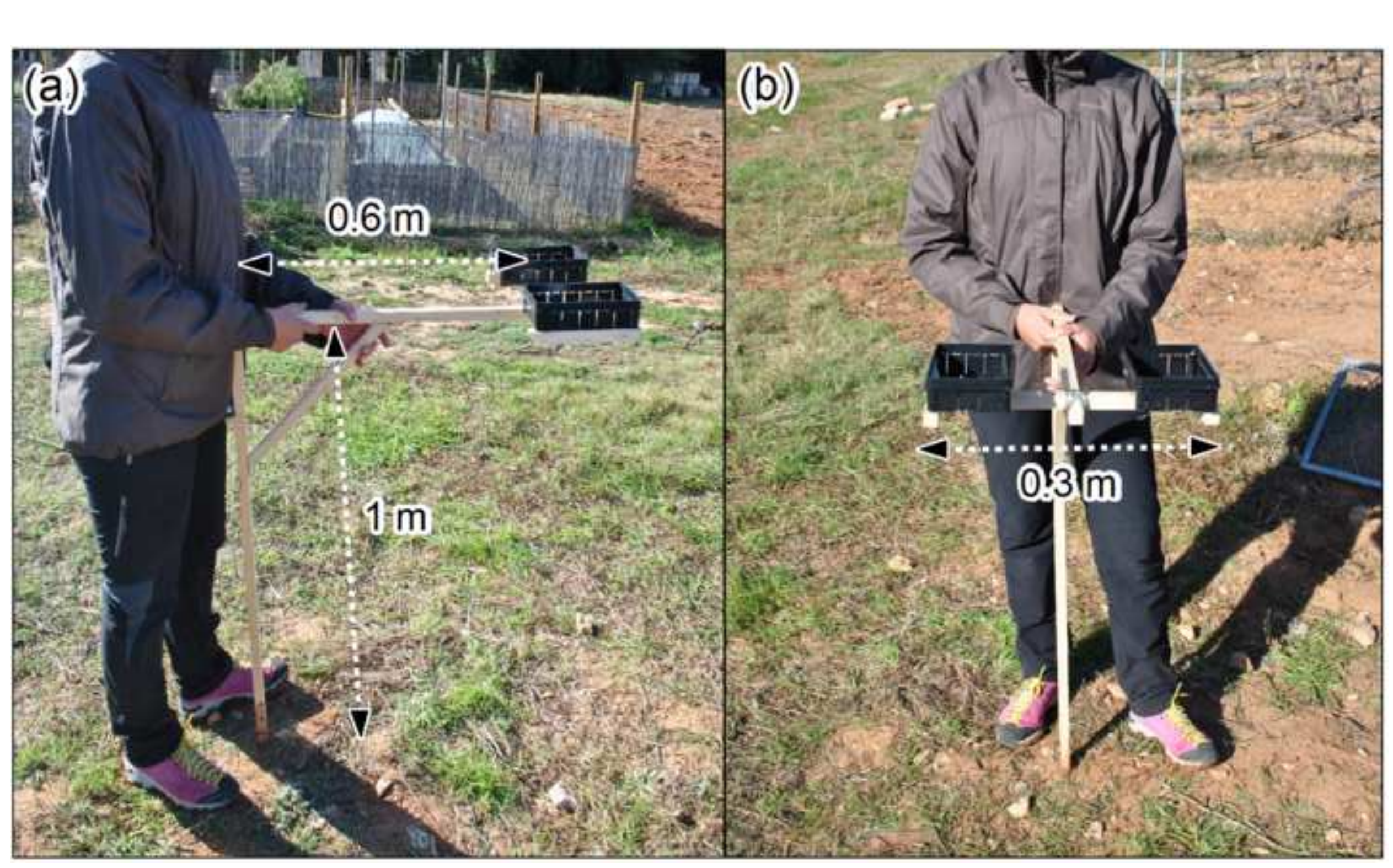

$$
\text { . }
$$

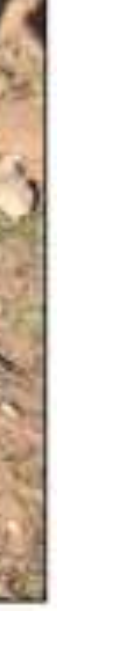


Click here to download high resolution image

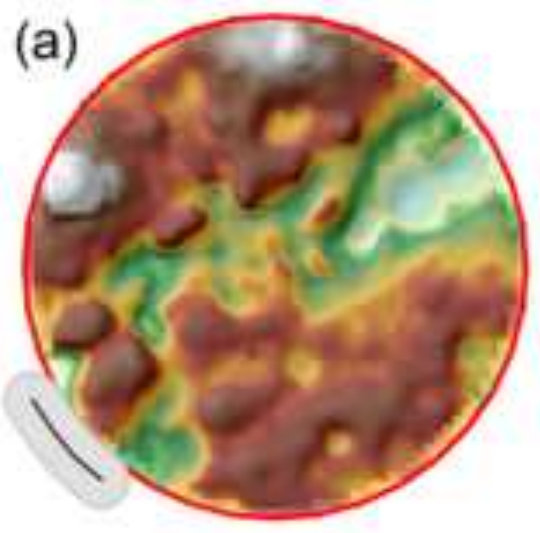

(b)

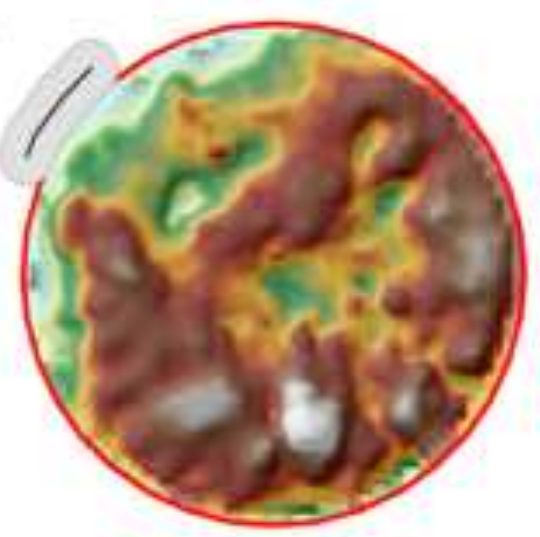

(d)

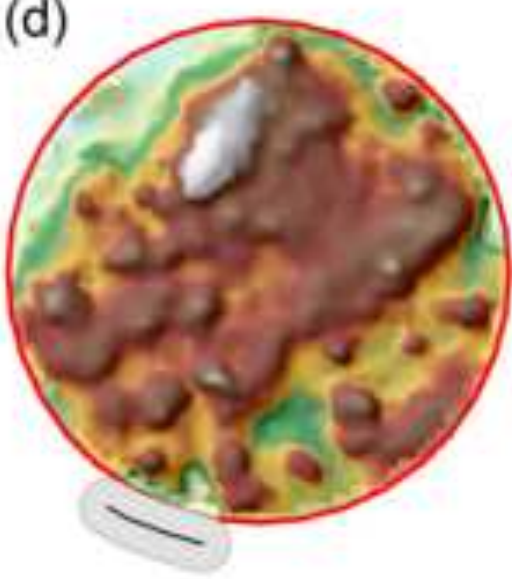

(e)

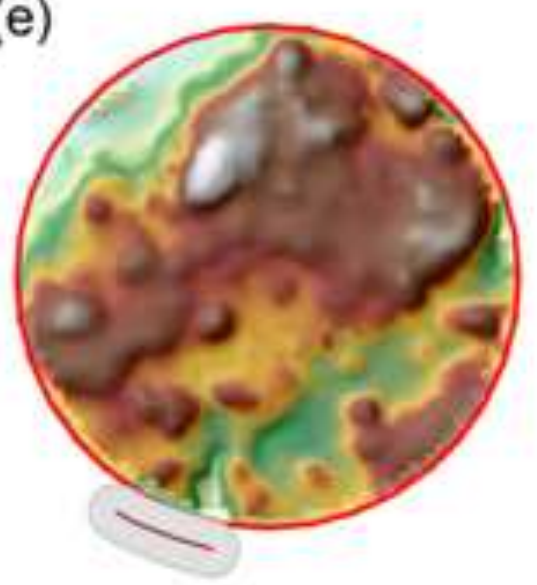

\section{DEM}

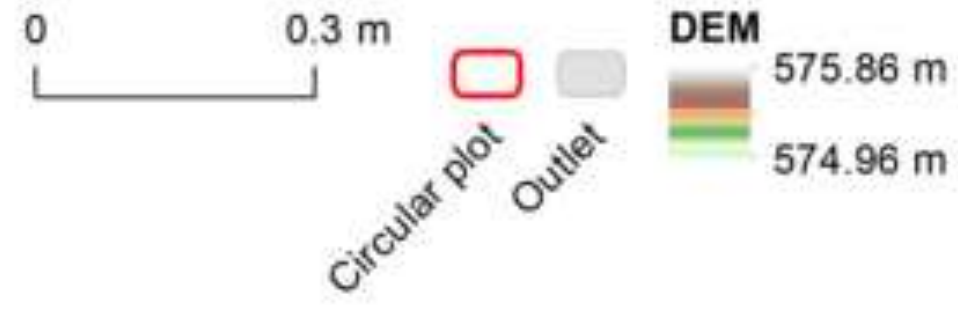

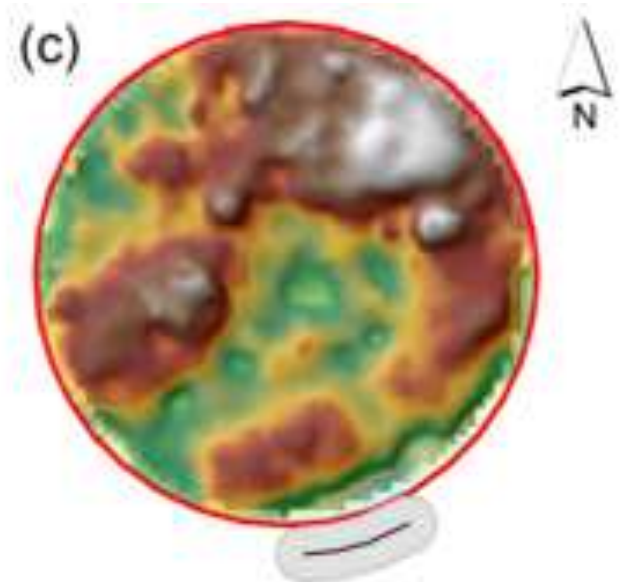

(f)
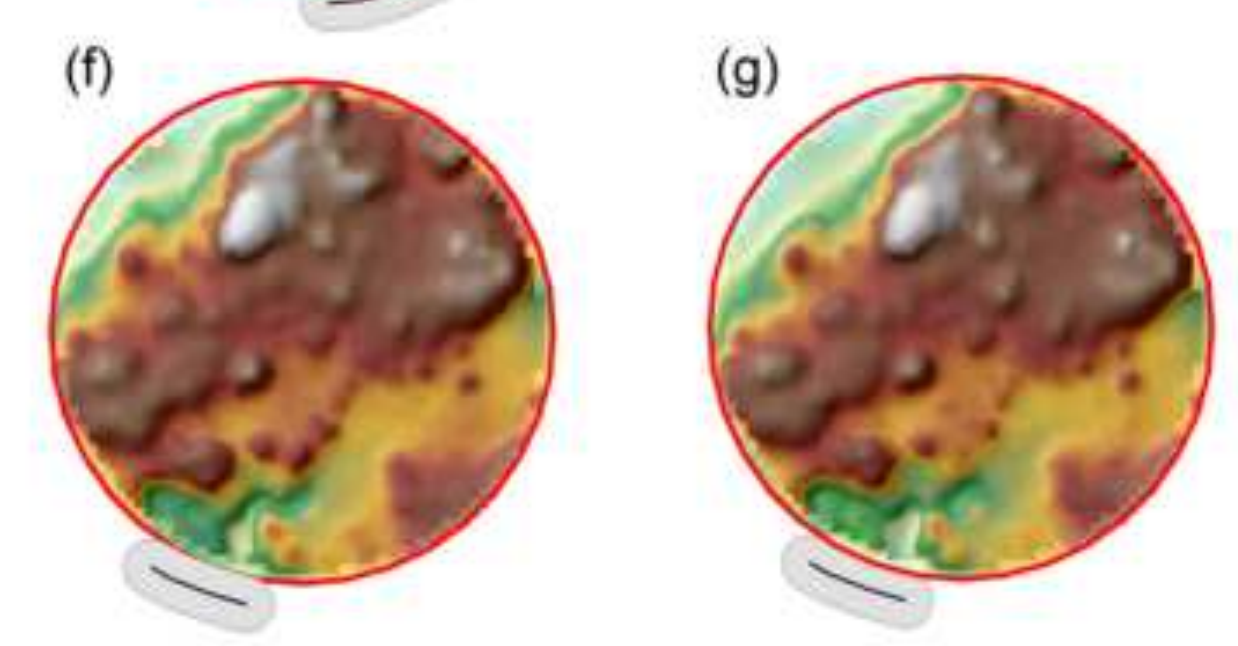

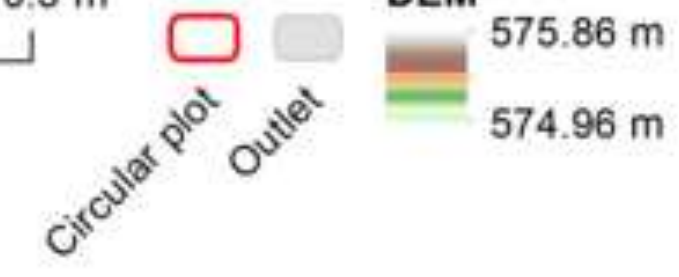




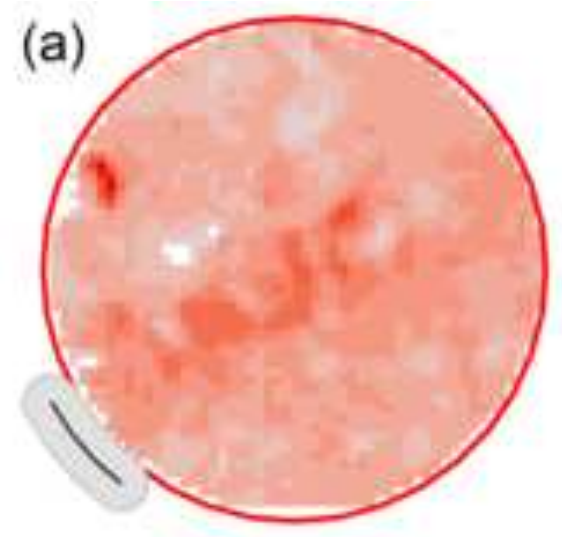

(b)

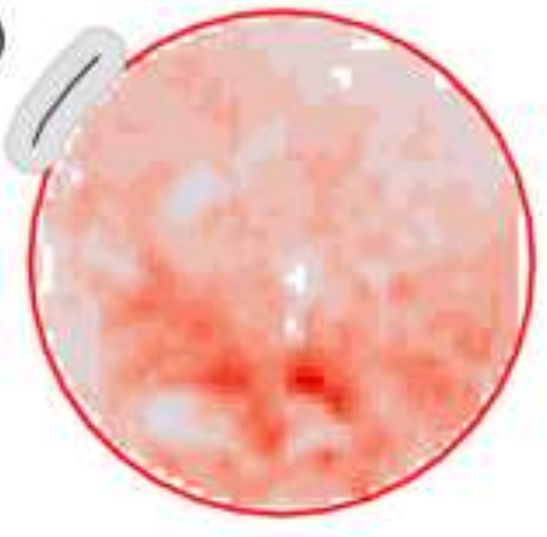

(d)

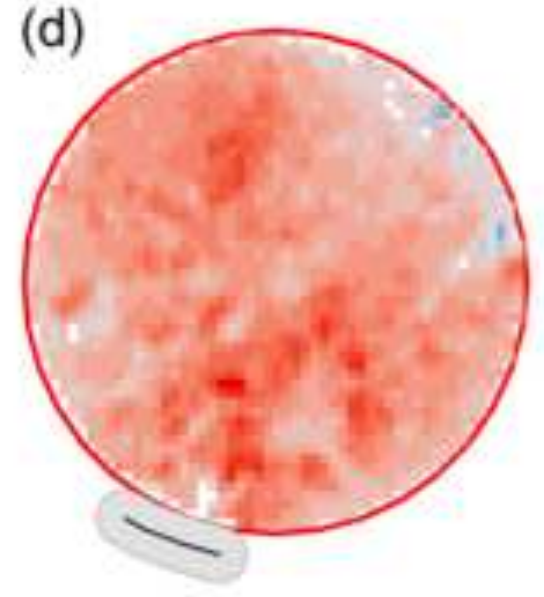

(e)

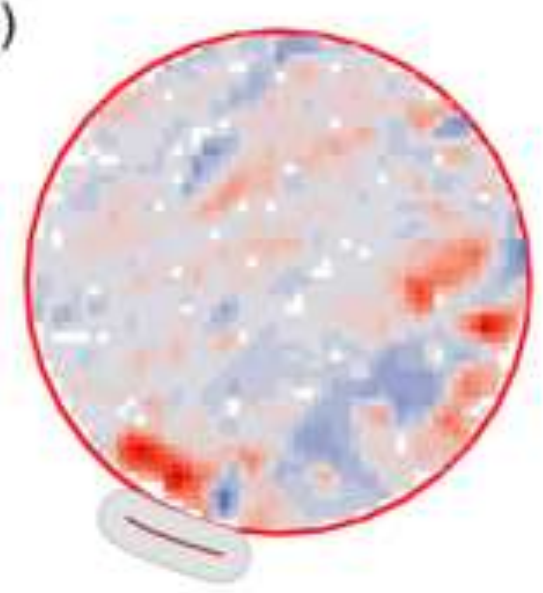

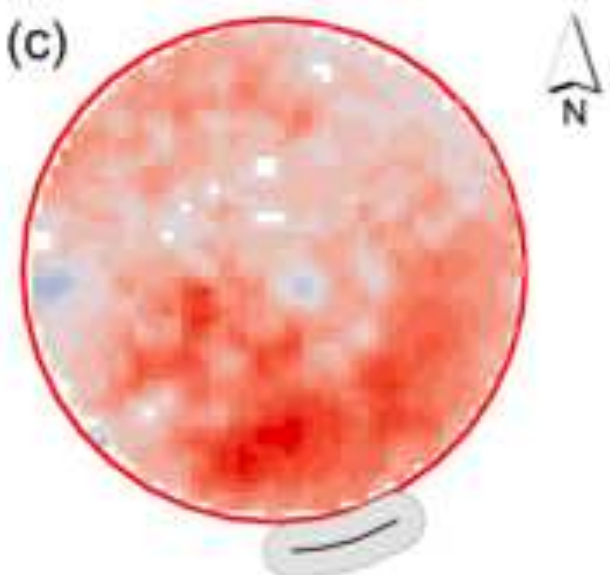

(f)

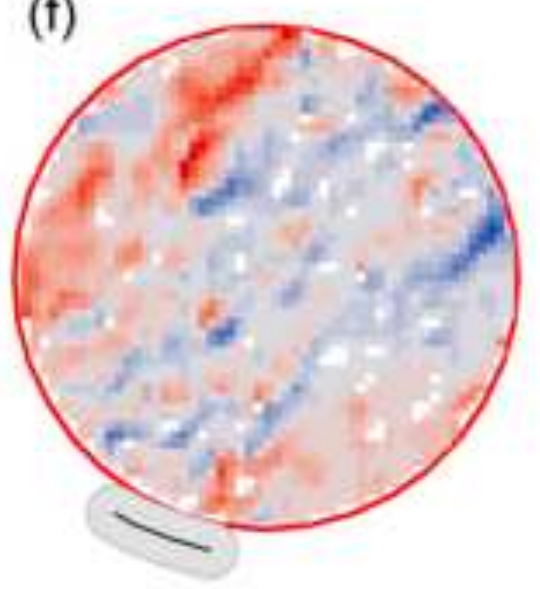

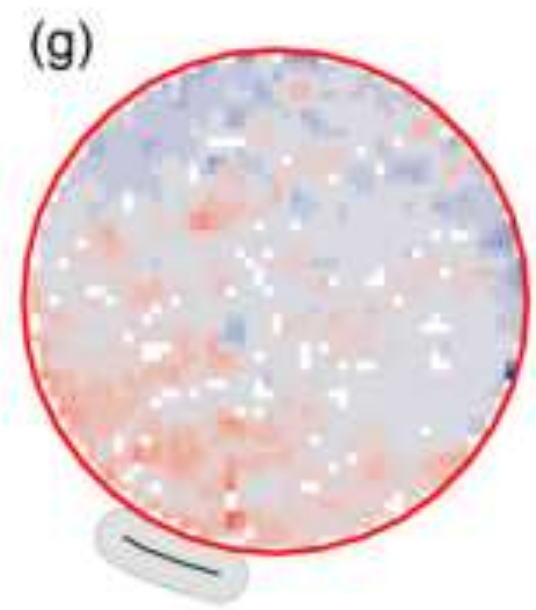

(g)

Elevation difference $(\mathbf{m m})$

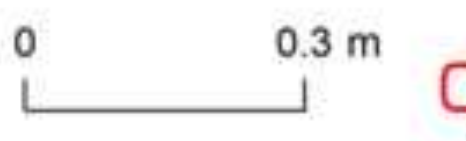

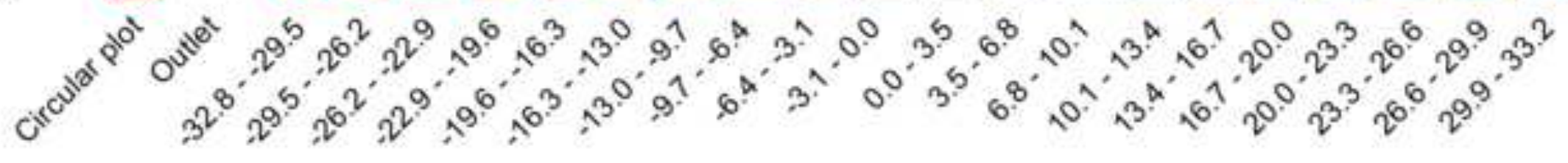


Click here to download high resolution image

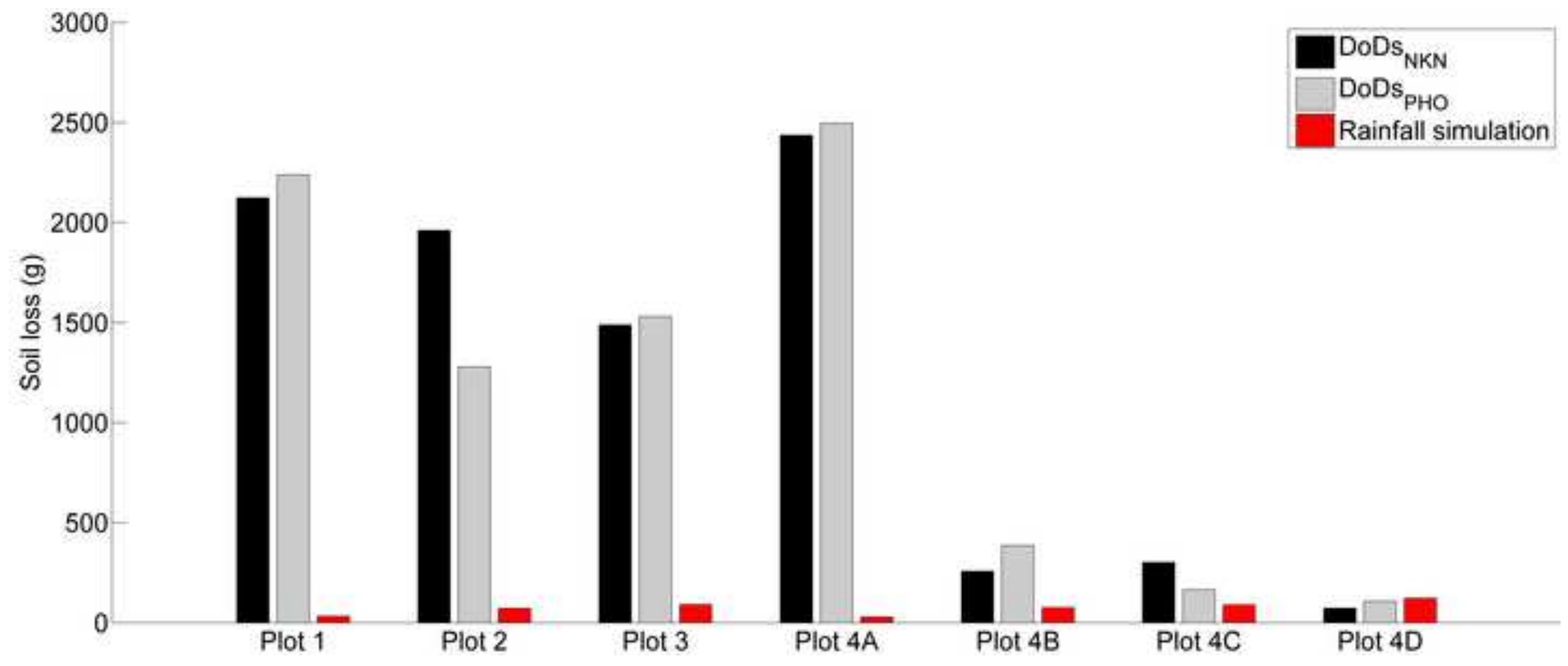




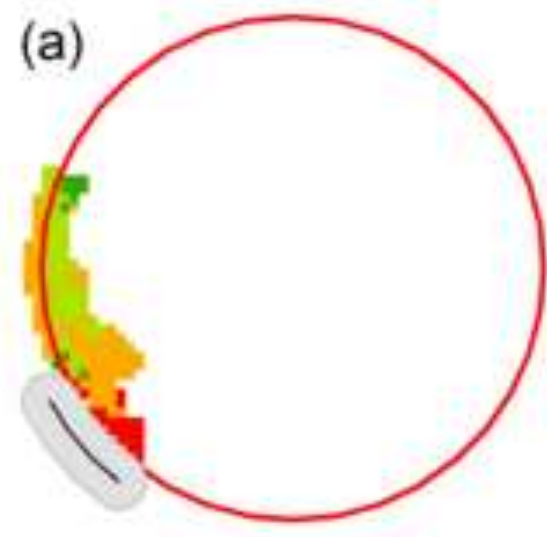

(b)

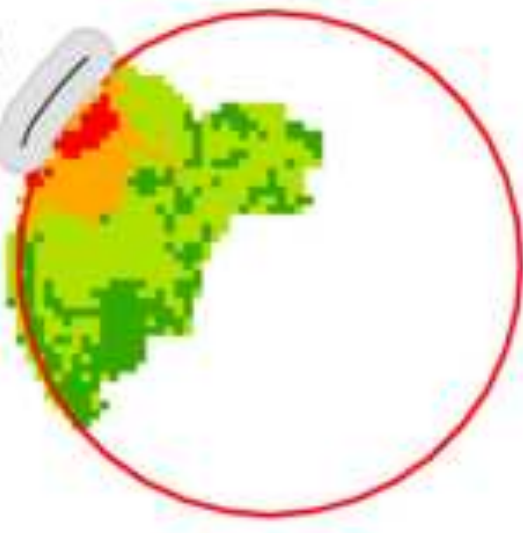

(d)

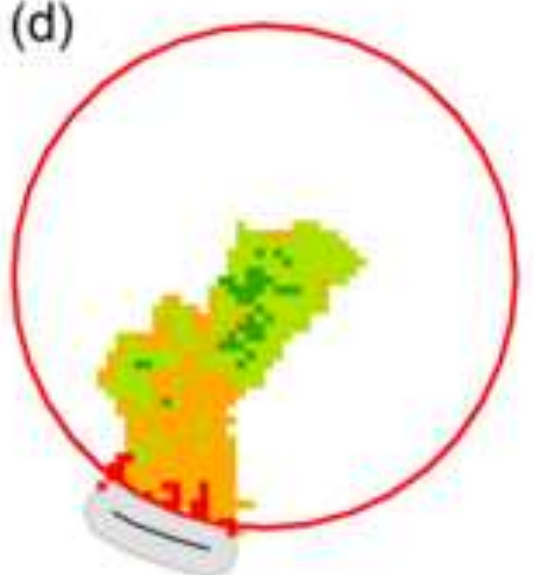

(e)

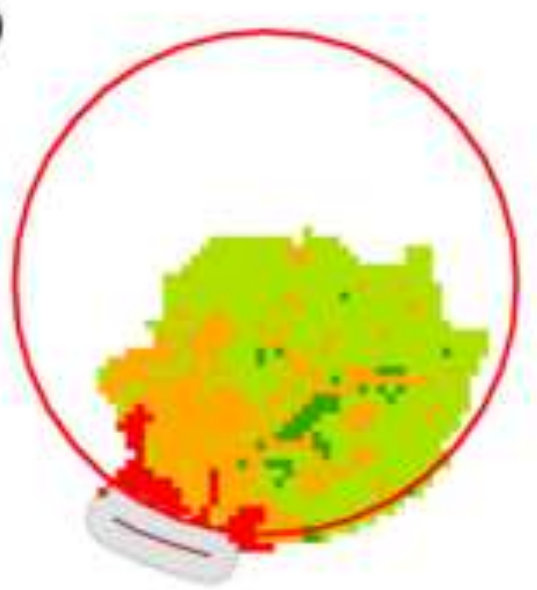

Connectvity Index

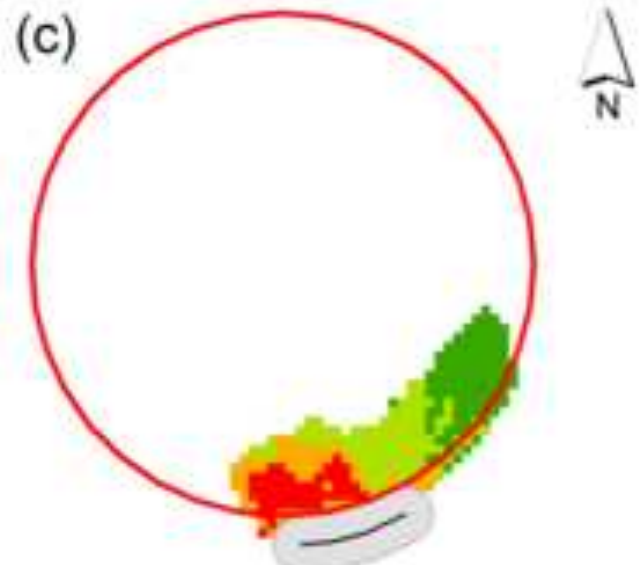

(f)

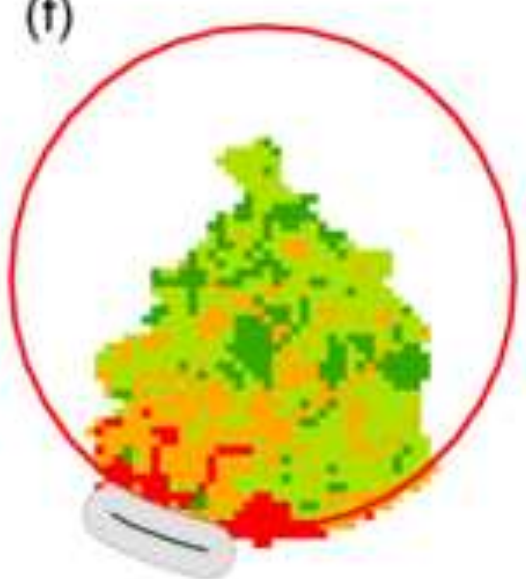

(g)

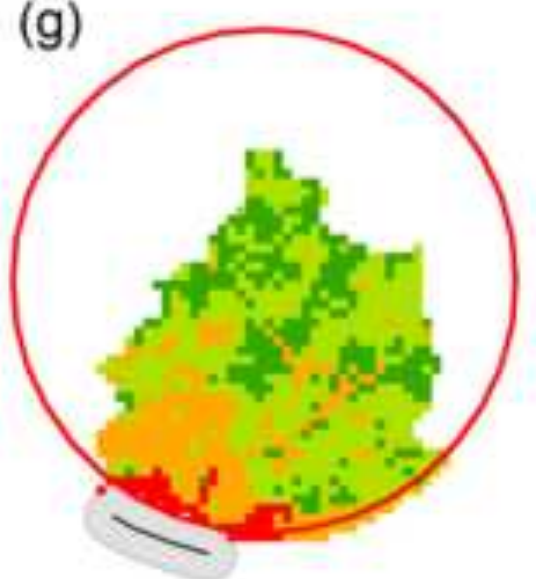

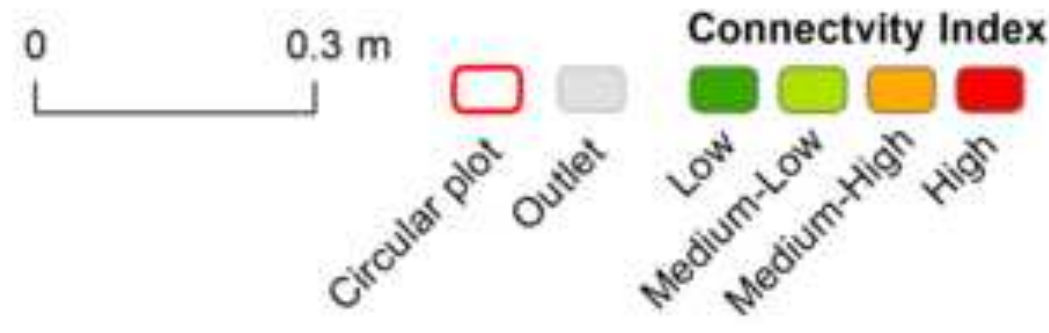


Click here to download high resolution image

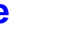

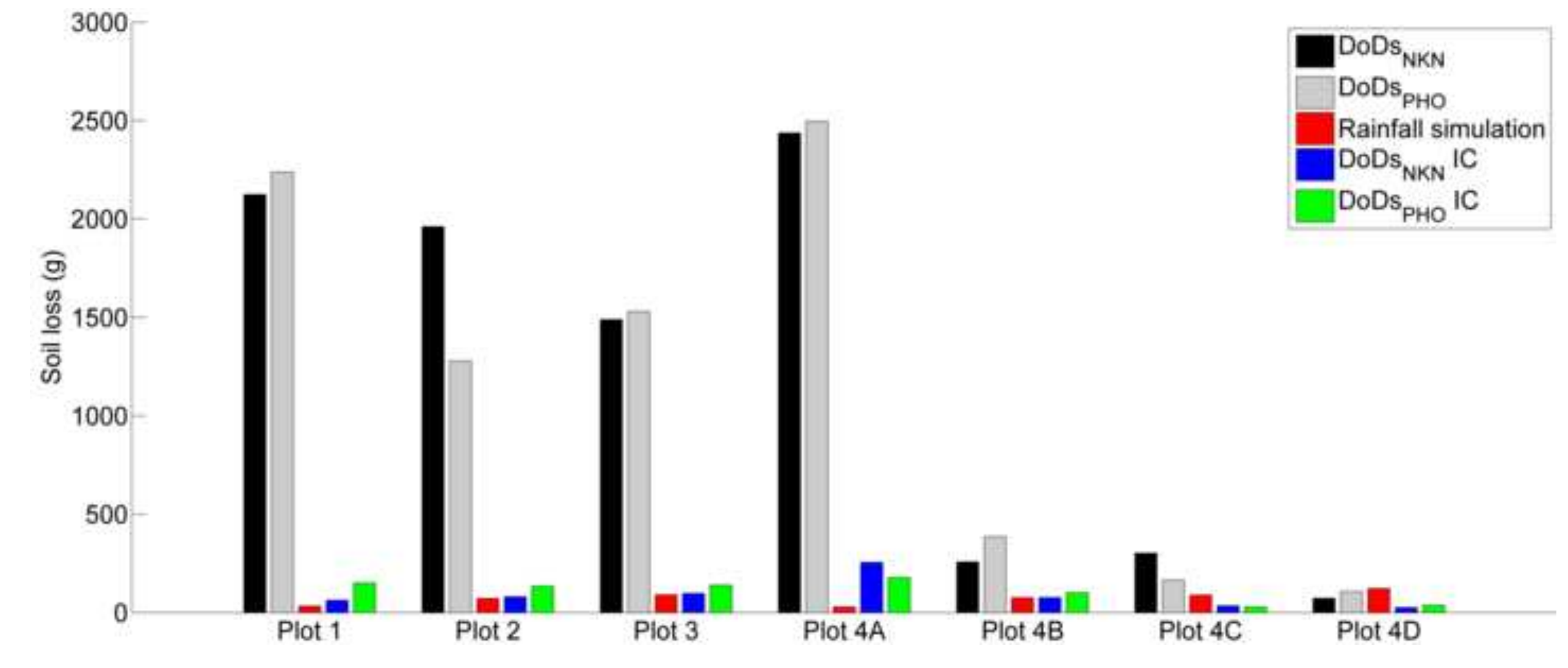

Rainfall simulation $\mathrm{DoDs}_{\text {NKN }}$ IC

$\mathrm{DoDs}_{\mathrm{PHO}}$ IC
DoDs $_{\text {NKN }}$ 